\title{
Englische Weltpolitik in englischer Beleuchtung
}

Von

\section{Ferdinand Tömnies \\ ord. Professor der Stantswiscenschaften an der Unicersitut Kiel}

Sechstes Tausend

\author{
Berlin \\ Verlag von Julius Springer \\ 1915
}


Tor buzen erschen in gleichem Verlag

\section{Dentschlands Platz an der Sonne}

Ein Briefwechsel englischer Politiker aus dem Jahre 1915

Yun

Ferdinand Tönnis:

ord Profezase der staatswissengchaften an der Cnireraität Kiel

$$
\text { Preis M. }-, 50
$$

Anhang zu der Schrift

"Englische Weltpolitik in englischer Beleuchtung" 


\title{
Englische Weltpolitik in englischer Beleuchtung
}

\author{
Von

\section{Ferdinand Tönnies} \\ ord. Professor der Staatswissenschaften \\ an der Universität Kiel
}

Seehstes Tausend

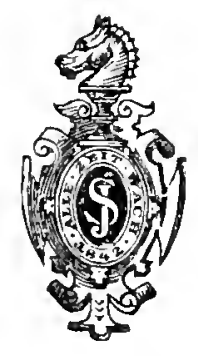

Berlin

Verlag von Julius Springer 
Alle Rechte, insbesondere das der Ubersetzung in fremde Sprachen, vorbehalten.

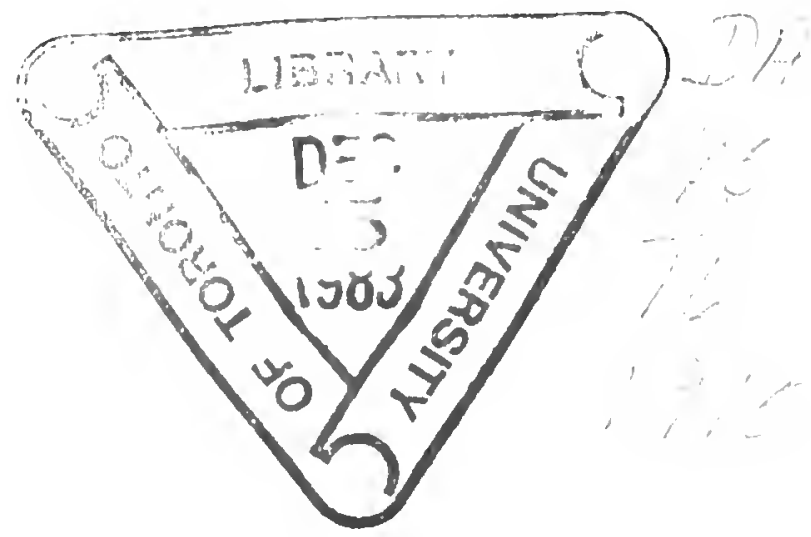

Universitäg-Buchdruckerei von Gustav Schade (Otto Francke', Berlin und Beruau. 


\section{Seiner Exzellenz}

\section{Herrn Prof. Dr. Adolph Wagner}

Wirkl. Geheimrat, Mitglied des Herrenhauses

zum 80. Geburtstage (25. Mä1z 1915)

dargebracht von seinem getreuen

Schüler und Verehrer 
And from hence shall proceed a general diffidence in mankind, and mutual fear one of another. (Und von da wird ein allgemeines Mißtrauen in der Menschheit ausgehen und gegenseitige Furcht vor einander.)

Thomas Hobbes.

The Elements of Law ed. Tönnies. Ch. XIV, 3. 


\section{Vorwort.}

Dies Büchlein ist verfaßt worden um der Wahrheit willen.

Die Zeugnisse der angesehensten englischen Autoren kömnen nicht widerlegt werden. Sie werfen das beste Licht auf die gegenwärtige europäische Krisis.

Das Büchlein ist nicht veriaßt worden, um den Nationalhaß zu schüren. Der Verfasser unterscheidet streng zwischen dem englischen Volke und der englischen Weltpolitik.

Sogar die jeweiligen Leiter dieser Politik kemnen zumeist die treibenden Kräfte dieser Politik nur unzulänglich.

Das englische Volk besteht aus sehr verschieden gearteten Teilen. Neben den wirklichen Engländern sind Schotten, Walliser, Iren und die mannigfachen Mischungen dieser Volksstämme vorhanden; dazu Ablëmmlinge von Deutsehen, Vlamen, Franzosen, Skandinaviern u. a. Außerdem sind Charakter und Denkungsart verschieden nach Tätigkeit oder Müßiggang, Beruf und Stand und sozialer Klasse; also überaus mannigfach und verwickelt. Freilich werden, noch mehr als in anderen Ländern, die oberen Schichten von den unteren bewundert und nachgeahmt.

Die wirkliche Herrschaft in Großbritannien und Irland ruht seit Jahrhunderten in den Händen einer Oligarchie von Grundherren; diese läßt die Spitzen der Handels- und Geldaristokratio neben sich gedeihen und nimmt sie sogar in sich auf; das Verhältnis zwischen beiden Herrschergruppen beruht auf dem stillschweigenden Einverständnis, daß Englands Bestimmung ist, die Erde zu beherrschen und auszubeuten zu beider Bereicherung. Seit 50 Jahren hat die eigentliche Volksmenge, besonders die Arbeiterschaft, auf diese ihre geborenen Herren durch Presse und parlamentarische Vertretung einen wachsenden Einfluß gewonnen in Sachen der inneren Politik. Die auswärtige Politik ist Domäne 
der Oligarchie geblieben. Das Volk hat nur Recht und Gelegenheit, zuzusehen, Beifall zu spenden - und zu zischen, wenn das Schauspiel voriiber ist.

Immer von neuem läßt das Volk sich erzählen und zum Beifall bewegen durch die Behauptung, daß sittliche Gründe maßgebend sind für die Leitung dieser Politik.

Wir wollen erwägen und prüfen, wie unbefangene und wissende Engländer, deren Autorität unter ihnen selber nicht angefochten ist, über diese Behauptung sittlicher Gründe der englischen Weltpolitik denken.

Ein angesprochener Freund der onglischen Nation und der englischen Literatur schrieb um die Wende des 18. zum 19. Jahrhundert:

,Die englische Nation.... ist das schätzbar'ste Ganze von Menschen, im Verhältnis gegen cinander betrachtet. Aber als Staat gegen andere Staten das verderblichste, gewaltsamste, herrschsüchtigste und kriegserregendste unter allen."

Der so schrieb, war der Philosoph Immanuel Kant. (Love Blätter aus Kants Nachlaß, herausgegeben von Reicke, I, S. 129.)

$\mathrm{Ob}$ ihm die von uns zu befragenden englischen Kritiker Recht geben? -

Universität Kiel, Weihnacht 1914 .

Der Verfasser. 


\title{
Inhaltsverzeichnis.
}

Einleitung

\section{Die englische Weltpolitik bis zum Falle Napoleons.}

\author{
Erster Abschnitt.
}

Kriege gegen Spanieu, gegen Holland, gegen Frankreieh, vom 16. bis zum 18. Jahrhundert.

1. Die Expansion. Elisabeth, Cromwell, Karl II. . . . . . . . . 11

Bukaniere. . . . . . . . . . . . . . . . . . 14

2. Handel und Krieg. - Die sittlichen Beweggründe . . . . . . 14

3. Die Glorie des älteren Pitt. - Triumph über Frankreich . . . 20

4. Der Abfall der nordamerikanischen Kolonien . . . . . . . . . 21

5. Der Sklavenhandel als Sänle des Reiches . . . . . . . . . . 23

6. Die Eroberung Indiens . . . . . . . . . . . . . . . . . . . 25

Clive 25. - Warren Hastings 26. - Die Zurückdrängung

Frankreichs 28. - Eroberung und Geschäft 29.

Zwoiter Absohnitt.

Kampl gegen die Iranzösisehe Republik und gegen Napoleon.

7. Angriff gegen die französische Republik. - Das europäisohe Gleichgewicht . . . . . . . . . . . . . . . . . . 31

8. Der Raubzug gegen Dänemark . . . . . . . . . . . 33

II. Die englische Weltpolitik im 19. und 20. Jahrhundert.

Dritter Abschnitt.

Händel in drei Weltteilen.

Allgemeine Betrachtung . . . . . . . . . . . . . 40

9. Afghanistan . . . . . . . . . . . . . . . . 41

10. Der Opiumkrieg und fernere Händel mit China. . . . . . . 46

11. Der Krim-Krieg . . . . . . . . . . . . . . . . . . . . 50

12. Die jonischen Inseln . . . . . . . . . . . . . . . . . . . 53

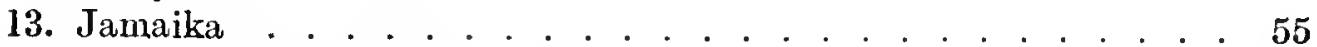

14. Der Krieg der Sklavenhalter in Amerika . . . . . . . . . 56

15. Der indische Aufstand . . . . . . . . . . . . . 58 


\section{Vierter Abschnitt.}

\section{Der neuere Imperialismus.}

16. Ägypten . . . . . . . . . . . . . . . . . . . . . . . . . 60

Das Bombardement von Alexandria 61. - Denshawai 65. Der Sudan 66.

17. Der Burenkrieg . . . . . . . . . . . . . . . 67

18. Persien . . . . . . . . . . . . . . . . . . 71

19. Der Weltkrieg 1914 ............... . 74

20. Schlußbetrachtung . . . . . . . . . . . . . . . 78

Eine Parabel . . . . . . . . . . . . . . . . . . . 80 


\section{Einleitung.}

Warum hat England dem Deutschen Reiche Krieg angesagt?

Der König und seine Minister, Schriftsteller aller Art, in Zeitungen, Zeitschriften, Büchern geben darauf eine helltönende Antwort: es ist geschehen aus sittlichen Beweggründen!

„Wir bekämpfen Preußen im Namen der vormehmsten Sache, für die Menschen kämpfen können. Diese Sache ist das europäische Völkerrecht als der sichere Schirm und Schild aller Nationen, der großen und kleinen, ganz besonders aber der kleinen. Der Lehre von der Allmacht des Staates, der Lehre, daß alle Mittel gerechtfertigt sind, die zu seiner Selbsterhaltung notwendig sind oder scheinen, setzen wir die Theorie einer europäischen Gesellschaft oder wenigstens eines europäischen Vereins von Nationen entgegen; wir setzen entgegen die Lehre von einem europäischen öffentlichen Recht, durch das alle Staaten verbunden sind, die Verträge zu achten, die sie geschlossen haben. Wir wollen und können nicht die Ansicht dulden, daß Nationen ,,in der Haltung von Gladiatoren" einander gegenüberstehen; wir setzen uns ein für die Herrschaft des Rechts... Wir sind ein Volk, in dessen Blut die Sache des Rechts das Lebenselement ist."

So die 6 Mitglieder der Oxforder Fakultät für neuere Geschichte ${ }^{1}$ ), die in Anspruch nehmen dürfen, daß ihre Stimme gehört werde.

Sie sind die Wortführer einer öffentlichen Meinung, die in Großbritannien weite Verbreitung gefunden hat. $\mathrm{Ob}$ a uch in Irland? Wird auch in Irland geglaubt, daß die Sache des Rechts das Lebenselement im Blute des Engländers ist? daß England aus Edelmut, mit Wohlwollen sich der kleinen Nationen annimmt? für sie streitet wider den „,Militarismus" um der Humanität und Gerechtigkeit willen?

„England tat sein Bestes, um den irisehen Handel zu rernichten und den irischen Ackerbau zu ruinieren. Gesetze, ron der

1) Why we are at war. Great Britains Case. 2. ed. revised. Oxford, Clarendon Press 1914, p. 115, 116.

Tönnies, Englische Weltpolitik. 
Eifersucht englischer Grundherren eingegeben, verboten die Ausfuhr irischer Rinder und Schafe nach englischen Häfen. Die Ausfuhr von Wolle wurde verboten, damit sie nicht die Profite engliseher Wollproduzenten vermindere. So wurde Verarmung dem Fluch der Mißregierung hinzngesetzt, und die Armut vertiefte sich mit dem raschen Anwachsen der eingeborenen Bevölkerung, bis Hungersnot das Land in eine Hölle verwandelte." ... ,Die Mordtaten und Tumulte, die von Zeit zu Zeit aus dem allgemeinen Elend und der allgemeinen Unzufriedenheit entsprangen, wurden in rauher Weise unterdrückt durch die herrschende Klasse..." ,Eine Weile hielten die protestantischen Landeigentümer, in Oranier-Vereinen zusammengeschweißt, das Land nieder durch schieren Terror und Blutvergießen," .... ,Irland wurde tatsächlich in die Rebellion hineingetrieben durch die gesetzlose Grausamkeit der Oranier-Landmiliz und der englischen Truppen." Dies bezieht sich auf die Zeit, die der Union (1800) vorausging.

Sind es etwa Zitate, einem Handbuch für irische Agitatoren entlehnt? Nein, es sind die Ausdrücke, welehe ein englischer Historiker von allgemeinem Ansehen gebraucht, J. R. Green, M. A., ehemals Examinator in der Schule für moderne Geschichte zu Oxford ${ }^{1}$ ). Es sind historische Tatsachen.

Und die Union? ,Kcin Ire hat nötig, dem Akte der Union eine moralische Autorität zuzngestehen ... Nach meiner Meinung hat der Engländer viel mehr Ursaehe, wegen der Mittel zu erröten, wodurch jener Akt erreicht wurde." So der ,große alte Herr", William Ewart Gladst on ${ }^{2}$ ), vor einem Parlaments-Komitee 1890. Jene Mittel waren Drohungen und Bestechungen größten Stils.

Und Irland naeh der Union? Irland im 19. und 20. Jahrhundert? - Die Geschichte seiner Bevölkerung redet eine deutliche Sprache. Irland besa 1841 ca. 8,2 Millionen Einwohner oder ca. 97 auf den Quadratkilometer: keine sehr dichte Bevölkerung für die fruchtbare grüne Insel — dieselbe Dichtigkeit etwa, die jetzt Österreich besitzt -. Im Jahre 1911 aber, nach 70 Jahren, war die Bevölkerung von Irland auf ca. 4,4 Millionen

1) A short history of the English People, 19. Thousand. London 1875, p. 786,88. Das Buch ist in England in mehr als $1 / 2$ Million Exemplaren verbreitet.

2) Morley, Life of W. E. Cladstone III, 409. 
oder beinahe auf die Hälfte zusammengeschmolzen. In diesen 70 Jahren hat die Volksmenge aller anderen europäischen Länder fortwährend zugenommen; sie hat sich in manchen verdoppelt und mehr als verdoppelt. In Irland ist sie halbiert worden. Die Dichtigkeit ist von 97 auf 52 gesunken.

Will England etwa mit seinem ,Verein der Nationen“ ebenso auf die übrigen europäischen Nationen wirken, wie es durch seinen Verein mit dem benachbarten Irland auf Irland gewirkt hat?

Wie denken die übrigen Nationen über den Segen dieser ,,europäischen Gesellschaft", deren Vorsitz als Anwalt der Gerechtigkeit England führen will?

„Gerechtigkeit für Irland" forderte das Pathos Gladstones. Dreißig Jahre lang mußte gekämpft werden, um eine sichere Mehrheit für ein Gesetz zu gewinnen, das der irischen Nation das Recht, sich selbst zu regieren, zurückgeben wollte. Das Gesetz war endlich beschlossen - und der König von Großbritannien und Irland mußte erklären (im Juni 1914), daß man an der Schwelle des Bürgerkrieges stehe. Die Regierung mußte zusehen, wie die Rebellion planmäßig vorbereitet wurde, wie die Empörung gegen ein Reichsgesetz von englischen Politikern genährt, gerüstet, geleitet wurde, des Beifalls und der Unterstützung einer Partei sich erfreute, deren Stimmenzahl in Großbritannien derjenigen der regierenden Partei ungefähr gleich ist.... ,Wir setzen uns ein für die Herrschaft des Gesetzes," sagen die 6 Gelehrten, die vermutlich alle dieser Partei angehören. Und der Sinn dieser Empörung? Der Sinn war und ist, daß Irland nicht sein Recht haben solle, daß es ferner seufzen solle unter der Knechtschaft, die es seit Jahrhunderten gequetscht und erstickt hat, daß ihm die Freiheit der Selbstbestimmung verweigert wird.

Ob das moralische Argument - so mögen wir die Behauptung sittlicher und rechtlicher Beweggründe für die englische Weltpolitik nennen - auf irische Seelen überzeugend wirke, darf man billig bezweifeln. Wo man diese Politik nicht aus so unmittelbarer Nähe kennen gelernt, oder aber die Eindrücke vergessen hat, da wird jenes Argument immer Glauben finden. Es wird geglaubt, eben weil es gut ist: wenn Menschen nicht zornig oder erbittert sind, glauben sie lieber an gute als an gemeine und böse Beweggründe der anderen; wie sie auch sich selber jene lieber als diese zutranen. 
So ist das moralische Argument vorzugsweise auf weibliche Gemüter berechnet und findet in diesen am ehesten Widerhall, teils weil sie sich gern für edle Motive erwärmen und begeistern, teils weil auch gebildete Damen selten eine genaue Kenntnis von diplomatischen Tatsachen, noch seltener eine tiefere Erkenntnis der Geschichte besitzen. Beide Arten des Wissens sind aber notwendig, um das moralische Argument richtig zu beurteilen.

Die Volksseele ist der weiblichen Seele ähnlich. Es ist immer schwierig und mühsam, mit dem Verstande die Oberfläche der Dinge zu durchdringen. Es gehören Werkzeuge und Apparate dazu, die nicht jedem zur Verfügung stehen.

$\mathrm{H}$ a m let wundert sich,

daß einer lächeln kann und immer lächeln

und - ein Schurke sein.

Aber Hamlets Oheim und Stiefvater lächelt nicht nur. Nein, er führt auch edle, feierliche Reden. Er spricht mit Kummer von seinem verewigten Bruder, den er vergiftet hat, aber mit „weisem Kummer". Sein Denken habe mit seinen Gefühlen gestritten. Staatsklugheit gebot, daß er die verwitwete Königin zum Weibe nahm:

,mit einem frohen, einem nassen Auge"...

Shakespeare hat mehr als einmal den Heuchler in klassischen Zügen geschildert, der niederträchtige Absichten im Herzen, Honigseim sittlicher Beweggründe und frommer Gesinnung auf den Lippen trägt.

Man hat die Heuchelei das Nationallaster der Engländer genannt. Ein berühmter englischer Schriftsteller der neuesten Zeit, Bernard Shaw, bemerkt in seinen Erörterungen über den gegenwärtigen $\left.\mathrm{Krieg}^{1}\right)$ :

„Wir wissen, daß selbst in Kreisen, die dem englisehen Volke am meisten freundlich gesimnt sind, eine Meinung im Umlaufe ist, die dahin geht, daß unsere ausgezeichneten Eigenschaften entstellt werden durch eine unverbesserliche Heuchelei."

Er meint, dieser Ruf könne nicht ganz von ungefähr entstanden sein. Insbesondere sci er begründet durch das Verhalten

1) "Common sense about the war". London, ,The New Statesman" 1914. 
englischer Staatsmänner. Als einen Typus in dieser Beziehung nennt er Sir Edward Grey.

In Wahrheit ist der bewußte, absichtlich und fortwährend Komödie spielende - unverschämte - Heuchler eine verhältnismäßig seltene Erscheinung. Die Rolle des Ehrenmannes ist für den Niederträchtigen, die des Sittenstrengen für den Tartüff so schwer durchzuführen, daß er im Leben wie auf der Bühne ziem. lich bald entlarvt zu werden pflegt.

Viel häufiger, weil viel leichter, ist die halb- oder gar nur viertelbewußte Heuchelei, das Betragen des Mannes, der vielleicht nicht durch sehr böse, aber durch mittelmäßige, gewöhnliche, unschöne Beweggründe geleitet wird, und es versteht, diesen einen schimmernden Aufputz zu geben, sie mit frommen und tugendhaften Reden zu verzieren. Dabei liegt sehr oft eine Mischung der gelobten Schamhaftigkeit mit der getadelten Verstellung zugrunde; denn, wie Lord Bacon in einem seiner Essays treffend bemerkt, Nacktheit des Geistes ist unziemlich wie die des Körpers ; man darf hinzufügen: auch bei Kleidern, die den Sinn verhüllen sollen, wird mehr Wert darauf gelegt, daß sie anderen gefallen, als daß sie echt und gediegen sind. Auch wird der Kluge sein Antlitz, das so leicht die wahre Denkungsart verrät, lieber in heilige und scheinbar natürliche Falten legen, als eine unbequeme und nur aus der Ferne täuschende Maske davorbinden. Utbung macht auch darin den Meister, und Gewohnheit wird zur zweiten Natur.

Diese sonderbare Mischung von Schamhaftigkeit und Heuchelei ist kaum einem Individuum, sicherlich keinem Volke gänzlich fremd. Aber es ist eine merkwürdige Tatsache, daß gerade in der englischen Nation, die im Bösen wie im Guten Stärke und Größe nicht verleugnet, eine ausgeprägte Neigung und eine offenbare Begabung dafür sich findet, und daß englische Politiker, die im Privatleben vielleicht lauter und ehrlich sind, in Staatsangelegenheiten als Meister in der Kunst sich bewähren, die Sokrates als die besondere Kunst der Sophisten gebrandmarkt hat: der Kunst, durch krumme, gewundene Reden die schlechtere Sache zur, ,besseren" zu machen.

Es ist kaum zufällig, daß die englische Sprache ein besonderes unübersetzbares Wort für diese eigentümliche Haltung des Geistes gefunden hat, die in schrägen, verstohienen, aber hochtönenden 
Worten, zur Verschleierung von Beweggründen bestimmt, ihren reinsten Ausdruck findet. Es ist das Wort ,cant", das die Sprachgelehrten vom lateinischen cantus herleiten, als ob ein singender Vortrag diese innerlich tief unaufrichtige und doch halbwegs selbstgeglaubte Redeweise erleichtere und begünstige.

Denn zum Sonderbaren des cant gehört auch dies. Je öfter er wiederholt, oder je lauter er verkündet wird, um so mehr wird er nicht nur gläubig, ja enthusiastisch aufgenommen, sondern sogar von denen, die ihn ursprünglich erfanden, selbst geglaubt, und um so zuversichtlicher, daher auch um so wirkungsvoller immer von neuem geltend gemacht.

Es fehlt den Engländern, unter denen der Wahrheit liebende Mensch keineswegs eine seltene Erscheinung ist, nicht an Selbsterkenntnis in bezug auf die verschämte Heuchelei (wie man das Wort cant vielleicht übersetzen darf). Lord Byron hat sich immer aufs neue mit Widerwillen und Bitterkeit darüber ausgelassen ${ }^{1}$ ). Eine besondere Schrift, die im Jahre 1887 Sidney Whitmann²) über den cant publizierte, gab zu vielen Kommentaren Anlaß. In Deutschland wurde das Bismarckische Lager aufmerksam darauf. Lothar Bucher, der im Exil mit den englisehen Dingen vertraut geworden war, verfaßte 2 Artikel für die ,Grenzboten“ (1888. S. 377 ff., 533 ff.) unter dem Titel ,Ein böser Geist im heutigen England" (vgl. Bucher, Kleine Schriften S.328-352). Whitman will cant als das englische Nationalgebrechen darstellen und den ungesunden Einfluß schildern, den er auf seiner Landsleute Denkungsart und Handlungsweise ausïbe. „Unsere Bigotterie und unsere Trunksucht sind allerdings weit rerbreitet, aber sie sind immerhin nur sporadisch, verglichen mit cant, der mittelbar oder unmittelbar mit fast jeder Form unserer Selbstsucht und unseres Lasters verbunden ist" (p. 22). Carlyle habe (nach seinem Biographen Froude) cant als die Kunst bezeichnet, Dinge scheinen zu lassen, was sie nicht sind; cine Kunst von so tödlieher Art, daß sie dic Scelen derer vernichte, die sie üben, da sie diese iiber das Stadium bewußterF̈̈lsehung hinaus in einen Glauben an ihre eigenen Illusionen hineinfiihre und sie auf den elendesten aller möglichen Zustände hinunterl)ringe, den wo man in anfrichtigerWeise unauf-

I) Vgl. Countess of Blessington, Conversations with Lord Byron, passim.

2) Conventional cant, its results and remedy. London 1887. 
richtig ist. An die Spitze seiner Darstellung stellt Whitm an ein Kapitel über „Pharisäismus“. Er behandelt weiterhin den ,,sozialen" cant, den cant in den Sitten, in der Presse, der Politik, den Lebensgrundsätzen der englischen Nation, d. h. vorzugsweise der Bourgeoisie (,Mittelklasse").

Die also enthïllten Tatsachen haben keine Widerlegung gefunden. Auch die eifrigsten Anwälte der englischen Ansprüche darauf, die erste Nation der Welt zu sein, müssen eingestehen, daß es mit dem cant eine eigentümliche Bewandtnis habe. Aber niemand glaubt, daß der cant ausgerottet wercen könne. In der auswärtigen Politik und in Kriegen hat er immer gewuchert. Lord Cromer, einer der angesehensten Männer des Landes (obgleich von deutscher Abstammung aus der Familie Baring) nannte noch vor kurzem die Redewendiung vom ,britischen Geist des anständigen Spieles“ (fair play) die cant-Phrase des Tages ${ }^{1}$ ).

Daß auch die Stürme des gegenwärtigen Krieges (1914/15) ganze Sandberge von cant an den Strand der Tagesliteratur werfen, kann nicht im geringsten Wunder nehmen.

Von dem Büchlein der 6 Oxforder Gelehrten ist schon die Rede gewesen.

Selbst eine so ernsthafte und geistvolle Wochenschrift wie der New Statesman (geleitet von Herrn Sidney Webb und Frau Beatrice Webb-Potter) brachte noch am 24. Oktober einen langen Artikel über clie Frage: , Warum gingen wir in den Krieg ?" Und ciie Antwort war: ,wegen Belgiens" - worauf ein Korrespondent (Herr Sadler) in der folgenden Wochennummer Einwände erhob und bemerkte: „Die Antwort schmeckt nach Henchelei.“

Allerdings: der cant schmeckt immer nach Henchelei, auch wem er nicht schiere und schamlose Heuchelei sein sollte. Aber jener Artikel hatte ganz recht, sofern er sagen wollte: der cant Sir Edward Greys über den Bruch der belgischen Neutralität und die heilige Pflicht Englands, für Belgien einzutreten, habe die öffentliche Meinung zugunsten des Krieges gewomnen. Die öffentliche Meinung Englands ist in einer wundervollen Weise dem cunt zugänglich. Sie ist wie ein automatisches Musikwerk: es brancht nur eine cant-Münze hineingeworfen $\mathrm{zu}$ werden - sogleich leiert sie ihre moralisch klingende Weise mechanisch ab.

1) Lord Cromer, Essays p. 9. 
„In der politischen Literatur Europas werden England 4 Eigensehaften zugesehrieben. Es wird behauptet, England sei in den höchsten Fragen der auswärtigen Politik unzuverlässig, stolz, selbstisch und streitsüchtig." So ein neuerer englischer Autor, der einer berühmten politischen Familie entstammt ${ }^{1}$ ). Er hätte die fünfte Eigenschaft nicht vergessen sollen, die das Charakterbild der englischen Weltpolitik ausfüllt: den gewohnheitsmäßigen cant, die eigentümliche Würze der übrigen so treffend bezeichneten Eigenschaften.

Ein einziger Affekt liegt aber allen diesen Eigenschaften zugrunde. Es ist die Furcht - englische Staatsmänner nennen sie Vorsicht und Wachsamkeit --, es ist die Furcht ror Dieben und Bettlern, die eine psychologische Schwäche vieler reicher Leute ist; die Furcht, von dem Konkurrenten geschlagen zu werden, die jeder Geschäftsmann nur allzu gut kennt. Die Furcht kann begründet sein; sie kann aber auch leicht in eine nervöse Ängstlichkeit, in ein melancholisehes Gespenstersehen entarten, und in einen Zustand rersetzen, worin der Mensch aus lauter Angst ,zu jeder Schandtat fähig" ist. Dieser pathologische Zustand ist oft durch das englische Wort spleen bezeichnet worden.

Aber sind unsere Urteile nicht durch Parteilichkeit bestimmt? Ist es nicht Feindseligkeit, was die englische Politik in ein solches Licht stellt? Spricht nicht die Geschichte dafür, daß England für Gerechtigkeit und Freiheit gestritten, daß es mit der Großmut des Löwen der kleinen und schwachen Staaten des Erdballs sich angenommen hat? - daß also seine Weltpolitik durch sittliche Beweggründe bestimmt wurde?

Un diese Fragen zu beantworten, wollen wir die Bücher der Geschichte öffnen. Wir werden nicht Historiker als Zeugen verhörn, die der Parteilichkeit irgendwie verdäehtig sein können, nicht anslänlische Historiker, die vielleicht ron dem Haß gegen das politische England angesteckt sind, sondern englische Historiker, und zwar vorzugsweise solehe, deren Autorität in Fngland selber nicht bestritten wird, ja, die als Forscher und Jenker den crsten Rang einnehmen.

Darum stellen wir an die Spitze dieser Zeugen den Verfasser der Werke ïber, ,die Expansion von England“" und über ,das

$\left.{ }^{1}\right)$ Hon. Ceorge Peel, The enemies of England. London 1902, p. 89. 
Wachstum der britisehen Politik", Sir J. R. Seeley. Die erste dieser Schriften soll uns als Fundament für die Beurteilung der Beweggründe engliseher Weltpolitik dienen ${ }^{1}$ ).

Seeley, Professor der Gesehiehte in Cambridge, wurde für seine Verdienste als Gelehrter geadelt und erfuhr auch sonst die höehsten Auszeichnungen.

Auch hat er nieht etwa den vorherrschenden militaristischen - vulgär als Jingotum bezeichneten - Strömungen der letzten Jahrzehnte sieh entgegengeworfen. Im Gegenteil. Ein hervor-

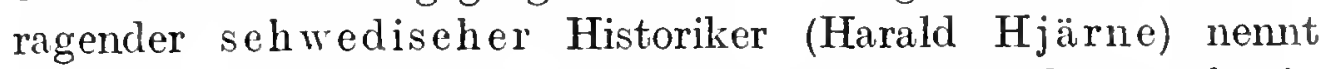
ihn den Herold des Imperialismus und meint, er könne als ein englischer Treitschke betraehtet werden. Im eigenen Lande ist seine Geltung viel höher als die Geltung Treitsehkes in deutschen Landen. So wird von Lord Cromer, dem ,Ägypter", Seeley mit Gibbon, Guizot, Mommsen als einer der bedeutendsten Schriftsteller und Denker genamnt, die die Welt hervorgebracht habe. So rühmte sehon Joseph Chamberlain in einer seiner Parlamentsreden, ,unsere größten Denker und Sehriftsteller haben dies - (imperialistisehe) - Problem uns vor Augen gestellt" und nennt als solche Seeley, Froude, Lecky. Die erste Ausgabe der ,Expansion" erschien 1883, wurde 7 mal neu aufgelegt, die zweite ron 1895 ist später noch mindestens $6 \mathrm{mal}$ neugedruckt worden $\left.{ }^{2}\right)$. Wo sind ähnliche Erfolge Treitschkes?

In englisehen Schriften und Zeitungen werden Aussprüche Treitschkes breitgetreten und in abgeschmackter Weise mit solchen ron Nietzsehe und Bernhardi verbunden, um daraus zu beweisen, wie kriegeriseh (,,ehanvinistisch“, ,militaristisch") die Gesinnung der hentigen Deutschen sei.

Nicht in diesem Simne wollen wir Äußerungen Seeleys und anderer ausgezeichneter Autoren zusammen- und entgegenstellen.

Die Gesinnungen unserer Gewährsmämner sind uns gleichgültig. Nur um dem Verdachte zu wehren, daß solehe ausgesucht würden, die England und seiner Politik unfreundlich gegen-

1) Alle Stellen, bei denen keine Quelle besonders genannt wird, sind diesem Buche entnommen; die Ziffern in Parenthese bezeichnen die Seitenzahlen der Ausgabe von 1906. schienen.

") Die „Expansion of England" ist auch in der Tauchnitz-Edition er- 
überstehen, wird es erwähnt, daß Seeley ein imperialistischer Historiker ist. Von W. H. Lecky, den wir mehrmals herangezogen haben, dürfte das gleiche gelten. Als einer der gelehrtesten und bedeutendsten Schriftsteller ist er auch im deutschen Sprachgebiet wie sonst im Auslande rühmlich bekannt.

Etwas anders ist die Bedeutung Justin Mc. Carthys, der nächst Seeley am häufigsten als Zeuge aufgerufen wird. Für die Regierungszeit der Königin Victoria (1837-1901) war dies geboten, weil es kein anderes Werk larüber gibt, das in England eine solche Popularität und ein solches Ansehen genösse, wie die „Geschichte unserer Zeit" in ihren 3 Abschnitten: 1. bis 1880 , 2. 1880-1897, 3. 1897-1903. ,Leicht und geschmackroll geschrieben, und im ganzen in hervorragender Weise verständig und gemäBigt, enthalten diese Bände eine glänzende Erzählung rom liberalen Standpunkte aus." So wird dies Werk charakterisiert in der neuesten Ausgabe der Encyclopaedia Britannica (Vol. XVII p. 201). Von J. R. Green ist schon Erwähnung getan worden.

Die übrigen Zeugen sprechen für sich selber. Neben Historikern (zu denen hier auch die Verfasser von Lebensbeschreibungen gerechnet werden) werden hin und wieder auch andere Gewährsmänmer aufgerufen, weil sie dazu dienen können, Urteile zu charakterisieren, die entweder durch die Weite ihrer Verbreitung orler durch das Gewicht ihrer Träger hervorgehoben zu werden rerdienen.

Es genüge hier, die Namen Edmund Burke, Richard Price, Herbert Spencer, Gladstone, John Morley (Gladstones Biosraph), John Bright, G. M. Trevelyan (Brights Biograph), Lord Cromer, W. S. Blunt, ron Historikern noch James Mill (auch als Philosoph berühmt), Kaye, Malleson, Holland Rose zu nennen.

Alle diese Gewährsmänmer gehören zu den Zierden der englischen Nation oder Literatur und Gelehrsamkeit.

An einigen Stellen ist noch rom Dictionary of National Biography und von der neuesten Ausgabe der ,Encyclopaedia Britannica" Gebrauch gemacht worden, deren Artikel ron den besten Kennern der Sachen verfaßt worden sind.

Endlich sind auch einzelne ÄuBerungen von Zeitschriften angezogen worden, deren Ansehen mbestritten ist. 


\section{Die englische Weltpolitik bis zum Falle Napoleons.}

Erster Abschnitt.

\section{Kriege gegen Spanien, gegen Holland, gegen Frankreich, vom 16. bis zum 18. Jahrhundert.}

\section{Die Expansion. Elisabeth, Cromwell, Karl II.}

,Zwischen der Revolution (von 1688) und der Schlacht bei Waterloo kann man rechnen, daß wir 7 große Kriege geführt haben, von denen der kürzeste 7 Jahre, der längste ungefähr 12 Jahre dauerte. Von 126 Jahren wurden 64 Jahre, also mehr als die Hälfte, in Kriegen zugebracht" (24).

Von den 7 Kriegen dieser Periode sind 5 ,,von Anfang an Kriege mit Frankreich, die beiden anderen, obschon in dem einen Spanien, im anderen Englands eigene Kolonien die kriegführende Macht waren, wurden binnen kurzem (und endeten als) Kriege mit Frankreich (28). Nach der 7jährigen Pause, die dem spanischen Erbfolgekrieg folgte, kann man die folgenden Kriege , fast als einen einzigen" betrachten, sie bedeuten ,ein großes und entscheidendes Ringen zwisehen England und Frankreich" (31).

,Die Ausbreitung Englands in der Nenen Welt und in Asien ist die Formel, die für England die Geschichte des 18. Jahrhunderts ausdrückt ..." ,Der große dreifache Krieg um die Mitte dieses Jahrhunderts (1744-1763) ist nicht mehr oder weniger als der große entscheidende Zweikampf zwischen England und Frankreich um den Besitz der Neuen Welt" (33). — ,Wir hatten einen Mitbewerber in der Besiedelungsarbeit, einen Mitbewerber, der in einigen Beziehungen den Vorsprung vor uns hatte, nämlich 
Frankreich" (34). - „Die Feststellung, daß Ausbreitung das Hauptmerkmal der englisehen Geschichte im 18. Jahrhundert war .... bedeutet, daß die europäisehe Politik und die Kolonialpolitik nur versehiedene Seiten der einen großen nationalen Entwicklung sind" (42).

Seeley wendet anch den Blick zurück auf die Vorgeschichte dieses Zeitraumes, auf clas britische Ancien Régime.

„Es seheint uns klar zu sein, daß wir die große wandernde, arbeitende, kolonisierende Rasse sind, abstammend von Seeräubern und Wikingern. Das Meer, so meinen wir, gehöre uns durch den Willen der Natur, und auf dieser Hochstraße arbeiten wir, die Erde zu unterjoehen und zu bevölkern" (94). In Wahrheit ist die ,,maritime Größe Englands weit mehr neuzeitliches Wachstum, als die meisten von uns sieh eimbilden. Sie datiert ron den Bürgerkriegen des 17. Jahrhunderts und von den Taten Robert Blakes ... Es gibt freilich Seehelden vor der Zeit Blakes. Da ist Franeis Drake und Richard Grenville und John Hawkins. Aber die Flotte der Elisabeth war nur die englische Flotte in ihrer Kindheit, und die Helden selber sind kaum etwas anderes als Freibenter (are not far removed from buccaneers)" (96). ,Von dem Gesiehtspunlte gesehen, unter dem hier die englische Geschiehte betra ehtet wird, ist diegroße Begebenheit des 17. Jahrhunderts ror 1688 nicht der Bürgerkrieg oder die Hinrichtung des Königs, sondern die Einmischung Crom wells in den europäischen Krieg. Dieser Akt kamn beinahe als Begründung des englisehen Weltreichs betraehtet werden" (130). Die elsten Stuarts kehrten ihr Antlitz mehr nach der Alten Welt als nach der Nenen. ,A ber diese Reaktion nimmt ein Ende, als die republikanisehe Partei zur Macht gelangt. Es beginnt nun eine Politik, die freilich ganz geriß nieht sehr durch Gewissens bed en ken gehemmt wird, die aber gescheit, entschlossen und erfolgreieh ist. Sie ist ozeanisch und bliekt nach Westen wie die Politik der letzten Tahre der Elisabeth": (131). Die Kolonia]politik Cromwells interessient hamptsächlich als das Muster, noch dem Karl II. sich richtet. ,Moralische Vortreffliehkeit ist schwerlich eins ihrer Merkmale, und wenn sie religiös ist, so würde dies rielleieht, wenn das Protektorat länger gedauert hïitte, sieh als ihr gefährliehster Charakterzug erwiesen haben. Vichts ist gefährlieher als ein Inperialismus, der eine Idee auf sein 
Bamer sehreibt, und für diesen Imperator Oliver war der Protestantismus, was die Ideen der Revolution für Napoleon und für seinen Neffen waren" (133). „Wir mögen wohl sehaudern bei der Vorstellung von der Gefahr, die durch den Sturz des Protektorats beseitigt wurde" (134). Diese imperialistische Politik entwiekelte sieh vorzugsweise in bezug anf die Nene Welt. „Cromwells Politik hat hier eine ausgesprochen unbesehränkte und skrupellose Färbung. Rein aus seiner eigenen Willkür, ohne mittelbar oder unmittelbar das Volk zu befragen, und der Opposition in seinem Rate zum Trotz, stürzt er das Land in einen Krieg mit Spanien. Dieser Krieg wird begonnen nach Art der alten Elisabethanischen Seeräuber (sea-rovers) durch einen plötzlichen Landungseinfall, ohne vorausgegangenen Streit oder Kriegserklärung, in San Domingo" (134). Sir J. Stephen empfahl einmal seinen Zuhörern, ,wenn sie Neigung hätten zum Bilderstürmen, diese anzuwenden auf den seeräuberischen Cromwell" (upon the buccaneering Cromwell) (ib.). Am meisten charakteristisch für diese Periode und ihre Fortsetzung ist aber nicht der Krieg mit Spanien, sondern der Krieg mit Holland. „Wenn Cromwells Bruch mit Spanien durch seine ge waltsa me Plötzlichkeit am sehlagendsten den Geist der nenen kommerziellen Politik verrät, so kam sie doeh mißdeutet werden" (135). Man könnte meinen, sie sei gegen Spanien als die große katholisehe Macht geriehtet gewesen. „Das starke Beweisstück, daß ein anderer Grund rasch in den Vordergrund tritt, nämlich die große Handels eifersucht, die durch die Nene Welt hervorgerufen wird, liefert die Tatsache, daß durch das ganze mittlere 17. Jahrhundert England und Holland große Seekriege von einem Charakter, wie er niemals zuvor bekannt war, geführt haben" (ib.). Karl der Zweite wird oft wegen der schrankenlosen Unsittlichkeit seiner auswärtigen Politik getadelt. In Wahrheit folgte er aber nur den Beispielen, die von der Republik und von Crom w ell gegeben waren. Daher wurde seine Regierung auch unterstützt von einigen Lenten, welche die Tradition der Republik geerbt hatten. „Anthony Ashley Cooper, ein Mann von Cromwellschen Ideen, unterstützte sie, indem er den alten Satz zitierte: Delenda est Car. thago. Mit anderen Worten: „Holland ist unser großer Nebenbuhler im Geschäft, auf dem Ozean und in der Neuen Welt. Lasset uns also Holland zerstören mit Hilfe einer katholischen Macht": 
(136). Das waren die Grundsätze der Republik und des Protektors, die, obgleich Puritaner, erkannt hatten, ... daß die Rivalität der Seemäehte um die Geschäfte und um die Herrschaft in der Neuen Welt die Stelle der kirchliehen Streitigkeiten einnahm als die Frage des Tages" (ib.). - Die Folge war: Eroberung. So wurde Jamaika unter Cromwell von Spanien, Bombay unter Karl von Portugal, New York ebenso unter Karl von Holland gewonnen.

\section{,Bukaniere.6}

Es wird also von diesem Historiker, der seme Begeisterung für das „Größere Britannien“, so sehr er des objektiven Urteils sieh befleißigt, nieht verhehlt, die Begründung des Reiehes Nünnern zugeschrieben, die er als, Buecaneers" bezeiehnet. Diese Zusammenstellung tritt hier nicht zum ersten Male auf. So heißt es schon in einem Büchlein aus dem Jahre 1837, das der Verherrlichung kühner Seereisen gewidmet ist: Obgleich der Name Bukaniere, , verknüpft mit einer Tugend und mit 1000 Verbreehen $^{\text {(1) }}$ ), aus riel späterer Zeit stamme als die Ära Drakes und seines verwegenen Nachfolgers Oxenham, ,so liegt doeh keine Verletzung der Wahrheit darin, wenn man ihnen den Leumund zuschreibt, welchen jener Name anzeigt: den Leumund nämlich sehonungslosen Plïnderns zu Wasser und zu Lande, im Frieden und im Kriege ${ }^{\text {" }}$ ). - Die eigentlichen Bukaniere — ,ein Name, der nur allzubald mit jeder Art von Blutschuld und Ungehenerlichkeit befleekt war' ${ }^{\text {(3) }}$ - gehören dem 17. Jahrhundert an; sie sind aueh unter dem Namen Flibustier bekannt, und nannten sieh selber die ,Brüder der Küste"

\section{உ. Handel und Krieg. - Die sittlichen Beweggriinde.}

Mehr und mehr tritt also an Stelle der Freibeuterzüge der Seekrieg, zuerst der Krieg gegen Holland, dann der große Zweikampf mit Frankreich um die Nene Welt. Die Darstellung Seeleys

1) Byron The corsair Ges. III v. 24. Übers. Gildemeister I S. 146.

$\left.{ }^{2}\right)$ Lives and voyages of Drake, Cavend ish and Da mpier, including a riew of the History of the Buecaneers. London 1837, p. 183.

s) a. a. O. S. 194, wo auch von der ,,vollkommenen Gewissenlosigkeit dieser Desperados" gesprochen wird. 
gipfelt in Herausheben der Bedeutung dieses Zweikampfes. Er soll das weithin sichtbare Beispiel geben, daß ,die Ausbreitung Englands weder ein ruhiger Prozeß gewesen ist, noch bloß in jünster Zeit vor sich gegangen ist: daß vielmehr das 18. Jahrhmolert hindureh jene Ausbreitung ein aktives Prinzip der Friedensstörung war, eine Ursaehe von Kriegen, die sowohl an Gröle als an Zahl nieht ihresgleichen haben" (125).

Weleher Art waren die Ursachen und Beweggründe dieser Kriege? Hören wir auch darauf dic Antwort des philosophischen Historikers.

„Es scheint mir der Haupteharakterzug dieser seiner Entwicklungsphase, daß England zugleich auf den Handel und auf dien Krieg expicht ist" (127). ,Die Kriege des 18. Jahrhunderts waren unvergleichlich größer und belastender als diejenigen des Mittelalters. In geringerem Grade waren schon die Kriege des 17. Jahrhunderts bedeutend. Diese beiden sind aber genau die Jahrhunderte, in denen England mehr und mehr ein handeltreibendes Land wurde. In Wahrheit wurde England zu jener Zeit um so mehr kriegerisch, je mehr es dem Handel sich hingab. Und es ist nicht schwer zu zeigen, daß eine Ursache wirksam war, die Krieg und Handel gleichzeitig wachsen ließ. Diese Ursaehe ist das alte Kolonialsystem (128), dessen Wesen darin besteht, daß es ,der Kolonie nicht sowohl die Stellung eines verbündeten Staates, als vielmehr die eines eroberten Landes gibt" (77). — Der Handel mag an und für sich den Frieden begünstigen; wenn er aber durch Anordnungen einer Regierung von einem verheißungsvollen Gebiete ausgesehlossen wird, dann begünstigt der Handel ganz ebenso natürlich den Krieg. Wir wissen dies durch unsere neuere Erfahrung mit China" $\left.(128)^{1}\right)$. Das alte Kolonialsystem ,zerlegte die neue Welt in Territorien, die wie Landgüter betrachtet wirden, deren Besitz und Genuß der jeweilig kolonisierenden Nation zustand. Die Hoffnung, solche prachtvollen Landgüter zu erwerben und die Vorteile zu genießen, die aus ihnen sich ziehen ließen, stellte den stärksten Stachel für den Handel dar, den man nur je gekannt hatte, und es war ein Stachel, der ohne UnterlaB Jahrhunderte hindureh

1) Anspielung auf den Opiumkrieg. Vgl. unter 10. 
gewirkt hat ... Aber untrembar rom kommerziellen Stimulus war der Stimulus internationaler Rivalität. Das Ziel jeder Nation war nunmehr, ihr Geschäft zu rermehren, nicht dadureh, daß man wartete auf die Bedürfnisse der Menschen, sondern dadureh, daß man sich in aussehließenden Besitz irgendeines reiehen Gebietes in der Neren Welt setzte. Möge nun sonst ein natürlicher Gegensatz zwisehen dem Geiste des Handelsgesehäftes und dem Geiste des Krieges bestehen oder nicht - Handel, der nach dieser Methode betrieben wird, ist fast identisch mit Krieg und mu beinahe notrendig Krieg im Gefolge haben. Was ist Eroberung, wenn nicht Aneignung ron Territorium? Aneignung von Territorium aber wurde unter dem alten Kolonialsystem die oberste nationale Angelegenheit. Die 5 Nationen des Westens (Spanien, Portugal, Frankreich, Holland, England) waren in einem leidensehaftlichen Wettsegeln um Territorium begriffen, d. h. sie waren in ein Verhältnis zueinander gesetzt, worin das Traehten naeh Reichtum ganz natïrlich zu Streitigkeiten führte, ein Verhältnis, worin, wie gesagt, Handel und Krieg unlösbar miteinander rerflochten waren, so daß Handel zu Krieg führte und Krieg den Handel förderte. Sehon ganz frühzeitig zeigte sich der Charakter des also eröffneten neuen Zeitalters. Man erwäge die Beschaffenheit jenes langen, sprunghaft verlaufenden Krieges zwisehen England und Spanien, worin die Expedition der Armada das auffallendste Ereignis bildete. Ieh habe erklärt, daß die englischen Seekapitäne Seeräubern sehr ähnlich sahen, und wahrlieh ist für England der Krieg durchweg eine Industrie, ein Weg zum Reichtum, das am meisten blïhende Geschäft, die an meisten rorteilhafte Kapitalanlage jener Zeit. Jener spanische Krieg ist tatsächlich die Wiege des englischen auswärtigen Handels. Die erste Generation ron Engländerm, die Kapitalanlagen suehte, legte es in jenem Kriege an. Wie wir jetzt unser Geld in Eisenbahnen und was weiß ich wuchern lassen, so nahm damals der Privatmann ron lebhafterem Geschäftssinne Parten in dem neuen Schiff, das John Oxenham oder Franz Drake ansriisteten in Plymouth, bestimmt wie es war, der Silberflotte aufzulavern oder die spanisehen Städte im Golf ron Mexiko anzufallen. Und doch waren die beiden Länder nicht einmal in förmlichem Kriegszustande miteinander. So 
machte das Monopolsystem in der Neuen Welt Handelsverkehr und Kriegsverkehr ununterscheidbar roneinander. Die Blüte Hollands war der nächste und noch auffallendere Beleg desselben Gesetzes. Was, sollte man denken, wäre verderblicher als ein langer Krieg, zumal für einen kleinen Staat? Und doch machte Holland sein Glück in der Welt durch einen Krieg ron mehr als 80 Jahren mit Spanien. Wie kam das? Weil der Krieg die gesanten unbegrenzten Besitzungen seines Gegners in der Neuen Welt seinem Angriff bloßlegte, die ihm im Frieden rerschlossen gewesen wären. Durch Eroberung machte Holland für sich ein Kolonialreich, und das Kolonialreich verschaffte ihm den Reichtum“ (130). - In Hollands Fußtapfen trat England. Den Kriegen gegen Holland folgte das Bündnis. Gemeinsam wandten sioh beide Länder gegen die neu emporkommende Kolonialmacht Frankreichs. Das Ministerium Colberts bedeutet den bewußten Eintritt Frankreichs in den Wettbewerb der westlichen Staaten um die neue Welt. Bei dem Bündnis der beiden Seemächte, das Wilhelm ron Oranien zum König ron England machte (1688), handelt es sich scheinbar um das gemeinsame protestantische Interesse gegen die katholische Reaktion, die in der Aufhebung des Edikts von Nantes ihren Ausdruck fand. Auch hat zunächst und unmittelbar dieser Beweggrund sicherlich mitgewirkt. Wenn man aber zurückblickt rom Utrechter Frieden (1713) auf die Ereignisse, die in ihm gipfelten, so gewinnt man die richtige Ansicht ron den stärkeren und tiefer liegenden Beweggründen. Denn in den Punktationen dieses Friedensvertrages verrät der „spanische Erbfolgekrieg“ seinen, ,intensir kommerziellen Charakter" (151). ,In Wirklichkeit ist es der geschäftsmäßigste (the most business-like) ron allen unseren Kriegen, und er wurde geführt im Interesse englischer und holländischer Kaufleute, deren Geschäft und Lebensunterhalt auf dem Spiele stand." Die drohende Vereinigung des spanischen Reiches mit Frankreich hätte ihnen beinahe die ganze Neue Welt rerschlossen gehabt; die Franzosen begannen eben, den Mississippi zu erforschen und zu besiedeln. ,Hinter all der höfischen Narretei des Grand Siècle stehen kommerzielle Interessen, die jetzt die Welt beherrschen wie niemals zuror, und so blieb es während des größten Teils des prosaischen Jahrhunderts, das jener Krieg eröffnete" (132). In der Geschichte der Ausbreitung Englands bezeichnet der 
Ctrechter Friede eine der bedeutendsten Epochen. England war nun der erste Staat in der Welt und blieb eine Reihe ron Jahren ohne Riralen. Hollands Abnahme machte sich bemerkbar. Frankreich War für eine Zeitlang gelähmt. Englands positirer Gewinn war außer Gibraltar. Minorka. Neuschottland, Neufundland, der berufene Assiento, jener Staatstertrag. der dem englischen Kaufmann das Monopol des Sklarenhandels nach dem spanischen Amerika rerlieh. - Englands Kolonialreich war dem Umfange nach noch unbedeutend im Tergleich mit dem spanischen und sogar mit demjenigen Portugals. Auch Frankreich war noch in mancher Hinsicht iiberlegen. Frankreichs Kolonialpolitik schien erfolgreicher zu sein. Gegen Spanien und Frankreich richtet sich jetzt die Rivalität Englands, aber der Hauptdruck fällt auf Frankreich als Englands Nachbar in Amerika und in Indien. Die entscheidende Begebenheit in dem großen Duell zwischen England und Frankreich ist der 7 jährige Krieg und die neue Stellung, die England einnimmt infolge des Pariser Friedens ron 1762. . Hier ist der Giptelpunkt der englischen Macht in 1S. Jahrhundert: ja im Vergleich zu andern Staaten ist England seitdem niemals wieder so groß gewesen" (160). In dieser seiner kulminierenden Phase wird England zum Gegenstand der Eifersucht und Furcht für ganz Europa. wie Spanien und nach ihm Frankreich es im 17. Jahrhundert gewesen waren:" (161). Der ,kommerzielle Staat", den Seele humen) Werkes über das Wachstum der englischen Politik widmet, war etabliert: , ein Staat". heißt es darin, ,trat in die Erscheinung, der dem antiken Karthago so sehr ähnlich war, wie die großen Staaten der heutigen Welt den kleinen Staaten des Altertums gleichen können $\left.{ }^{1}\right)^{*}$.

Dieser Höhepunkt war also erreicht durch eine lange Reihe ron Kriegen. Ihrem Wesen nach waren alle diese Kriege Angriffskriege. Welcher Art und wie rerschieden auch die Forwände oder unmittelbaren äußeren Anlässe sein mochten, die inneren und wahren Beweggründe, die England bewogen, diese Kriege zu führen, sind alle ron einer Art: das materielle Interesse, das Trachten nach Handelsgewinn und infolge daron Handelseifersucht und Mißgunst gegenüber den Konkurrenten, die

i) Seeley, Growth of british policy II, p. 381 . 
aus solchen Beweggründen mit Gewalt rertrieben oder niedergemacht werden

So belehrt uns das sachkundige und sicherlich nicht zuungunsten seines Taterlandes gefärbte Trteil Sir J. R. Seeleys.

Im großen und ganzen hält $\in \mathrm{r}$ sich ron Werturteilen frei. Er willnicht preisen und nicht rerurteilen, sondern rerstehen. Weiler aber immer ron Englands Macht und Größe redet, so rerwahrt er sich ausdrücklich dagegen. daß er .:die Eroberungen zu rerherrlichen oder die Mittel, die ron seinen Landsleuten dafür angewandt wurden, zu rechtfertigen meine" (155). Er zeigt: wie England seine 1 Piralen im Wettbewerb um die Teue Telt geschlagen hat. Aber er hat nicht den leisesten Gedanken, deshalb für England eine überlegene Tüchtigkeit oder Tapferkeit in Anspruch zu nehmen. Er will seine Leser nicht ermuntern: Drabe oder Hawtins, oder die Republik oder Cromwell oder gar die Regierung $\mathrm{K}$ arls des Zweiten zu loben. .Freilich, es ist nicht leicht, das sittliche Verhalten derer: die das größere Britannien aufgebaut haben, zu billigen, wenn es auch genug z11 bewundern gibt in ihren Leistungen. und riel weniger zu tadeln oder darob zu schaudern, als in den Taten der spanischen Abenteurer." (156). Er betrachte die Sachen als Denker: :um die Gesetze zu entdecken, nach denen Staaten sich erheben, sich ausbreiten, blühen oder rerfallen in dieser Welt" (ib.). Er will auch Licht auf die Frage werfen, ob das größere Britannien, da es nun rorhanden sei, roraussichtlich weiter bïhen und dauern oder in Terfall geraten werde. , Vielleicht mag man fragen, ob wir erwarten oder wïnschen sollen, daß es gedeihe, wenn Terbrechen an seiner Herstellung teilgehabt hat" (ib.). Aber der Gott, der sich in der Geschichte offenbare, urteile gewöhnlich nicht auf diese Art. Aus gesetzwidriger Erwerbung ron Staatsgebiet folge nicht die Wahrschemlichkeit, daß es wieder verloren werde. .. Wenn wir das britische Weltreich mit anderen Weltreichen reagleichen in bezug auf seinen Ursprung: so werden wir sehen, daß es in gleicher Weise wie diese entstanden ist: daß seine Gründer die gleichen Motire gehabt haben, und zwarnicht Forzugsweise anständige Motive: daß sie riel wilde Habgier, gemischt mit Heroismus, entfaltet haben; da sie durch moralische Skrupel sich wenig haben beunuhigen lassen. wenigstens nicht in Behandlung ihrer Feinde und ihrer Rivalen, 
obwohl sie oft tugendhafte Selbstrerleugnung im Verkehr miteinancler geübt haben" (157). Verglichen mit anderen Reichen sei ihnen eher ein besseres als ein schlechteres Zeugnis zu geben; namentlich das spanische sei noch ungleich mehr mit Grausamkeit und Raubgier befleckt. Man begegne aueh edlen Zügen in der Geschichte der britischen Konquistadoren. ,Ihre Verbrechen andrerseits sind derart, wie sie beinahe allgemein gewesen sind in der Kolonialgeschichte" (157).

Vermutlich werden Spanier, Franzosen, Holländer zu einem etwas anderen Ergebnis bei Abwägung dieser Verbrechen gegeneinander gelangen.

Aber gewiß ist, daß sie alle um 1770 als Kolonialmächte England gegenüber in den Hintergrund gedrängt waren.

\section{Die Glorie des älteren Pitt. - Triumph iiber' Frankreich.}

Um diese Zeit stand der ältere Pitt, seit 1766 Earl of Chatham, auf der Höhe seiner Erfolge, seines Einflusses, wenngleich seine Popularität die Erhebung zum Peer nicht überlebte. Er hatte den Krieg gegen Frankreich durchgefïhrt, gegen fortwährenden heftigen Widerstand, trotz anfänglicher Mißerfolge in Amerika und in Deutschland, wo er den genialsten Feldherrn des Zeitalters für sich fechten ließ. Bekannt ist sein Ausspruch, er erobere Amerika in Deutsehland. ,Nieht zufrieden damit, Frankreichs Flotten beinahe vernichtet zu haben, wünsehte er, dieses Land seines ganzen Kolonialreiches zu berauben und ihm jeden Anteil an der Fischerei von Neufundland, die in seinen Augen die Brutstätte für Frankreichs Seeleute war, abzusehneiden. Vor einiger Zeit, sagte or inmitten seiner Triumphe, wäre ich noch zufrieden gewesen, Frankreich auf die Knie zu beugen; jetzt werde ich nicht ruhen, bis es anf dem Rüeken liegt. Er bekannte einmal mit überraschender Offenheit, er liebe einen elırenhaften Krieg; von dem Elend, das der Krieg hervorruft, scheint er sich niemals eine richtige Vorstellung gemacht zu haben $\left.{ }^{1}\right) .{ }^{\text {" }}$

Leeky hebt hervor, daß er als Liebhaber des Krieges in voller Úbereinstimmung mit den Wünsehen des Volkes gewesen sei.

1) Lecky, Hist. of the 18. century II, 512. 
Er hatte sich zum Ziele gesetzt, den Patriotismus im Sinne der Machtvermehrung gegenüber dem, unvermeidlichen und natürlichen Feinde" (Frankreich) anzufachen und der Schwäche, Anarchie und Korruption ein Ende zu machen, von der nach seiner Ansicht die neuere englische Politik erfüllt war. Die Selbstsucht, die Unfähigkeit, die Intrigen und die Eifersüchteleien der Großen des Landes betrachtete er als Hauptursachen jener Úbel $^{1}$ ). Sein Vaterland mit kriegerischem Ruhm zu krönen, war sein Ziel und sein Erfolg. Er machte mit vollem Bewußtsein seine Politik dem Handelsinteresse dienstbar.

\section{Der Abfall der nordamerikanischen Kolonien.}

Aber die glänzende und siegreiche Entwicklung des britischen Kolonialreichs in 18. Jahrhundert setzte sich nicht ohne Unterbrechung fort. Es erfolgte ein Rückschlag, eine plötzliche Erschütterung, deren weitreichende Folgen man nicht ahnte, als sie sich ereignete: der Abfall der amerikanischen Kolonien, die beinahe das ganze damalige Kolonialreich ausmachten. „Wie eine Seifenblase breitete das größere Britannien rasch sich ans und platzte dann. Es hat seitdem aufs neue seine Ausbreitung vollzogen. Können wir die naheliegende Schlußfolgerung vermeiden?" (176).

Seeley wehrt diese Schlußfolgerung ab, weil an der amerikanischen Revolution das alte Kolonialsystem schuld gewesen sei, das die Kolonien wie einen Sklaven behandelte. Noch sei kein klares und durchdachtes neues System an dessen Stelle getreten. Für das allein mögliche erklärt Seeley ein System, das die Kolonien zu Teilen von England mache, wie sie sonst für Besitzungen Englands gehalten und als solche behandelt wurden.

Tatsächlich steht noch heute das alte Kolonialsystem in voller Kraft gegenüber Indien und allen kleineren Kronkolonien, gegenüber Ägypten, Persien und allen Gebieten der ,Einflußsphären“*

${ }^{1)}$ Lecky III, 111. Nach dem Falle Pitts ließ sein Nachfolger, Lord Bute, Preußen im Stiche (1762). Pitt bezeichnete dies als hinterlistig, betrügerisch und verräterisch. Bute und sein König boten zugleich der Zarin Ostpreußen, der Kaiserin Schlesien an, um den Frieden zu erkaufen. J. R. Green nennt dies, schamlose Gleichgültigkeit gegen die nationale Ehre“, nur durch glückliche Zufälle sei England vor dieser Erniedrigung bewahrt geblieben: Short History, p. 743. 
In den Worten Edmund Burkes (in seiner berühmten Rede über amerikanische Stenern am 19. April 1774) war die Kolonialpolitik ron Anfang an ausschließlich kommerziell, und das kommerzielle System war das System eines Monopols. ,Kein Geschäft wurde von diesem Zwange frei gelassen, außer um die Kolonisten in den Stand zu setzen, über das zu verfügen, was wir im Verlaufe unseres Geschäftes nieht nehmen konnten; oder um sie in den Stand zu setzen, über die Artikel zu verfügen, die wir ihnen aufzwangen und wofür sie, olne ein gewisses Maß von Freiheit, nicht bezahlen konnten .... Dies Prinzip des kommerziellen Monopols geht durch nicht weniger als 29 Parlamentsakte hindurch, von 1660 bis zur unseligen Periode von 1764." Burke nennt den Zustand Amerikas während dieses Zeitraums einen Zustand bïrgerlicher Freiheit, kommerzieller Knechtsehaft $\left.{ }^{1}\right)$.

Um dieselbe Zeit schrieb Richard Price seine, ,Beobachtungen ïber das Wesen der bürgerlichen Freiheit, die Prinzipien der Regie"ung und die Gerechtigkeit und Politik des Krieges mit Amerika". Dies Büchlein erschien in vielen Auflagen, wurde in fast alle europäischen Sprachen übersetzt und rief melır als 60 Entgegnungen hervor. Es ist eine flammende Anklage gegen die damalige englische Weltpolitik.

„,Die Schande, der ein Reich sich nnterwerfen muß dadurch, daß es Zugeständnisse maeht, ist nichts im Vergleich zu der Schande, die Angreifer zu sein in einem unrechtmäßigen Streit." Eine Schande sei der Hader mit Amerika, weil unverträglich mit den eigenen Empfindungen der Engländer in ähnlichen Fällen; schandbar sei der Krieg ferner auf Grund der Úberzeugung, die zu ihm führte und unter deren Eindruek er unternommen wurde (nämlich des allgemeinen Geschreis, das Volk von Neu-England sei ein Volk von Feiglingen); die Art und Weise aber, wie der Krieg geführt worden sei, mache ihn noch schandbarer. „Französisehe Papisten wurden aus Frankreich herangezogen. Dio wilden Indianer und ihre eigenen Sklaven sind angestachelt worden, die Kolonisten anzugreifen; und Versuche sind gemacht worden, den Beistand einer großen Horde von Russen zu gewinnen. Mit gleichen Absichten sind deutsche Truppen ge-

1) Speeches and Letters (in Morleys Universal Library): p. 38. 
mietet worden; und die Verteidigung unserer Festungen und Garnisonen wurde deren Händen anvertraut."

Durchaus in Ubereinstimmung mit Price stellen auch die neueren englischen Historiker den Soldatenschacher, der deutschen Fürsten mit Recht zur Schande gerechnet wird, als eine Schmach hin, die nicht minder auf Großbritannien fiel und die Gefühle der Kolonisten stark verbittert habe ${ }^{1}$.

\section{Der Sklavenhandel als Siiule des Reiches.}

Des Sklavenhandels gedenkt Seeley im Zusammenhange seiner Bemerkungen iiber die ,Verbrechen", mit denen das englische Kolonialreich (gleich dem spanischen und anderen) aufgebaut sei. Er nennt ihn , ,das größte dieser Verbrechen“. „England hatte schon zur Zeit der Elisabeth einen Anteil am Sklavenhandel, als John Hawkins als der erste Engländer sich hervortat, der seine Hände mit den Greueln dieses Handels befleckte. Man findet bei Haklu yt ${ }^{2}$ ) die eigene Erzählung des Hawkins, wie er 1567 an ein afrikanisches Dorf herankam, dessen Hütten mit trockenen Palmblättern bedeckt waren, wie er es in Brand steckte und das ,Glïck" (!) hatte, von 8000 Einwohnern 250 Personen, Männer, Frauen und Kinder einzufangen“" (158). ... „Wie unser Kolonialreich selber, so war unsere Teilnahme am Sklavenhandel das allmählich gewachsene Erzeugnis des 17. Jahrhunderts. Durch den Utrechter Frieden (1713) wurde der Sklavenhandel sozusagen aufgerichtet und wurde, nach dem Ausdruck Leckys ${ }^{3}$, ein zentrales Objekt der englischen Politik. Von diesem Zeitpunkt an, fürchte ich, hatten wir den Hauptanteil und besudelten uns mehr als andere Nationon mit den ungeheuerlichen und unsagbaren Greueln des Sklavenhandels" (ib.). Gemildert werde diese Schuld ein wenig dadurch, ,daß wir unsere eigenen Vergehen bekannt machten, sie bereuten und schließlich Verzicht darauf leisteten"

1) Vgl. Lecky, A Hist. of the eighteenth century Ch. 12. Sir G. O. Trerelyan, The american revolution, P. II, Vol. I, p. 34--56.

$\left.{ }^{2}\right)$ Vgl. Hakluyt, The principal navigations, voyages, traffiques and discoveries of the English nation, made by sea or on land. London 1598, 2 Voll.

3) Hist. of England in the 18. century II, 13. 
(159). Aber im ganzen habe diese Epoche (die erste Hälfte des 18. Jahrhunderts) das englische Volk säkularisiert und materialisiert wie nichts zuror, auch nicht die Restaurationszeit des leichtsinnigen Königs Karl II; niemals seien , schmutzige Motive" so auf der Höhe gewesen (Seeley meint: bis 1883).

In der Tat wird man sich der Vermutung nicht entziehen können, daß die Wirkungen, die der Sklavenhandel - der immer mit Sklavenjagd und Sklarenraub verbunden war - auf die moralischen Qualitäten des dadurch bereicherten Teiles des englischen Großbürgertums geiibt hat, nicht eben gïnstige gewesen sein können; und wenn in diesem Lande, mehr und frïher als in anderen Ländern, bittere Klagen der Menschenfreunde und Philosophen ïber die Brutalitäten des Reichtums laut geworden sind, so wird man sich der Art, wie große Stücke dieses Reichtums erworben wurden, erinnern müssen, um die Gründe solcher Klagen zil verstehen.

Im Jahre 1750 erließ das Parlament ein Gesetz gegen die Entführung ron Negerkindern (Kidnapping); es erwies sich aber als ,,völlig wirkungslos $)^{\prime}$. Zwanzig Jahre später rühmte sich der ältere Pitt (Graf von Chatham), seinen Eroberungen in Afrika während des 7 jährigen Krieges sei es zu danken, daß beinahe der ganze Sklavenhandel in britische Hände gekommen sei. Und so blickte die Menge auf diesen Handel als auf eine „Grundsäule des Reiches und rerhöhnte die wenigen Menschen, die daran Anstoß nahmen, als Verrïickte $\left.{ }^{2}\right)^{\prime}$.

1) Rose, Pitt and the national reviral, London 1909, S. 455.

2) Rose, l. e. Der Hafen von Liver pool verdankt vorzugsweise dem Sklarenhandel sein Aufblühen. Denn von allen Gesehäften, die hier ihren Sitz hatten, war dies Gesehäft, ,bei weitem das gewinnreichste ". „Es ist bereehnet worden, daß von 1783-1793 Liverpooler Sklavensehiffe 878 Rundreisen (von Liverpoel nach der Guineaküste, ron da nach Westindien und zurück in die Mündung des Mersey) machten, 303737 Sklaven an Bord hatten und diese für $15186850 £(=$ ea. 304 Millionen MIark) rerkauften." Man kann sich demnach vorstellen, welche Empörung der Gedanke, diesen Handel zu rerbieten, erregt hat. „Auch Bristol, obschon es nur 18 Schiffe in diesem Handel hatte, war in heller Entrüstung; denn es war in hohem Grade abhängig von der Zuckerraffinierung und der Rumfabrikation." ...., „Personen von rednerischer Begabung sehilderten in grellen Farben den Verfall von Großbritanniens Handelsmarine, die Abnahme des englisehen Reiehtums und das Elend einer ZuekerHungersnrit dureh Aufhören des Sklarenhandels." Rose, S. 463. 


\section{Die Eroberung Indiens.}

Úber die Eroberung Indiens hören wir zuerst den Philosophen James Mill, der die erste große Geschichte Indiens schrieb, selber Beamter der Kompagnie, die den größten Teil dieser Eroberung vollzogen hat. Er sagt: ,Die beiden wichtigen Entdeckungen, auf denen die Eroberung Indiens beruhte, waren: 1. die Schwäche der Eingeborenenheere gegen europäische Disziplin, 2. die Leichtigkeit, diese Disziplin Eingeborenen in europäischen Diensten beizubringen .... Diese beiden Entcleckungen haben die Franzosen gemacht." Soeley, der diese Stelle anführt (233), fügt hinzu, es sei völlig unrichtig, zu reden, als ob die englische Nation die Nationen Indiens erobert habe. Sie seien bezwungen durch eine Armee, von der durchschnittlich nur $1 / 5$ alls Engländern bestand. Die ïbrigen $4 / 5$ bestanden aus den Eingeborenen selbst, so daß man sagen könnte, Indien habe vielmehr sich selber erobert. In Wahrheit gab es nie einen nationalen Staat Indien. In Wahrheit handelte es sich nicht sowohl um eine Eroberung als um eine innere Revolution, das Ergebnis von Känpfen, die darauf gerichtet waren, der Anarchie ein Ziel zu setzen. Der Talisman, vermöge dessen die Kompagnie in die Lage kam, dem Reiche des Großmogul ein Ende zu machen, „,war nicht eine physische oder moralische Úberlegenheit, wie wir uns gerne einbilden, sondern eine überlegene Disziplin und ein militärisches System; diese konnten auf die Eingeborenen Indiens übertragen werden" (245).

Ob es Eroberung zu nennen sei oder nicht, gewiß ist, da:s ausschließlich Gewalt - „Blut und Eisen“ - zuerst der ostindischen Kompagnie, sodann dem Staate Großbritannien die Herrschaft über den größten Teil Vorderindiens verliehen haben. Die Führer in den entscheidenden Kämpfen des 18. Jahrhunderts waren 2 Männer, die sich durch starken Willen und nicht geringe Intelligenz auszeichneten: Lord Clive und Warren Hastings.

Clive (1725-1774) wird in der neuesten Ausgabe der Encyclopaedia Britannica (Cambridge 1910) der erste in eines Jahrhunderts glänzender Folge von jenen ,Soldaten-Politikern" (so sage man in Orient) genannt, denen Großbritannien die Eroberung und Befestigung seiner größten Dependance verdanke. Nach seiner definitiven Heimkehr fällte das Haus der Gemeinen 
einen Spruch über ihn (mit 155 gegen 95 Stimmen), daß Lord Clive,,erlangte und in seinen Besitz brachte $234000 £$ (etwa $t^{3 / 4}$ Millionen Mark) während seiner ersten Verwaltung Bengalens"; einstimmig wurden dann aber seine großen Verdienste um das Vaterland anerkannt. Der Fall Omich and wurde nichterwähnt. Omichand war ein landesverräterischer Hindu, der von Clive durch eine Urkundenfälschung gröblich betrogen wurde und infolgedessen dem Wahnsinn verfiel; der Biograph der Enzyklopädie nennt diesen Fall den einzigen von ,fragwiirdiger Ehrlichkeit". Die 234000 £ waren offenbar nicht fragwürdig. Lord Clive machte, noch nicht 50 Jahre alt, seinem Leben freiwillig ein Ende. Daß Gewissensbisse ihn geplagt haben, ist nicht wahrscheinlich, wenn er auch wußte, ,daß ein großer Teil seiner Landsleute einen grausamen und perfiden Tyrannen in ihm sah". Er litt an Anfällen ron Schwermut und hatte schon als junger Bureauschreiber in Madras zweimal einen Selbstmordversuch gemacht. Später war er leidenschaftlich dem Opiumgenuß ergeben.

Warren Hastings, als Jüngling Kontorschreiber in Kalkutta, wurde mit 39 Jaluren (1771) Gouverneur von Bengalen, einige Jahre später General-Gouverneur von Ostindien. Seine Handlungen in diesen amtlichen Stellungen veranlaßten den größten Staatsprozeß, von dem die Geschichte weiß. Der Prozeß, len das Haus der Gemeinen gegen ihn ror dem Hause der Lords fiihrte, dauerte vom 13. Februar 1788 bis zum 23. April 1795. Hauptankläger war kein Geringerer als Edmund Burke. Der Prozeß verlief schleppend, es war aber auch ein ungeheures Material zu bewältigen. Er endete mit Freisprechung von den schweren Staatsverbrechen, deren Hastings bezichtigt war, aber mit Verurteilung in die Kosten (80000 £). Das Urteil der Nachwelt - wenigstens in seinem Vaterlande - hat sich mehr und mehr zu seinen Gunsten gewandt. Selbst Maca ulays berühmter Aufsatz, der die bedentenden Eigenschaften des Mannes in helles Licht stellt, gilt heute als parteiisch und ungenan. Heute wird er als der Held verherrlicht, der zuerst ein System der bürgerlichen Verwaltung für Indien geplant und der schlimmsten Korruption unter den Beamten der Kompagnie, der systematischen und massenhaften Ausplïnderung der Eingeborenen ein Ende gemacht habe. Immerhin wird zugestanden, daß er unregelmäBige Dinge getan, den Buchstaben des Gesetzes verletzt, Ver- 
tragstreue gebrochen, Witwen beraubt hat und alles andere als ein gewissenhafter Politiker war. Die Greuel, zu denen er sich berechtigt gehalten hatte, lagen damals in unendlich weiter räumlicher Entfernung. Heute ist die zeitliche Entfernung hinzugekommen. Unter den Mohammedanern Bengalens dürfte das Gedächtnis dieser Zeit in etwas anderem Sinne lebendig geblieben sein als bei Warren Hastings' Landsleuten, wenn auch von diesen versichert wird, daß die Eingeborenen seinen Namen ,,verehren “1). „Die Klugheit und der Ruhm seiner Herrschaft - urteilt J. R. Green - komnte nicht deren schreckliche Ruchlosigkeit verbergen. Er nahm das Geld, wo er es kriegen konnte. Er verkaufte für eine wïste Summe die Dienste britischer Truppen, um die freien Stämme der Rohillas zu zermalmen. Er erpreßte eine halbe Million vom Rajah von Benares. Durch Folter und Hunger entwand er mehr als eine Million aus den Händen der Prinzessinnen von Oudh. Durch Maßregeln, die kaum weniger gewissenlos waren, hatte er von Anfang an seine Macht erlangt $\left.{ }^{2}\right) . "$ Gewiß ein würdiger Nationalheid !

Schon 6 Jahre, ehe der Prozeß begann, am 9. April 1782, legte Henry Dundas (damals neuemannter Schatzmeister der Marine, später als Viscount Melville erster Lord der Admiralität) dem House of Commons, ,die Ursachen und die Ausdehnung der nationalen Mißgeschicke im Orient dar. Er verbreitete sich über die schlechte Aufführung der indischen Präsidentschaften und des Hofes der Direktoren (der ostindischen Kompagnie): jener, weil sie die Nation um Eroberungen in Kriege stürzten, weil sie eingegangene Verträge verachteten und verletzten; weil sie das Volk von Indien plünderten und unterdrückten; dieser - ler Direktoren - weil sie Vergehungen nur tadelten, wenn solche nicht mit Profit verknüpft wären, dagegen eine sehr beständige Nachsicht übten gegen die größten Missetaten, so oft daraus ein augenblicklicher Gewinn sich ergebe. Die dreistündige Rede mündete in einer Reihe von Resolutionen, die das Haus feierlich votierte $\left.{ }^{3}\right)^{6}$.

Der Dichter Cowper klagte damals:

,England ist strenge und verkündet Tod

Für kleine Räuber, doch wenn Unterschleif

1) Vgl. Enc. Brit. 11. ed. s. r. Dict. Nat. Biogr. Warren Hastings.

2) Green, Short history p. 766 .

a) James Mill, A Hist. of the British India. Book V. Ch. 9. 
An öffentlichem Gold geschah, ist Leben sicher Und Freiheit auch; oft gibt's noch Ehren obendrein. Heimische Diebe müssen hängen, aber wer In seine Taschen, überladen und geschwollen schon, Den Reichtum indischer Provinzen legt, Den läßt man laufen, dessen seid gewiß1)."

Der Verlust der 13 Kolonien und die Aneignung Indiens wägen einander auf. In dem fortwährenden Wechsel der Geschicke, der den großen Wettstreit mit Frankreich bezeichnet, bedeutete jener Verhust eine Niederlage, dieser Gewinn einen Sieg. Das Ergebnis war mehr als ein Ausgleich. „In Indien hatten die Franzosen in weit entschiedenerer Weise als in Nordamerika den Vorsprung vor uns; wir hatten dort zunächst durchaus das Gefühl unserer geringeren Bedentung im Vergleich mit ihnen und fochten im Geiste einer hoffnungslosen Selbstverteidigung" (Seeley 35). Furcht vor den Franzosen war der entscheidende Beweggrund. „Hinter jeder Bewegung der einheimischen Mächte sahen wir französischeIntrige, französisches Gold, französischen Ehrgeiz, und niemals, bis wir Herren des ganzen Landes waren, wurden wir die Empfindung los, daß die Franzosen uns daraus vertreiben wollten .... (36). Anch hier also lag ,der Wettbewerb der westlichen Nationen um den Reichtum der Regionen, die im 15. Jahrhundert entdeckt worden waren" (305), zugrunde. Und es lag die niemals ruhende Fu r cht der englischen Politik zugrunde. So war demn die Zurückdrängung Frankreichs aus Indien die Vorbedingung der Herrschaft über die Hindus. „Diese Tatsache, rerbunden mit der anderen ebenso schlagenden Tatsache des großen Handels, der jetzt zwischen England und Indien besteht, führt sehr natürlich zu der Theorie, daß unser indisches Reich von Anfang bis zu Ende aus dem Geiste des Geschäfts emporgewachsen ist. Nachdem wir unsere Ansiedlungen an der Küste sowohl gegen die eingeborenen Mächte als gegen den Neid der Franzosen verteidigt hatten — so ist der Gedankengang -, wurden wir von dem Ehrgeiz erfaßt, unsern Handel weiter ins Innere auszudehnen; wir stießen da von ungefähr auf nene Staaten, wie Mysore und den Mahratta-Bund, die anfangs abgeneigt waren, mit uns in Verkehr zu treten, aber im Eifer unserer Habsucht

1) Vgl. Trevelyan, The american revolution II, l, p. 27. 
brauchten wir Gewalt, ließen unsere Heere los auf sie, brachen ihre Zollhäuser nieder und überfluteten dagegen ihre Gebiete mit unseren Waren. Auf diese Weise hatten wir Schritt für Schritt unser indisches Geschäft gefördert, und schließlich, als wir jede große einheimische Regierung nicht allein eingeschüchtert, sondern schlechthin über den Haufen geworfen hatten ...., da wurde, nach Entfernung aller Hemmungen, unser Geschäft enorm" (305/6). Seeley will diese Ansicht nicht ohne weiteres gelten lassen. Die Zusammenhänge seien verwickelter. Die Fortschritte des Geschäfts seien unabhängig von den Fortschritten der Eroberung gewesen. Bis 1813 sei der Handel unbedeutend geblieben, trotz der vorausgegangenen ungeheuren Annexionen; or habe erst sich entfaltet, nachdem die Gesetzgebung die ostindische Kompagnie ihres Monopols beraubt und die Gesellschaft so gut wie aufgehoben hatte. Die Perioden der Fortschritte des Handels und die der Fortschritte der Eroberung entsprechen einander nicht. Von Schutz und Verteidigung der Faktoreien habe das Imperium seinen Ausgang genommen. „In der unmittelbar folgenden Periode freilich, der revolutionären und korrupten Periode von Britisch-Indien, ist es unleugbar, da 3 wir angestachelt waren durch nackte Raubsucht. Die gewaltsamen Maßnahmen ron Warren Hastings gegen Benares, in Oudh und Rohilcund hatten die Natur von pekuniären Spekulationen" (313). Die spätere Geschichte von Britisch-Indien sei von anderer Art gewesen. - Der Scharfsinn des Historikers versagt hier. Seine Ausführungen vermögen nur zu zeigen, daß der Zusammenhang zwischen Handel und Eroberung in späterer Zeit weniger offenbar gewesen ist. Den ungeheuerlichen Mißbräuchen der Verwaltung, wodurch die Kompagnie sich ein Denkmal bleibender Schande gesetzt hat, machte ein Gesetz Pitts von 1784 und im Anschluß daran die Reformen des Lord Cornwallis, der 1786 bis 1793 Generalgouverneur war, ein Ende. Von dieser Zeit ab bestand keine Pcrsonalunion mehr zwischen den Gouverncuren und den kaufmännischen Räuberhauptleuten. Wenn aber Lord Wellesley 1798 als Generalgouverneur die Einmischung und Annexion zum Prinzip erhob und seine Nachfolger erst recht danach handelten, so werden sie nicht nur persönlich ihre Rechnung dabei gefunden haben; sie haben ohne Zweifel auch gewußt, daß sie die Quellen einer unermeßlichen Bereicherung durch den 
Handelsverkehr und die Bestenerung eröffneten. Die Taten des Lord Dalhousie, der 1847-1856 Indien regierte und ohne jeden Rechtstitel 1856 vom Königreich Oudh Besitz ergriff, wie er vorher (1851-52) Pegu den Birmanen gewaltsam abgenommen hatte, mögen nicht unmittelbar durch Habsucht bestimmt gewesen sein - Seeley meint: wenn Verbrechen, so seien es Verbrechen des Ehrgeizes gewesen (315) - ; so war es doeh nur das Handelsinteresse der Heimat und ihrer Regierung, was ihn gewähren ließ und ihn unterstützte. In der früheren Epoche war das kommerzielle Motiv teilweise durch die größere Lust und Bequemlichkeit des unmittelbaren Raubes, in der späteren durch die seheinbar rein militaristische Politik des Imperiums verhüllt. Denkt man aber die Beweggründe der Habgier weg, so wird die Eroberung Indiens durch England sinnlos. Denn sie hat nicht nur viel Blut - wenn auch zumeist nur das Blut eingeborener Söldner -, sondern auch sehr viel Geld gekostet. Es handelte sich auch hier um eine nationale Kapitalanlage im größten Stile. Als großes Verdienst wurde dem Warren Hastings angerechnet, daß er die öffentlichen Einkünfte - die zunächst der Kompagnie zuflossen - von 3 Millionen auf 5 Millionen $£$ gebracht habe.

Noch ehe Hastings' Taten und Untaten im einzelnen bekannt waren, schrieb der schon genamnte Riehard Price (a. a. O. S. 103): ,Wendel eure Augen nach Indien. Dort ist mehr getan worden, als jetzt (1778) in Amerika versueht wird. Dort haben Engländer, bewogen durch Lust am Plündern und den Geist der Eroberung, ganze Königreiche entvölkert und haben Millionen unsehuldiger Mensehen dureh die schandbarste Unter(lrückung und Raubsucht ruiniert. Die Gerechtigkeit der Nation hat geschlafen über diesen Ungeheuerlichkeiten. Wird auch die Gerechtigkeit des Himmels schlafen? Werden wir nicht jetzt verflucht auf beiden Hälften des Erdballs?"

Eine furchtbare Abrechnung vollzog sich in der sogen. Menterei (1857-1858), die in Wahrheit eine soziale und religiöse Rebellion war. $\mathrm{Vgl} .15$. 
Zweiter Abschnitt.

\section{Kampf gegen die französische Republik und gegen Napoleon.}

\section{Angriff gegen die französische Republik. - Das enrop:iische Gleichgewicht.}

In einer Aufzählung der 7 großen europäisehen Kriege, die England 1688-1815 unternommen habe, nennt Seeley die beiden letzten: Kriege gegen das revolutionäre Frankreieh. In Wahrheit war es der eine große Krieg, wemn auch unterbrochen durch den Frieden von Amiens (1802), dessen Bedingungen England nicht einhielt. Dieser große Krieg wird von Seeley als Fortsetzung und Abschluß des Streites um die Neve Welt und um Indien dargestellt. „Wie im amerikanischen Kriege (dem Abfall der Kolonien) Frankreich an England Rachenimmtfür die Austreibung aus der Neuen Welt (durch den'Pariser Frieden 1763), so macht es unter Napoleon titanisehe Anstrengungen, seine verlorene Stellung dort wiederzugewinnen" (39). Die erste Veranlassung des Krieges gab eine kontinentale Frage. Der französische Nationalkonvent hatte am 16. November 1792 beschlossen, daß die Schiffahrt in der Schelde-Mündung frei sein solle. Er gab damit kund, daß er an die von England der alten Monarchie abgenötigten Verträge - es waren nicht weniger als 5 seit dem Utreehter Frieden - sich nieht gebunden halte. In diesen Verträgen war das im westfälischen Frieden den Holländern eingeräumte Recht, Ausländer von der Scheldemïndung auszuschließen, von Frankreich anerkannt worden. Durch den BündnisVertrag von 1788 hatte überdies England diese und andere Rechte den Niederlanden garantiert. „Es war lange ein Grundsatz in Whitehall (der Straße der englischen Regierung) gewcsen, da $B$ die Pays Bas niemals an Frankreich fallen dürften. Um solches Unheil zu verhüten, hatte England mehr als ein Jahrhundert lang Gut und Blut daran gegeben ${ }^{1}$." "Scheinbar gab die Hinrichtung Ludwigs des Sechzehnten den Anstoß zum Kriegsausbruch. Man hatte scheinbar einen sittlichen Beweggrund,

1) Holland Rose, Pitt and the great war, p. 83. 
dem Treiben der Jakobiner Halt zu gebieten. Der jüngste englische Historiker der Epoche glaubt keineswegs an diesen Beweggrund. „,In keinem Sinne war der Prozeß die Ursache des Krieges. Die Frage drehte sich wesentlich um das Verhalten der Franzosen gegen unsern holländischen Verbündeten" (Rose a. a. O.S. 117). „Für Pitt und Grenville war der Krieg nicht ein Krieg um Meinungen - Monarchie gegen Republik —; es war ein Kampf, um das Gleichgewicht der Macht zu bewahren, weil unsere Staatsmänner zu allen Zeiten erkannt haben, daß dies Gleichgewicht unverträglich sei mit der Herrschaft Frankreichs über die Niederlande" (ib. 100). Das europäische Gleichgewicht ist eine andere Formel fïr die unbedingte, unter beliebigen Vorwänden durchgeführte Bekämpfung jeder europäischen Macht, die dem englischen Weltreich gefährlich zu werden droht oder scheint; und die Verbündung mit jeder anderen europäischen Macht, die gerade, aus irgendwelchen anderen Ursachen, gleichfalls im Gegensatz zur rivalisierenden Großmacht sich befindet. Die „Erhaltung" des europäischen Gleichgewichts durch England bedentet daher in der Wirkung immer Störung des europäischen Gleichgewichts und europäischen Krieg. Denn, wenn die anderen Mächte so gruppiert sind, daß sie einander das Gleichgewicht halten oder nach kurzem Kriege wieder ins Gleichgewieht kommen würden, so legt England mit Vorliebe sein Gewicht in die Wagschale, die seinen, Englands, Gegner „,in die Luft fliegen" lassen soll: dadurch erregt oder schürt und verlängert es die Kriege, um seinen Gegner zu demütigen, zu verkleinern, zu berauben. So hat die englische Weltpolitik den Nimbus gewonnen, Europa vom Tyrannen Bonaparte zu befreien. Man mag die Vorstellung ausbilden, wie sich das Schicksal Frankreiehs und Europas gestaltet hätte, wenn es England nicht als notwendig erschienen wäre, die französische Republik zu bekümpfen; daß vielleicht Napoleons militärisches Genie niemals Gelegenheit gefunden hätte, gegen Österreich ınd gegen Preußen sich zu entfalten. Aber solche Betrachtungen sind müßig. Die Bekämpfung Frankreichs (und des seit 1713 zur Dependance Frankreiclıs gewordenen Spanien) war das durchgehende und wesentliehe Motiv der englisehen Weltpolitik. Wenn irgendwo, so stehen wir hier vor dem ungeheuren Schauspiel eines Zusammenprallens der Weltmächte, deren Bahnen so vorgezeichnet waren, 
daß sie einander treffen und aufeinander stoßen mußten; denn eine Richtung auf Weltbeherrschung lag von ihren Anfängen her in der französischen Revolution, so gut wie sie der alten französischen Monarehie zu eigen gewesen war, und dadurch, daß er dieser Tendenz zum Durchbruch verhalf, wurde der ,kleine Korporal" der Testamentsvollstrecker dier Revolution.

Es ist in hohem Grade fesselnd, den Wendungen und Wandlungen der englischen Politik in diesem endlich - mit Hilfe der deutschen Großmächte - siegreichen Ringen nachzugehen. Ein Hauptkampfmittel Englands war immer der Gebranch des Kaperrechts und besonders auch die Durchsuchung neutraler Schiffe, die suf den „Convoi“" (Geleit durch Kriegsschiffe) nicht achtete. Dagegen richtete sich der Bund cer, ,bewaffneten Neutralität", der, auf russische Anregung, 1779 geschlossen, fast alle Scemächte gegen England vereinigte und zu gleichem Zwecke 1800 ernenert wurde. Daraus entsprang ein schwerer Konflikt und im folgenden Jahre Krieg zwischen England und Dänemark. Der dänische Minister Graf Bernstorff meldete nach Petersburg: England versage jede Entschädigung und treibe die Sache zum Äußersten; Englands Übermut und Gewaltsamkeit habe eine solche Höhe erreicht, daß nur eine neue Úbereinkunft der darunter leidenden Mächte sie zu dämpfen vermögen werde ${ }^{\mathbf{I}}$ ).

\section{Der Raubzug gegen Dänemark.}

Aber die willkürliche Auslegung des Völkerrechts, wodurch England von jeher die neutralen Seemächte gegen sich aufgebracht hatte, wurde bald durch eine Handlung in clen Schatten gestellt, die ganz Europa mit Unwillen und Entsetzen erfüllte. Diese Handlung war der Utberfall des inzwischen durchaus neutralen und friedlichen dänischen Reiches - die Beschießung und Verbrennung Kopenhagens.

Am 7. Juli 1807 war der Tilsiter Friede geschlossen worden. Am 21. Juli erhielt Canning einen geheimen Bericht über Napoleons Vorhaben in bezug auf Dänemark und die geheimen Artikel des Tilsiter Friedens. Weder Briefe noch Personen konnten

1) Nach dem neuesten dänischen Geschichtsschreiber Ed vard Holm, Danmark-Norges Historie VII, 1 (1912), S. 10. Aus diesem vortrefflichen Werke ist viel neues über die ganze Zeit zu lernen. 
damals von Tilsit nach London in 14 Tagen kommen. (In der Tat bezog sich der Bericht auf ein angebliches Gespräch zwischen Napoleon und dem Zaren vom 25. Juni ${ }^{1}$ ).) Am 26. Juli erhielt Admiral Gambier den Befehl seiner Regierung, in die Ostsee zu segeln. „Am 3. August erklärte der englische Gesandte Ta ylor dem Grafen Bernstorff zu Kopenhagen in einer ministeriellen Konferenz, die englische Regierung habe die bestimmtesten und unzubezweifelndsten Nachrichten erhalten, daß Rußland durch die geheimen Artikel des Tilsiter Friedens sich mit Frankreich in eine gegen England gerichtete Verbindung eingelassen habe, welcher Dänemark bereits beigetreten sei. Und in der Mitte des Augusts erklärte der Staatssekretär Canning offiziell, die englische Regierung habe jetzt die authentische Anzeige erhalten, daß nunmehr die Herzogtümer Schleswig und Holstein von den französischen Truppen wirklich besetzt seien $\left.{ }^{2}\right) . "$

Die Herzogtümer sind niemals von französischen 'Truppen besetzt gewesen. Ein geheimer Traktat, der dem Tilsiter Frieden folgte, hatte allerdings unter gewissen Veraussetzungen einen Zwang gegen Dänemark in Aussicht genommen. Da Canning auch im Hause der Gemeinen den Úberfall durch angebliche Kenntnis dieser Artikel rechtfertigen wollte und deswegen zur Rede gestellt wurde, mußte er einräumen, ,die Minister seien nicht im Besitze irgendeines geheimen Artikels, aber — behauptete er - der wesentliche Inhalt (the substance) eines solchen geheimen Artikels sei der Regierung vertraulich mitgeteilt worden, und zwar zu einer viel früheren Zeit" (es war darauf hingewiesen worden, daß erst am 8. August die Nachricht vom Friedensschluß und der

1) Engl. Hist. Rer. Oct. 1901, p. 717 .

2) So berichtet ein Kundiger in der anonymen deutschen Schrift, die noch im gleichen Jahre (1807) erschien: ,Ist es England gelungen, seinen Raubzug gegen Dänemark zu rechtfertigen? - Eine Untersuchung, veranlaßt durch die englische Deklaration rom. 25. Sept. 1807." - Kiel, in der Akademischen Buchhandlung, 1807. 157 S. Verfasser ist der Legationsrat Joh. Daniel Timotheus Manthey. Die Richtigkeit seiner Gesichtspunkte (außer daß er Napoleon viel zu harmlos nahm) wird bestätigt durch die neueste gründliche Untersuchung von Erik Möller in Dansk Historisk Tidskrift 1810/12, p. 309-422. Möller beweist auch, daß der wirkliche Inhalt des geheimen Traktats völlig verschieden war von dem, was man in London vermutete. Wichtig ist auch die Darstellung bei Edvard Holm, a. a. O., S. 252-340. 
Text des Vertrages Englands Küste erreicht habe): er sagt niemals, zu welcher Zeit. Auch in der ,Declaration“, gegeben Westminster, den 25. September 1807, behauptet die englische Regierung, die positivste Nachricht erhalten zu haben, daß ,der gegenwärtige Beherrscher von Frankreich" beschlossen habe, das Gebiet von Holstein mit einer Kriegsmacht zu besetzen ,zu dem Zwecke, Großbritannien von allen gewohnten Kanälen des Verkehrs mit dem Kontinent auszuschließen; den dänischen Hof zu veranlassen oder zu nötigen, den Sund gegen britischen Handel und britische Schiffahrt zu sperren; endlich sich der dänischen Marine für die Invasion von Großbritannien und Irland zu bedienen“. Diesen (vermuteten) Plänen sollte vorgebeugt werden. Ein neuerer englischer Historiker ${ }^{1}$ ), der Cannings Genie feiert und $\mathrm{ihm}$ intuitive Geisteskräfte zuschreibt, muß zugleich einräumen: „Es kann jetzt als fest bewiesen angesehen werden, daß die Kenntnis, worauf er zuerst seinen Entschluß gründete, überaus mager war. Teilweise ... war sie schlechthin falsch; aber daß sie falsch war, wußte er erst am 10. August" (am 2. September begann das Bombardement!).

Die Aktion begann damit, daß der britische Gesandte in Kopenhagen instruiert wurde, dem dänischen Minister beruhigende Zusicherungen zu geben über die Anwesenheit der britischen Flotte in der Ostsee, da sie keine Bedrohung für Dänemark bedeute, sondern lediglich bestimmt sei, mit Schweden zusammenzuwirken und die britische Landarmee (die nach Stralsund gebracht war) zu schützen. Diese Instruktion datiert vom 16. Juli. Am 28. Juli wurde ein außerordentlicher Gesandter (Jackson) zum dänischen Kronprinzen (und Regenten) abgeordnet, der am 29. eine ,spezielle und sehr geheime" Instruktion (von Canning eigenhändig) erhielt, worin es heißt: ,Sie werden sorgfältig beherzigen, daß die Besitznahme der dänischen Flotte der eine und unerläßliche Hauptzweck ist, auf den Ihre gesamten Unterhandlungen zu richten sind, und ohne welche keine andere Abmachung oder Einräumung als von irgendwelchem Werte oder Wichtigkeit betrachtet werden kann. Daher wird es sogar in dem Falle, daß

1) Ungenannt in Edinb. Rev., April 1906, S. 345-361. Daß es ein Historiker ist, der hier redet, ist offenbar. Er ist in der Lage gewesen, aus den Staatsarchiven zu sohöpfen. 
die dänische Regierung den Bündnisvertrag einzugehen bereit sein sollte, wie er in dem Ihnen mitgeteilten Antrag vorgeschlagen ist, notwendig sein, daß diesem Vertrage ein geheimer Artikel hinzugefügt wird, wonach die Auslieferung der dänischen Flotte unverzüglich, und ohne daß die Formalität der Ratifikation des Vertrages abzuwarten ist, stattfinden soll1)." Jackson brachte sein Ultimatum zuerst an den Minister Bernstorff, damn (am 9. August) wurde er in Kiel vom dänischen Kronprinzen empfangen. Die Verhandlungen waren ohne Ergebnis. Am 16. August fand die Landung der britischen Soldaten statt zu Wibeck (zwischen Helsingör und Kopenhagen). Versuche wurden noch von den Admiralen gemacht, eine friedliche Auslieferung abzunötigen. Dann begann am 2. September das Bombardement von Kopenhagen, vom 5. September ab mit furchtbarer Wirkung. Die schöne Kathedrale (Fruekirke), mehrere zur Universität gehörige Gebäude und 305 Häuser gingen in Flammen auf. Es folgte die Kapitulation und die gewaltsame Wegführung der ganzen dänischen Flotte.

Von der Tiefe der sittlichen Entrïstung, die dies Verfahren in Dänemark und in den Herzogtümern hervorrief, kann man sich eine Vorstellung bilden durch die Reihe von Flugschriften, die ,Englands Tygerpolitik gegen das neutralitätfeste Dänemark“" anklagten und die Rache des Himmels auf den Frevler herabbeschworen. Die wertvollste dieser Schriften ist die schon angezogene des Legationsrats Manthey, ron der noch der neneste dänische Bearbeiter jener Ereignisse (siehe oben) sagt, daß3 sie mit großer Kraft die hergebrachte dänische Auffassung geltend mache, und diese werde durch archivalische Forschungen aufs äußerste bekräftigt.

Es heißt darin u. a. (S. 104): ,,Jetzt, wo der Schleier zerrissen ist, der den Fürsten und Nationen bisher Englands Selbstsucht und Ehrgeiz verbarg, jetzt erwäge man, ob so manche Krone gesunken und so manches blühende Land verheert sein würde, wenn nicht Englands Politik, Englands Gold und Englands geheime Verbrechen das große Gärungsmittel gewesen wären, durch welches in unserem merkwürdigen Zeitalter die empörte Masse in Aufruhr geriet, durch welches Auflösungen, Trennungen und neue Verbindungen bewirkt wurden, und das Ganze einer

1) Rose in Engl. Hist. Review, Jan. 1896, p. 86. 
Formveränderung entgegenstrebte, deren dereinstige Vollendung der Menschheit vieles Blut und viele Tränen kostet." Die Schrift nennt (S. S) den Charakter jener Deklaration ,,im Ganzen schwach, zuweilen boshaft, immer aber ein Gewebe von Heuchelei, Arglist und Unverstand".

Es gab kein Land in Europa, das nicht in ähnlicher Weise der Empörung und dem Schauder Ausdruck gegeben hätte. In Amerika dürften diese Gefühle nicht minder laut geworden sein.

Aber auch in England selbst fand das allgemeine Entsetzen einen kräftigen Widerhall. In der Political Review für September 1807 wird die Untat eine ,,Szene komplizierter Unbill“ genannt, und nachdem alle Entrüstung über die Grundsätze, mit denen man sie verteidige (Macht allein gibt Recht u. dgl.) ausgegossen worden, heißt es: ,Wenn irgend etwas den Ekel und den Schauder, den wir fühlen, so oft wir den Gegenstand erwägen, vermehren kann, so ist es die Sprache der Humanität und des Mitleids, die ron unseren Höchstkommandierenden bei dieser Expedition geführt wurde. Diese kränkende Sprache (der cant) müsse noch mehr als die Sprache der Feindseligkeit die Gefühle der Dänen verwunden und reizen ${ }^{1}$ ).

Die Adreßdebatten des im Januar 1808 zusamunengetretenen Parlaments bezogen sich vorzugsweise auf diesen Gegenstand. Während die Adresse selber die glorreiche Tat rühmte, reichten 6 Lords einen Protest ein des Inhaltes : , Kein Beweis feindlicher Absicht ron seiten Dänemarks sei beigebracht worden uıd kein dringender Notfall bewiesen, um den Angriff auf Kopenhagen zu rechtfertigen, und so gereiche die Maßregel dem Charakter der Nation zur Unehre und ihren Interessen zum Nachteil." Stärker noch drückt ein einzelner Peer (Lord Erskine) sich aus (sein Protest füllt 4 Druckseiten des Berichtes, es heißt darin): Solange die Gerechtigkeit des Anfalles nicht erwiesen werde, habe Großbritannien seine moralische Stellung in der Welt: rerloren. - Auch im Unterhause machte die Opposition sich in schärfster Weise geltend. William Windham, der noch

1) Reflections on the war with Denmark, extracted from Flowers Political Review. Die Benutzung des äußerst seltenen Sonderdrucks verdanke ich dem gütigen Entgegenkommen der K. Bibliothek zu Kopenhagen. 
vor kurzem Kriegsminister in Pitts zweitem Ministerium gewesen war, erklärte, der einzige Weg, die Flecken zu tilgen, von denen das Land besudelt wurde, bestehe darin, daß man die Greuel öffentlich eingestehe; er klagte die Minister an, daß sie das Ansehen der Nation geopfert hätten. „,Die Ruinen Kopenhagens sind das Denkmal ihrer Schande." Ein andermal meinte derselbe berühmte Redner, die Regierung habe den Grundsatz, daß Ehrlichkeit die beste Politik sei, offen verleugnet, und wenn Leute anfingen, ihre Theorie ihrer üblen Praxis anzupassen, so sei das ein Zustand der hoffnungslosesten Verderbnis; dies neue System der Sittlichkeit werde sich als ein dauerndes Unrecht gegen die Welt erweisen. Mehrere andere Abgeordnete nannten die Versuche der Rechtfertigung widerspruchsvolles und verlegenes Hinundhergerede; man wisse nicht, welche von den Geschichten, die die Regierung auftische, man glauben solle. Es sei zwar ein grober Ausdruck, aber durchaus zutreffend, wenn man sage, daß sie das Haus um seine Meinung beschwindeln wolle. Ein Mitglied nannte die Wegführung der Flotte schlechthin ,Diebstahl“. In London wurde es sprichwörtlich: ,Ehrlos wie der Zug nach Kopenhagen.“

Noch im Jahre 1822 sprach der Dichter Thomas Campbell in Versen, die er einem dänischen Freunde widmete, von der ,skandalösen Geschichte"; wenn England zu Gericht gesessen hätte über diesc herzlosen Tories, so hätten sie dafür ,baumeln" müssen usw.

Neuere englische Historiker betrachten die Sache kalt. H. W. Wilson (Trin. College, Oxford) sagt: ,Daß der Angriff notwendig war, wird niemand heute leugnen. England kämpfte um sein Dasein; und, wie unangenehm auch die Aufgabe war, einen schwachen Neutralen niederzuschlagen, England riskierte seine eigene Sicherheit, wenn es in Napoleons Hand eine Flotte von solcher Bedeutung ließ $\left.{ }^{1}\right)$." Etwas anders im gleichen Bande der Cambridge Modern History J. Holland Rose (Cambridge): ,,Großbritannien erlitt einenVerlust seiner moralischen Reputation, der teilweise den Gewinn aufwog, der durch den Zuwachs an materieller Stärke zu seiner Flotte und das vermehrte Gefühl der Sicherheit erzielt war. Die Völker des Kontinents, unkundig der Gründe, die das Handeln Englands bestimmten, erklärten

1) Cambridge Modern History, Vol. IX, p. 236. 
es für wenig besser als eine Seeräuberei. Erst sehr allmählich verflüchtigte sich dieser üble Eindruck ...11)."

Eine äußere Ähnlichkeit besteht zwischen dieser Tat und dem Verfahren des Deutschen Reiches gegen Belgien 1914. In beiden Fällen handelte es sich darum, dem Feinde zuvorzukommen; in beiden war die Meinung, daß dieser seinerseits die Neutralität nicht achten werde. Aber man beachte die ungeheuren Unterschiede: 1. 1807 war diese Meinung eine bloße auf Gerüchten beruhende Vermutung; 1914 war sie in Tatsachen begründet. 2. 1807 hatte Dänemark selber die Neutralität peinlich beobachtet, der Regent des Landes neigte sogar stark zu England; 1914 hatte Belgien seine Neutralität gröblich verletzt durch eine Militärkonvention, die es mit England eingegangen war. 3. Das angegriffene Dänemark hatte keine Verbündeten, und selbst wenn Napoleon ihm hätte helfen wollen, so wäre er durchaus außerstande dazu gewesen. Úberdies lag die Hauptmasse der dänischen Landarmee in Holstein, und die Regierung war so ahnungslos, daß sie nicht einmal diese nach Seeland kommen ließ. Hingegen das angegriffene Belgien hatte die mit ihm heimlich verbündeten Großmächte, England und Frankreich, hinter sich; beide waren in der Lage, ihm Hilfe zu leisten. 4. England stellte Dänemark die Wahl zwischen Krieg und einem Bündnis; als Pfand für dies Bündnis forderte es die Auslieferung der dänischen Flotte, um die es ihm allein zu tun war! Das Deutsche Reich stellte die Wahl zwischen Krieg und einer Neutralität, die nur den Durchmarsch gestatten sollte, wofür vollkommene Entschädigung feierlich versprochen wurde. Es ist von manchen Lehrern des Völkerrechts ein Recht des Durchzuges durch neutrales Gebiet behauptet worden, besonders für die Fälle, wo die eine Kriegspartei ohne den Durchzug durch das neutrale Gebiet der anderen Partei gar nicht beikommen kann. Dieser Fall lag, infolge der französischen Maasbefestigungen, in offenbarer Weise vor.

1) a. a. O., S. 299. 


\title{
II. Die englische Weltpolitik im 19. und 20. Jahrhundert.
}

\author{
Dritter Abschnitt. \\ Händel in drei Weltteilen.
}

Allgemeine Betrachtung.

Die Reihe großer Kriege - meint Seeley — beginnt nicht nur mit dieser Periode (1688-1815), sondern scheint auch mit ihr zu enden. "Seit 1815 haben wir lokale Kriege in Indien und einigen unserer Kolonien [und in China! und in Persien!] gehabt, aber von Kämpfen gegen europäische Großmächte, wie die genannte Periode sie 7 mal gesehen hat, haben wir in einer mehr als halb so langen Periode (1816-1882) nur einen [den Krim-Krieg]

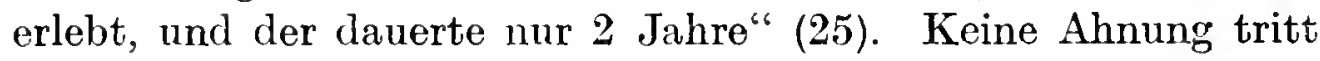
hier entgegen von dem, was das 20. Jahrhundert uns offenbar gemacht hat. Ferner vergißt der geistreiche Gelehrte, daß auch der Krieg gegen Frankreich im 18. Jahrhundert zum guten Teil anf kolonialem Boden - in Nordamerika - geführt wurde; und daß, in Analogie dazu, die meisten Kämpfe, die in Asien während des 19. Jahrhunderts entbrannten, ein latenter Krieg gegen Rußland gewesen sind; zu schweigen von Kriegen der Türken und der Japaner, hinter denen die britische Weltmacht stand. Denn die englische Weltpolitik hat in diesem ganzen Zeitraum niemals geruht und in ihrem Wesen sich nicht verändert.

Ihr Feld und Ziel liegt aber nicht mehr hauptsächlich in der Neuen, sondern in der Alten Welt, nicht mehr in Amerika, sondern in Asien, zu welchem Weltteil Afrika die Brücke bildet. Das ist die Richtung, die in der zweiten Hälfte des 18. Jahrhunderts angebahnt wurde. Den Besitz Indiens zu erweitern, zu halten und zu sichern, erseheint als die wichtigste unter den großen Auf- 
gaben, die durch endliche Verdrängung Frankreichs aus dem Wettbewerb um die Seeherrschaft gestellt waren. War die Furcht vor Frankreich bisher - über 100 Jahre lang - ein immer von neuem reizender Stachel, so tritt die Furcht vor Rußland nunmehr an dessen Stelle. Zugleich wirkt natürlich das direkte Handelsinteresse, das die Interessensphären und Herrschaften auszudehnen gebietet. Mit ihm geht das fiskalische Interesse Hand in Hand.

So ziehen sich die Unruhen und kriegerischen Bewegungen, in denen der Ware der Großindustrie auf jenen Gebieten uralter Kultur die Wege geebnet und die Tore gesprengt werden, fast das ganze 19. Jahrhundert hindurch. Mit der allmählichen Beseitigung der Herrschaft der Kompagnie, die schon seit 1784 stark eingeschränkt war, zuerst ihres Monopols (1815: nur für China blieb es bis 1833), dann ihrer Handelsfunktionen, endlich ihres Daseins (1858), läuft nicht nur die durchgreifende und wohlgelungene Reform der Verwaltung, sondern auch die planmäßige Eroberung parallel: sie gipfelt in der Etablierung des sog. Kaiserreichs Indien (1876).

Auch die neneren Wege der englischen Weltpolitik sind durch Felsen und Dickichte mit eisernen Beilen und Äxten gehauen worden, und Blut ist dabei in unendlichen Mengen geflossen.

\section{Afghanistan.}

Der erste größere Konflikt, in den Großbritannien durch diese, mit gewohnter Energie und Rücksichtslosigleit verfolgten Ziele hineingerissen wurde, war der Krieg mit Afghanistan.

Fehden zwischen diesem Reiche, den indischen Sikhs, und dem Afghanistan benachbarten Persien, lagen zugrunde. Uberall stritten englische und russische Einflüsse wider einander. So wetteiferten beide lange un die Gunst des in Kabul residierenden Herrschers über das östliche Gebiet, Dost Mohammed. Die Russen hatten die Vorhand. Sie griffen gleichzeitig, im Verein mit Persien, Herat, den Hauptort des westlichen Gebietes, an. Der im Jahre 1936 ernannte General-Gouverneur von Indien, Lord Auckland, hielt den Augenblick für gekommen, einzugreifen. Er verband sich mit den Sikhs und setzte Dost Mohammed ab. Einen unfähigen und unbeliebten Prätendenten, der trotz besseren 
Rechtstitels in Verbannung lebte, setzte er an die Stelle (7. Angust 1839). Die englische Regierung billigte und unterstützte diesen Staatsstreich. Eine Zeitlang schien alles zn gedeihen, man jubelte in London über den herrlichen Erfolg. Im November 1841 erhoben sich die Afghanen gegen den aufgedrungenen Fürsten. Das Ergebnis war eine vollkommene und als schmachvoll empfundene Niederlage der englischen Schutztruppe. Sie mußte schließlich zu schleuniger Räumung des Gebietes mit Auslieferung aller Kanonen, bis auf 6, die ihr für den Rückmarsch gelassen wurden, sich bequemen. Dost Mohammed, der als Gefangener nach Indien gebracht war, kehrte heim. Sein Sohn Akbar Khan hatte den Aufstand geleitet. Der Rückzug der Engländer durch den Koord-Kabul-Paß erimert an die große Retirade von 1812, endete aber weit schlimmer. Es war ein ebenso strenger Winter; die Lage war übler dadurch, daß viele Frauen und Kinder mitgeführt wurden. Akbar Khan, der dem Zuge folgte, nahm nach einiger Zeit die überlebenden Frauen und Kinder in seinen Schutz. Auch der General Elphinstone, der Höchstkommandierende, mußte sich ihm ergeben. Die Armee selbst wurde fortwährend von den fanatischen Gebirgsstämmen angegriffen. Nachdem schon Tausende gefallen waren, fand sich der Rest im Jugdulhk-Paß gefangen. Es folgte eine schonungslose Niedermetzelung. Von dem ganzen Heere, das noch beim Antritt des Marsches mehr als 16000 Mann gezählt hatte, blieb zuletzt ein einziger Mann übrig, der unter die Manern von Djellalabad sich rettete, welche Stadt noch von einer englischen Besatzung gehalten wurde. Die Festung wurde von Akbar Khan belagert, aber vergebens. Englische Hilfstruppen nahten unter General Pollock. Die Belagerung wurde aufgegeben. Die Engländer drangen nach Kabul vor, befreiten die Frauen und Kinder, hielten aber trotz dieses Erfolges für geraten, das Land zu räumen und Dost Mohanmed wieder einzusetzen.

Der Nachfolger Aucklands, Lord Ellenborough, erließ am 1. Oktober 1842 eine Proklamation, worin er erklärte: Die Regierung Indiens werde von nun an zufrieden sein mit den Grenzen, welche dio Natur ihrem Reiche angewiesen zu haben scheine. Und: einem widerstrebenden Volke einen Herrscher aufzwingen zu wollen, wäre ebenso unverträglich mit der Politik wie mit den Grundsätzen der britischen Regierung. Der edle Lord schoint 
die bisherigen Eroberungen in Indien für ,natürlich" und die englische Herrschaft dort für den Gegenstand der Sehnsucht auf seiten der Inder gehalten zu haben.

Von der Bestürzung und Erbitterung, die das furchtbare Fiasko im „Mutterlande“ hervorrief, kann man sich eine Vorstellung machen, wenn man in die Tagesliteratur einen Blick wirft. Ein Schriftsteller, der damals mit ungemeiner Schärfe die britische Weltpolitik kritisch beleuchtete, war der Schotte David Urquhart. Im Verlaufe seiner Polemik gegen die Edinburgh Review, die als Organ der gerade am Ruder befindlichen Whig-Partei den Krieg zu verteidigen wagte, sucht er den Wahnsinn der Unternehmung durch ein erdichtetes Gespräch zwischen Lord Palmerston - der damals, und später noch oft, der Geist der britischen Weltpolitik war - und einem Mitgliede des Geheimen Rats (Privy Councillor) klarzustellen:

Lord Palmerston: Wir müssen nach Kabul marschieren, seinen Herrscher entthronen und einen anderen einsetzen.

Geheimer Rat: Sind wir angegriffen von den Afghanen, sind Verträge verletzt worden oder dergleichen?

Lord P.: Nein, nichts von alledem. Aber Dost Moh a mmed ist freundlich für Persien, und Persien ist freundlich für Rußland. Darum müssen wir Mohammed vernichten.

Geh. Rat: Was sollen wir denn machen mit Persien?

Lord P.: Oh, Persien ist zurückgeschlagen, die Belagerung ron Herat ist aufgehoben, wir haben da nichts zu fürchten.

Geh. Rat: Was sollen wir denn machen mit Rußland?

Lord P.: Oh, Rußland hat uns die befriedigendsten Versicherungen gegeben, und wir haben nichts von ihm zu fürchten. Ganz im Gegenteil: Rußland kann überhaupt nichts machen, denn seine Missionen und Feldzüge sind völlig gescheitert.

Geh. Rat: Die Gefahr ist vorüber, die Macht, aus der sie entsprang, stellt euch zufrieden, und dennoch geht ihr und sendet Armeen in das Gebiet eines befreundeten Volkes! -

Die Geheimen Räte und der Monarch - meint dam Urqu hart - müssen sofort gesagt haben: „Das ist ein Fall für Bedlam (das Irrenhaus)."

An einer anderen Stelle kontrastiert er das Verhalten Englands mit dem der Mongolen, von denen ein arabischer Historiker sage, daß sie planmäßig verwüsteten und mordeten, aber ,ohne 
Haß und ohne Rachsueht“. ,Wir sehaffen ein Heer nach ZentralAsien in die Mitte eines Volkes, so freundlieh gesinnt, daß es sogar bereit war, unsere Herrschaft auf sich zu nehmen - wir setzen einen Prätendenten ein - wir unterstützen Torheiten und Verbreehen im Innern - wir tun alles, was ein uns sehon durch Neigung und Aehtung untertanes Volk zu Haß und Verachtung aufreizen kann. Unser Heer wird vernichtet. Wir entschließen uns, daß wir nichts mehr mit dem Lande zu tun haben wollen, und doch senden wir wiederum ein Heer hin, um zu plündern und zu zerstören, ohne auch nur daran zu denken, das Land in Besitz zu nehmen; im Gegensatz zu den Mongolen, die aus Bereehnung, ohne Haß und Rachsucht, plünderten und zerstörten, kommen unsere Truppen, gebildet aus sogenannten Bürgern und Christen, um zu verwüsten und zu zerstören, ohne irgendwelchen $Z$ weck, bewogen aussehließlich dureh Haß und Rachsucht." Der Vorwand, daß der Zweek gewesen, die Gefangenen zu befreien, sei zu hohl und sinnlos, um Beachtung zu verdienen. ,Durch die neuen Verbrechen konnten sie nur gefährdet werden, so wie dadureh, daß wir den von uns auf so verbrecherische Weise entthronten Fürsten in Kneehtschaft hielten." -

Ein tragisches Schieksal fiel durch diese Grenel auf einen treffliehen und hochbegabten jungen Mann, Kapitän Burnes, der, ein Kenner Afghanistans, mit einer amtlichen Mission betraut, rergebens vor den falschen Maßnahmen gewarnt hatte. „Man sollte nie vergessen - bemerkt Sir J. W. Kaye, dem die beste Geschiehte dieses Krieges verdankt wird -, wenn man ein richtiges Crteil über Burnes' Charakter und Handlungsweise gewinnen will, daß beide gröblich entstellt worden sind in jenen Sammlungen offizieller Urkunden, die angeblich das beste Material für die Geschichtssehreibung darbieten, in Wirklichkeit aber oft nichts als einseitige Zusammenstoppelungen entstellter Dokumente sind, die rler ministerielle Stempel in Umlauf bringt, die Zeitgenossen betrügend, der Nachwelt eine Kette gefährlicher Lügen ïberliefernd." Justin Mc. Carthy, rer diese Stelle anführt, sagt, erst Jahre naehdem Burnes sein schreckliches Ende gefunden hatte (er wurde bei dem Tumult am 2. November 1841 ermordet), sei es an den Tag gekommen, daß die englische Regierung dem Hause der Gemeinen die von Burnes eingesandten Berichte in so verstümmelter und veränderter Form mitgeteilt hatte, daß 
es aussah, als ob er die Politik gebilligt und empfohlen hätte, ror der eindringlich zu warnen er sich angelegen sein ließ.

Mc. Carthy nennt die Geschichte dieser 4 Jahre (1839/42) eine Folge von solchen Mißgeschicken, Fehlem und Demütigungen, wie die englische Geschichte keine zweite aufzuweisen habe. „Fehler, die übler waren als Verbrechen, und eine Handlungsweisc, die zu decken für jeden Herrscher ein Verbrechen wäre, brachten es dahin, daß wenige Jahre nach dem Regierungsantritt der Königin Victoria wir in Afghanistan Soldaten hatten, die sich tatsüchlich fürchteten zu fechten, und englische Beamte, die sich nicht des Versuches schämten, durch erkanften Meuchelmord unsere meistgefürchteten Feinde beiseite zu schaffen ....". „Dies Kapitel unserer Geschichte wird uns lehren, wie eitel eine Politik ist, die auf schlechten und unedlen Grundsätzen beruht ... Wir waren von unserm Wege abgeirrt, um eingebildeten Gefahren zu begegnen ${ }^{1}$ ). Immer die Furcht als der stärkste Beweggrund wahnwitziger Untemehmungen!

Durch Schaden klïger geworden, hat sich England in der 'lat 4 Jahrzehnte lang der Einmischung in die Angelegenheiten Afghanistans enthalten. Inzwischen rïckte die russische Gefahr näher. Es kam zu neuen bitteren Kämpfen. Es kam nochmals zu einem Aufruhr in Kabul. Das gesamte Personal der britischen Gesandtschaft wurcie getötet (3. September 1879). Im vorhergehenden Jahre war ihr der Zutritt ins Land verwehrt worden. Der Gewalt nachgebend, hatten die Afghanen sie zugelassen. Nach erneuten Kämpfen mußte England den Anspruch, eine ständige Gesandtschaft zu unterhalten, wieder aufgeben und versprach abermals, das Land zu räumen. Seitdem hat sich das Foreign Office um die Gunst des Emirs bemüht. In der anglorussischen Konvention vom 31. August 1907 verzichtete England auf jede Absicht, den politischen Zustand von Afghanistan zu verändern, sich in die Verwaltung einzumischen, Gebiet zu annektieren. und verpflichtete sich, seinen Einfluß in keiner für Rußland bedrohlichen Weise zu gebrauchen. Rußland anerkannte Afghanistan als außerhalb seiner Einflußsphäre liegend. - Zugeständ-

1) Justin Mc. Carthy, A History of our own times, I, Ch. II, Tauchnitz ed., p. 171, 174/5. 
nisse an Rußland waren ein integrierendes Glied der Vorbereitungen zum gemeinsamen Angriff auf Deutschland $\left.{ }^{1}\right)$. -

\section{Der Opinmkrieg und fernere Händel mit China.}

Den Afghanen wollte die englische Politik einen verhaßten Herrscher aufnötigen, den Chinesen ungefähr um dieselbe Zeit eine verhaßte Ware.

Bekanntlich hat China sich lange gegen den Zutritt aller europäischen Händler und ihrer Waren gewehrt. Nachdem die Bahn gebrochen, hatte John Company - wie man in England die ostindische Kompagnie nannte - am meisten Erfolg. Der Hauptartikel war das Opium, aus Mohnpflanzen gewonnen, die in Indien angebaut werden; der Anbau geschieht ausschließlich in Regie. Nachdem das Monopol der Kompagnie gefallen, nahm der Handel um so größere Ausdehnung an. Es war ausschließlich Schmuggel; denn aller Verkehr mit Opium war durch chinesische Gesetze streng verboten. Der furchtbare Schade für Gesundheit und Moral, Leib und Seele, den der Opiumgenuß bekanntlich zur Folge hat, war der ausgesprochene Grund des Verbotes.

Aber die chinesischen Behörden waren außerstande, dem Schmuggel zu wehren; zumal da die englische Regierung diesen planmäßig förderte. ,Das Recht oder Unrecht der Frage scheint niemals vom Ministerium irgendwelcher Erwägung wert gehalten worden zu sein." Die Schmuggler wurden dreister und rücksichtsloser, die Klagen der chinesischen Behörden lauter. Die englische Regierung erklärte, daß sie nicht gesonnen sei, britische Untertanen in die Lage zu versetzen, die Gesetze des Landes zu übertrcten, mit dem sie Handel treiben. Niemand nahm diese Erklärung ernst. Aber der Kaiser Suan-Tsung glaubte nunmehr, einen entscheidenden Schritt wagen zu können. Durch den Gouverneur Lin ließ er in Kanton die Auslieferung der gesamten Konterbande von Opium verlangen. Zwanzigtausend Kisten des kostbaren Produkts wurden durch Fener rernichtet. Der englische Agent „zur Beaufsichtigung des Handels mit China" wandte sich an den Generalgouverneur von Indien um Beistand. Leben und Eigentum britischer Untertanen sei angegriffen und in Gefahr.

1) Vgl. 18. „Parsien“. 
Er möge so viele Kriegsschiffe senden, als er entbehren könne. Der Opium-Krieg war entfesselt. Die Feindseligkeiten zu Wasser und zu Lande setzten sich vom Februar 1840 bis zum August 1841 fort. England und das Opium trugen einen ,,glorreichen" Sieg davon. China mußte 5 Häfen öffnen, Hongkong abtreten, 4\% $\frac{1}{2}$ Mill. $£$ (90 Millionen Mark) Kriegsentschädigung und außerdem 11/4 Millionen $£$ (25 Millionen Mark) für das vernichtete Opium zahlen.

Das Gewissen der Nation blieb nicht stumm. Eine Flut von Schriften, die der Scham und sittlichen Entrüstung Ausdruck gaben, ergoß sich über das Land.

Im Hause der Gemeinen hielt William Ewart Gladstone eine seiner ersten bedeutenderen Reden ${ }^{1}$ ).

„,Ich kann nicht beurteilen, wie lange dieser Krieg noch dauern mag - heißt es darin -; aber soviel kann ich sagen : einen ungerechteren Krieg seinem Ursprunge nach, einen Krieg, der mehr darauf angelegt ist, in seinem Fortgange unser Land mit Schande zu bedecken, kenne ich nicht und habe nie davon ge$\left.\operatorname{lesen}^{2}\right) .^{\text {c }}$

Nach Abschluß des Verfahrens hatte der greise Herzog von Wellington die Aufgabe, ein Dankesvotum für Heer und Flotte im Oberhause zu beantragen. „,Der Sieger von Waterloo - bemerkt dazu Mc Carthy (I S. 139, Tauchnitz ed.) - für die Truppen, die über unbewaffnete, liilflose, kindliche Chinesen triumphierten!"

Die Opiumfrage war damit nicht aus der Welt geschafft. Der Import von Opium aus Indien nach China, der 1810/11 wenig mehr als $4000 \mathrm{Kisten}$ (sog. piculs $=601 / 2 \mathrm{~kg}$ ) jährlich betragen hatte, war $1835 / 39$ auf einen Jahresdurchschnitt von ca. 351/2 Tausend Kisten angewachsen. Er nahm, allen Protesten zum Trotz, weiter zu, so daß er 1855 mehr als 78000 Kisten über die Grenzen brachte. Die englische Regierung drängte China,

1) Hansards Parl. Debates 35, vol. 53, p. 819.

$\left.{ }^{2}\right)$ J. Morley, der Biograph Gladstones, bemerkt dazu (The Life of W. E. G. I, 226): „Die Sache regte ihn auf, wie von jedem erwartet werden mußte, der den Grundsatz vertrat, daß der Staat ein Gewissen haben müsse." Morley ist derselbe, der jahrelang als Viscount Morley die gegenwärtige Regierung im Oberhause vertreten hat. Er schied aus dem Kabinett aus wegen der Einmischung in den Krieg 1914. 
den Handel, den sie doeh zu unterdrücken unfähig sei, zu legalisieren und zu einer regulären fiskalisehen Einnahmequelle zu machen. So geschah es endlich durch einen Handelsvertrag des Jahres 1858. ,Gleichzeitig aber gab es in England eine erneute Bewegung gegen die Politik, den Chinesen Opium anfzunötigen. Schon vor 1833 waren solche Stimmen laut geworden; auch außerhalb der Opposition gegen die jeweilige Regierung hatte sich ein gewaltiger Komplex öffentlicher Meinung gebilciet und zog die Führer religiöser und philanthropischer Arbeit in cie Bewegung. Ermutigt wurde die Stimmung, gestärkt ihre Kundgebung cureh lie fast einstimmige Meinungsäußerung protestantischer Missionare, englischer und amerikanischer, die auf dem chinesisehen Felde arbeiteten: dahingehend, daß das Opiumranehen ein großes moralisehes Übel sei, das ihre Bemühungen, die Chinesen zur Erkenntnis der christlichen Wahrheit zu bringen, ernstlich behindere; daß es allen christlichen Nationen obliege, sich loszusagen von einem Handel, der den Namen des Ausländers und des Christen in Verruf bringe. Die Bewegung gipfelte in einer Denkschrift, die im August 1855 von Lord Shaftesbury dem Parlament überreicht wurde; Lord Shaftesbury war der Vorsitzende eines Komitees, das sich gebildet hatte, um alle Verbindung des englischen Volkes und seiner Regierung mit dem Opiumhandel anfzulösen $\left.{ }^{1}\right) . "$

In Amerika war der Widerwille gegen die Saehe stärker als in England. Auch war der Vertreter der Vereinigten Staaten der einzige, der bei den Verhandlungen der Jahre 1842/44 das chinesische Verbot des Opiumhandels ausdrücklich unterstützte, und viele amerikanische Kauflente in China sollen aus sittlichen Bedenken von jeher der Teilnahme daran sieh enthalten haben. Auch hat die amerikanisehe Regierung der Philippinen eine internationale Opium-Konferenz zu Schanghai veranlaßt, die am 1. Februar 1909 zusammentrat und es für die Pflicht der Regierungen erklärte, die Ausfuhr von Opium nach jedem Lande zu verhindern, das die Einfuhr verbiete.

Das Gedeihen des Handels blieb ununterbrochen (1880 betrug die Einfuhr gegen 97000 Pieuls $=$ ca. 6 Millionen $\mathrm{kg}$ ), bis in

1) Morse, The international relations of the Chinese Empire. London 1910 , p. $550 \mathrm{f}$. 
neuester Zeit, unter dem Einflusse der revolutionären Bewegung in China, ermeute Versuche gemacht worden sind, ihn zu unterdrücken. Auch der Anbau des Opiummohns, der in China selbst fortwährend zugenommen hatte, ist verboten worden.

Im englischen Selbstbewußtsein, ob es mehr religiös oder philosophisch-ethisch gefärbt, ist der Opiumhandel als eine schwere Last wirksam geblieben. Endlich hat im Jahre 1907 die britische Regierung sich erboten, die Ausfuhr aus Indien nach China allmählich einzuschränken, so daß sie binnen 10 Jahren aufhören sollte. Man darf gespannt sein, ob sich dies verwirklichen wird.

Inzwischen hat bekanntlich China unter tiefen und schweren Erschütterungen gelitten. Mit der sonderbaren Taiping-Rebellion, die mehr als ein Jahrzehnt (1855-1866) sich hinzog, verwickelte sich zeitweilig ein Angriff von seiten Englands, das, wie schon zuvor im Krimkriege und wie in allen Fragen des näheren und ferneren Orients, Frankreich in seinem Gefolge hatte.

Veranlassung zu diesem Kriege gab der Fall der Lorcha (Stromboots) „Pfeil“". Der „Pfeil“" war ein chinesisches Fahrzeug, das gelegentlich unter britischer Flagge fuhr, auf die es kein Recht hatte. Eine chinesische Wache hatte, am 8. Oktober 1856, 12 Mann von diesem Boote verhaftet wegen Seeräuberei. Der englische Konsul in Kanton verlangte die Auslieferung der Leute, indem er behauptete, es sei ein britisches Fahrzeug (es war eine Zeitlang als solches geführt worden, die Registrierung war aber erloschen). Auf die Weigerung der Chinesen wandte sich der Konsul an den Bevollmächtigten in Hongkong. Dieser verlangte nicht nur die Auslieferung, sondern überdies eine Entschuldigung und das Versprechen der chinesischen Behörde, solchen Akt niemals zu wiederholen. Da die Chinesen noch Einwände erhoben, wurde alsbald Kanton bombardiert. Die Operationen zu Wasser und zu Lande dauerten 22 Tage.

In England war man nicht durchaus damit zufrieden. Die Ungesetzlichkeit des Verfahrens lag allzu klar zutage. Im Oberhause erklärte der greise Lord Lyndhurst, weder Gesetz noch Vernunft könne es rechtfertigen. Unmöglich könne man ein chinesisches Boot in chinesischem Gewässer außerhalb des chinesischen Gesetzes stellen. ,Wird eine Lorcha, die einem Chine- 
sen gehört, dadurch, daß sie eine britische Flagge kauft, ein britisches Fahrzeug ?" hatte der chinesische Gouverneur gefragt. „Freilich“ - bemerkte Lord Lyndhurst — ,wenn wir von Verträgen mit orientalischen Nationen reden, so haben wir einen eigentümlich lockeren Begriff von Recht und einen ebenso lockeren Begriff von Moral in bezug auf sie." Der Antrag, das Verfahren zu verurteilen, blieb in den Lords mit 110 gegen 146 Stimmen in der Minderheit. Dagegen setzte im Unterhause Cobden ein Tadelsvotum mit schwacher Mehrheit durch. Es war ein Schlag gegen Lord Palmerstons Kabinett, den zum Teil dessen bisherige Anhänger führten. Dreist und zuversichtlich wie immer, löste Palmerston das Parlament auf. Er gab die Parole aus, ein unverschämter Barbar habe die britische Flagge verletzt, Verträge gebrochen usw. Die Parole zündete. Palmerston gewann einen glänzenden Wahlsieg.

Hatte auch die Sache des Piratenbootes und das Bombardement von Kanton gesiegt? Mc. Carthy urteilt: „Die Wahrheit ist, daß es selten ein so flagrantes und unentschuldbares Beispiel von hochfahrender Gesetzwidrigkeit im Verhalten einer starken gegen eine schwache Nation gegeben hat." Und G. M. Trerelyan meint noch 1913: „Es ist wahrscheinlich, daß jeder Mann, und wäre es der entschiedenste Imperialist, der heute die Behandlung von China durch Palmerston in der Pfeil-Affäre studiert, zu dem Schlusse kommen wird, daß der Minister die Stärke Großbritanniens gemißbraucht und einen Krieg zuwege gebracht hat, der in einer unwürdigen Streitsache seinen Ursprung hatte1)."

Langwierig genug war der so begonnene, von Louis Napoleon freudig unterstützte Krieg. Erst im Herbst $1860 \mathrm{kam}$ er zum Abschluß, nachdem die Pekinger Sommerpaläste 3 Tage lang von englischen und französischen Offizieren geplündert waren. Daß ein tiefer $\mathrm{Ha}$ der Europäer durch diese Methoden unter den Chinesen genährt worden ist, hat sich in späteren folgenreichen Ereignissen offenbart.

\section{Der Krim-Krieg.}

Nachdem Napoleon niedergeschlagen und damit der mehr als hundertjährige Kampf gegen Frankreichs Wettbewerb um

1) The Life of John Bright, p. 258. 
die See- und Kolonialherrschaft beendet war, sind bis gegen Ende des 19. Jahrhunderts die Augen der englischen Politik mit ängstlicher Spannung auf Rußland gerichtet gewesen. Aber nur ein europäischer Krieg, an dem England unmittelbar beteiligt gewesen ist, ging daraus hervor. Der Krim-Krieg war das Werk Lord Palmerstons, der den Ehrgeiz hegte, für sein Vaterland das zu leisten, was 100 Jahre vor ihm der ältere Pitt geleistet hatte. Was für diesen Frankreich, das war für Palmerston Rußland. Wie für Pitt, so war für Palmerston Krieg ein Gegenstand der Neigung, obschon beide nichts weniger als Feldherren waren. Bei beiden lag aber zugrunde die Furcht. Furcht vor dem Erstarken des Nebenbuhlers, und die Úberzeugung, daß äußerste Wachsamkeit Pflicht des Staatsmannes sei, ließen ihnen Krieg als notwendig erscheinen, sobald sie glaubten, dadurch den Plänen des Feindes zuvorzukommen. Alsbald erschien ihnen der Krieg nicht weniger ,lieỏenswürdig", wie er nur je dem großen Napoleon erschienen ist.

„Palmersto n glaubte von Anfang an, daß den Ansprüchen Rußlands mit Waffengewalt begegnet werden müsse, und daßihnen nicht auf andere Weise begegnet werden könne. Er glaubte, daß die Gefahr, welche für England aus der Vergrößerung Rußlands entspringe, eine Lebensgefahr sei, deren Abwehr nationale Opfer in jeder Ausdehnung erfordere. Er glaubte ferner, daß Krieg mit Rußland unvermeidlich sei, und er wollte ihn lieber früher als später .... Er verstand bei dieser Gelegenheit besser als irgendein anderer das vorwaltende Temperament des englischen Volkes ${ }^{1}$ ). “ Es war also ein offenbarer Präventivkrieg, den er unternahm.

Der Krieg wurde in Alliance mit Louis Napoleon zur Unterstützung der Türkei durch eine Invasion der Krimhalbinsel im September 1854 unternommen. Erst das Eingreifen des Königreichs Sardinien, dessen Politik Cavour leitete, verbesserte die Chancen der Verbündeten. Nachdem Sebastopol gefallen (9. Sept. 1855), Kaiser Nikolaus gestorben, erlahmte der Krieg durch allgemeine Unlust, ihn fortzuführen, und Napoleon III. begünstigte den Friedensschluß, der in seiner Hauptstadt im März 1856 geschah und seine Glorie erhöhte. - In England hat der Krimkrieg ein bitteres Andenken dadurch hinterlassen, daß er die schweren

1) Mc. Carthy, a. a. O., II, 208. Tauchnitz. 
Mängel der Heeresorganisation, insbesondere des Sanitätswesens ${ }^{1}$ ), an den Tag brachte. Anfangs war der Krieg populär gewesen, auch als Reaktion gegen den Pazifismus, dem sonst die liberale Geistesrichtung jener Zeit anhing. Aber bald wurden Ungeduld und Enttäuschung allgemein; ,,jedermann" sagte, der Feldzug sei eine Schweinerei. Auch nach dem Friedensschluß blieb die öffentliche Meinung mit der Führung des Krieges wie mit seinen politischen Ergebnissen unzufrieden. Weisen Männern, die zuvor eindringlich gewarnt hatten, mußte nachträglich Recht gegeben werden. An deren Spitze stand ein Mann, dessen Geist und Charakter heute kein ernster Mensch in Großbritannien anzufechten wagt: John Bright. Den größten englischen Redner des Jahrhunderts nannte ihn sein Gegner Lord Salisbury. Gleich nach der Kriegserklärung griff er in einer Reihe glänzender Parlamentsreden das Prinzip an, um des Gleichgewichts der Macht willen Krieg anzuzetteln, und das System der Alliancen, das damit verknüpft war. Berühmt wurde, als die Friedensverhandlungen in Wien geführt wurden, seine Wendung von dem Todesengel, der durch das Land gehe, ,fast könnt ihr seinen Flügelschlag vernehmen“. Die Wiener Verhandlungen scheiterten an der Neutralisierung des Schwarzen Meeres; $11 \mathrm{~m}$ sie durchzusetzen, führte Palmerston den Krieg noch ein Jahr lang weiter. Vierzehn Jahre später (1870) erklärte Rußland sich nicht mehr an diese Bestimmung gebunden; es zerriß den Vertrag wie einen Fetzen Zeitungspapier ${ }^{2}$ ) - nach dem Ausdruck Tre velyans, Life of John Bright, p. 247 - und England hatte das Nachsehen.

Gladstone, der dem Kabinett angehörte, das für den Krieg verantwortlich war, meinte später: es sei mehr Gefühl als Uberlegung gewesen, was den Krieg populär machte; es sei aber

1) Im November 1854 waren 2000 Verwundete und Kranke im Lazarett zu Skutari, und in diesem ganzen Monat wurden nur 6 Hemden gewaschen: Trevelyan, Lifo of John Bright, p. 242. Ein Leitartikel der Times, die damals noch mit Geist und zuweilen auch mit sittlichem Ernst gesehrieben wurde, verklagte am 23. Dez. 1854 die ,Inkompetenz, Faulheit, den aristokratischen Hochmut, die amtliche Gleichgültigkeit, Gunstbuhlerei, Routine, Perversität und Dummheit, die im Lager vor Sebastopol wüsten und wirtschaften", ib. 236.

2) Eine Konferenz der Mächte in London (Jan. 1871) erklärte feierlich die Klausel für erledigt. 
ebenso mehr Gefühl als Ưberlegung gewesen, das ihn in den „Abgrund des Odiums"s stürzte ${ }^{1}$ ).

Wir mögen es dahingestellt sein lassen.

Jedenfalls war für eine Zeitlang PaInerstons Politik der Einmischung in die Angelegenheiten Europas zum Schweigen gebracht. Sie fand ,,einen demütigenden Abschluß im Juni 1864, als das Haus der Gemeinen, einen starken Ausdruck der öffentlichen Meinung sich fügend, ihm (Palmerston) und Russell untersagte, zugunsten Dänemarks Kı'ieg mit den deutschen Großmächten anzufangen $\left.{ }^{2}\right)^{6}$. Einige Monate später sprach John Bright zu seinen Wählem in Birmingham: „Die Theorie des Gleichgewichts der Macht ist beinahe tot und begraben ...., wir mögen uns freuen, daß dieser elende Götze endlich gestürzt wurde, und daß es einen Aberglauben weniger gibt, die Gedanken englischer Staatsmänner und des englischen Volkes zu beherrschen."

Fünfzig Jahre später war der Aberglaube an die Zauberkräfte dieses Götzen lebendiger als je zuvor - wenigstens war er geeignet, die cant-Phrasen des Tages zu weihen.

\section{Die jonischen Inseln.}

Eine seltsame Herrschaft hatte Großbritannien aus der Napoleonischen Konkursmasse sich angeeignet, immer beflissen, im Mittelmeer seinen schweren Fuß niederzusetzen. Unter dem Namen Vereinigte Staaten der jonischen Inseln waren Korfu, Kephalonia, Zakynthos, Paxos, Leukas, Ithaka und Kythera als ,freier und unabhängiger Staat" durch einen besonderen Vertrag zwischen Großbritannien, Rußland, Österreich und Preußen eingerichtet - und unter den Schutz Großbritanniens gestellt worden. Ein Statthalter sollte die Gesetzgebung und Verwaltung überwachen. Dieser gab 1817 eine ,,Verfassung" — in Wirklichkeit wurde dadurch ein Regierungssystem gebildet, , clas bald despotisch genug wurde, um selbst einen Metternich $\mathrm{zu}$ befriedigen $\left.{ }^{3}\right)^{6}$. Dor Stathalter konnte schlechthin tun, was er wollte- bis nach 1848 Wandlungen eintraten. An Unruhen

1) Morley, Life of Gladstone, I, p. 495.

2) Trevelyan, Life of John Bright, p. 333.

2) Morley, Life of Gladstone, I, 598. 
fehlte es schon vorher nicht; in diesem bewegten Jahre fand ein Aufruhr auf Kephalonia statt, den der Statthalter ,,mit grausamer Strenge" unterdrückte. ,Zweiundzwanzig Personen wurden gehängt, dreihundert oder mehr ausgepeitscht, die meisten ohne jedes gerichtliche Verfahren." — ,Häuser wurden in Brand gesteckt, Gebäude und Weingärten zerstört mit wilder Brutalität." Ein Schreckensregiment folgte, das sich auf die anderen Inseln ausdehnte. Kraft seiner, hohen Polizeigewalt" konnte der Statthalter wen inmer er wollte aufheben, d. h. ,,seinem Heim, seiner Berufstätigkeit und seinem Erwerb entreißen. Diese hohe Polizeigewalt wurde hauptsächlich angewandt gegen Redakteure von Zeitungen. Ein unliebsamer Leitartikel wurde nicht selten geahndet durch Deportation nach einem öden Felseneiland, das ein Häuflein Fischer bewohnte". - Eine charakteristische Tatsache ist, daß Gladstone, der 1858 in besonderer Mission nach den Inseln entsandt wurde, umReformen einzuleiten, einen ausführlichen Bericht über diese Methode der Regierung verfaßte, der noch im Jahre 1903 im Archiv des Kolonialamts ruhte. ,,Alle, die davon Kenntnis nahmen, hielten für unzweckmiäßig, ihn zu veröffentlichen."

Unter den Ursachen der Unzufriedenheit stand in vorderster Linie der Wunsch, mit dem (seit 1832) neuen Königreich Griechenland vereinigt zu werden; demnächst die natürliche Auflehnung gegen die Tyrannei des britischen Gouverneurs - zugrunde lagen aber auch soziale Zustände des Bodenbesitzes und der Landwirtschaft, da auch die Grundherren zumeist Fremde (Italiener) waren. Der Konflikt zwischen der Volksvertretung (Assembly) und der Statthalterschaft wurde allmählich chronisch und für die Zentralregierung in London immer unerquicklicher. Obwohl noch im Mai 1861 Gladstone von der Abtretung als von einem ,Verbrechen gegen die Sicherheit Europas" in lauterstem cant gesprochen hatte, geschah sie dennoch am 29. März 1864. Damit ging ein Stück britischen Protektorates zu Ende, das von allen Berichterstattern und Historikern als ein Stück härtester Despotie bezeichnet wird.

England begnïgte sich, die Insel Malta zu behalten, die es den Franzosen abgenommen hat; die Franzosen ihrerseits hatten ebensowenig einen Rechtstitel auf den Besitz dieser Insel als ihre Nachfolger. 


\section{Jamaika.}

In noch auffallenderer Weise als auf den jonischen Inseln machte sich englische Mißregierung bemerkbar in der wichtigsten Kronkolonie Westindiens. Auf Jamaika war zwar 1838 die Sklaverei aufgehoben, aber der Druck, der auf den Negern lastete, war nicht gelinder, sondern schwerer geworden. Im Oktober 1865 kamen Unruhen zum Ausbruch, die etwas ernster waren als alltägliche Ereignisse, in denen sehr begründete Beschwerden der Neger sich äußerten. Und doch war es kaum mehr als ein gewöhnlicher Straßentumult. ,Es ist noch leute streitig, ob ein wirklicher Aufruhr vorgelegen hat ...., ob etwas mehr als der unvorbereitete Putsch einer unzufriedenen und aufgeregten Menge. "1) Der Gouverneur verkündete den Belagerungszustand über den ganzen Distrikt, mit Ausnahme der Stadt Kingston. In Kingston wohnte ein Neger, der ein kleines Geschäft hatte und Mitglied des Abgeordnetenhauses der Kolonie war. Er hatte sich als Vorkämpfer der Negerrechte bemerklich gemacht innerhalb und außerhalb des Hauses in tatkräftiger, aber durchaus gesetzlicher Weise. Alsbald wurde er verhaftet, und weil er in Kingston hätte vor die ordentlichen Gerichte gebracht werden müssen, nach einem anderen Orte gebracht und vor ein Kriegsgericht gestellt, das aus zwei jungen Seeoffizieren und einem Fähnrich der Infanterie bestand. Gordon wurde des Hochverrats bezichtigt, schuldig befunden und zum Tode verurteilt. Weil der folgende Tag ein Sonutag war, wurde das Urteil erst am Montag vollstreckt.

„, Der ganze Prozeß war schlechthin ungesetzlich, voll Anfang bis zu Ende, jeder einzelne Schritt darin eine Verhöhnung des Rechts. Wenn der tragische Ausgang nicht wäre, so wïrde man das Ganze eher für eine Posse halten als für nüchterne Wirk lichkeit." Mc. Carthy weist dies im einzelnen nach und beruft sich auf die Kritik des Oberrichters Co ckburn, der von dem Zengenbeweis gesagt hat, fast ${ }^{9} / 10$ davon hätte nach allen Regeln, nicht nur des bürgerlichen, sondern auch des militärischen Rechtsverfahrens verworfen werden müssen.

Inzwischen wurden die Racheakte weitergeführt. Der Putsch hatte den Tag nes Ausbruchs nicht überlebt. „Kein Soldat hat einen bewaffneten Aufständischen mit Augen ge-

1) Mc. Carthy, IV p. 117 Tauchn.? 
sehen. Nichtsdestoweniger wurde wochenlang im Namen der englischen Regierung das Hängen, Peitschen, Brandstiften fortgesetzt. Männer wurden gehängt, Frauen ausgepeitscht, lediglich, ,weil sie verdächtig waren, verdächtig zu sein“. 439 Personen sind getötet, über 600 gepeitscht worden; 1000 Häuser gingen in Flammen auf. Besonders wirksame Peitschen wurden aus Klavierdraht hergestellt: die später eingesetzte Kommission erklärte, es sei peinlich zu denken, daß irgendein Mensch ein solches Werkzeug für die Marterung von Mitgeschöpfen gebraucht haben sollte. Der Bericht der Kommission wurde im April 1866 bekanntgegeben. Die Abberufung des Gouverneurs erfolgte, obgleich die Meinungen des Publikums geteilt waren. Es bildeten sich Komitees für und wider die Härte des Verfahrens. Auf beiden Seiten begegnen die berühmtesten Namen des Zeitalters (der Mid-Victorian era): für den Gouverneur Disraeli, Tennyson, Kingsley, Carlyle, Dickens, Ruskin; für die Neger John Bright, Herbert Spencer, Huxley, Goldwin Smith, und als Führer dieser Gruppe John Stuart Mill. Auch die Gouverneurpartei wollte die Greuel und den an Gordon begangenen Justizmord nicht rechtfertigen - wenigstens gingen nicht alle so weit -; aber sie machten alle Gründe geltend, die für schonungslose Unterdrückung eines Aufruhrs zu sprechen schienen. Die Ankläger betonten dagegen hauptsächlich, daß der Aufstand unbedeutend und völlig erstickt gewesen sei, als das Schreckensregiment eröffnet wurde. Von der Gegenseite wurden die moralischen Eigenschaften des Gouverneurs herausgestrichen, diejenigen Gorlons herabgesetzt. Der berühmte Naturforscher Huxley bemerkte dazu trocken : kein Gesetz gebe einem Tugendhaften das Recht, einen minder Tugendhaften rom Leben zum Tode zu bringen.

\section{Der Krieg der Sklavenhalter in Amerika.}

Um die Negerware, an der englische Reeder so viele Millionen "verdient" hatten, handelte es sich bekanntlich auch im nordamerikanisehen Bürgerkriege, wenngleich erst allmählich dieser Gegenstand des Streites an die Oberfläche trat.

Mchr als einmal war die englische Regierung nahe daran, tätig für die Skla venhalter des Südens Partei zu ergreifen. Die öffent- 
liche Meinung, wenigstens die der oberen Schichten, die immer am meisten in der Lage sind, ihre Meinung zur Geltung zu bringen, war entschieden auf Seite der Rebellen. Sie war es teils aus aristokratischen, teils aus liberalen und freihändlerischen „,Gründen“. Die ethischen Gefühle gegen die Sklaverei, deren beredter Anwalt der unerschrockene John Bright vor anderen war, fanden in diesen Kreisen schwachen oder gar keinen Widerhall. Die Times berief sich darauf, daß die Sklaverei in der Bibel nirgends ausdrücklich verboten sei. Man war vollkommen sicher, daß der Norden eine schwere Niederlage erleiden werde: ,die einflußreichen Klassen waren Herz und Seele mit dem Süden $\left.{ }^{1}\right)^{\text {". }}$. Ebenso hegte Napoleon der Dritte nicht den geringsten Zweifel, daß die Sache des Südens triumphieren und daß es mit der Union für immer vorbei sein werde. Er wünschte auch, im Verein mit der englischen Regierung, die Konföderation durch Anerkennung zu unterstützen. Es ist merkwürdig, daß es, ,in Europa nur zwei Staaten gab, welche diese Gesinnung hegten und sie überall zu erkennen gaben": England und Frankreich. Lincoln und seine Freunde hatten auf die Sympathie des englischen Volkes und der englischen Regierung gerechnet. Sie fanden sich bitter enttäuscht, als sie fanden, daß ihr zeitweiliges Mißgeschick von englischen Staatsmämmern, Joumalisten, Predigern und ganz allgemein von der ,guten Gesellsehaft" verhöhnt wurde, daß alle diese Kreise ganz offen den Erfolg ihrer Feinde wünschten. Ein schwerer Konflikt entstand durch den Zwischenfall des englischen Kauffahrers Trent, der von einem Kreuzer der Vereinigten Staaten durchsucht wurde; er hatte Abgesandte der Südstaaten an Bord, die der Kapitän zu Gefangenen machte. Große Empörung in London, weil der nordstaatliche Plebejer gewagt hatte, die Praxis nachzuahmen, die der englische Aristokrat seit Jahrhunderten geübt. die zum System der bewaffneten Neutralität in Europa und zum Kriege mit den Staaten 1812 geführt hatte. „Ja, Bauer, das ist ganz was andres —." Präsident Lincoln gab bald nach und ließ die Gefangenen frei. Aber der Fall hinterließ Erbitterung, hauptsächlich, nach Mc. Carth ys Urteil, infolge derhochfahrenden Art, in der die englische Regierung sich dabei benommen hatte. Wenn hier England den Vertreter des Völkerrechts spielte, so kam

1) Mc. Carthy, III, S. 255, 277. Tauchn، 
bald ein noch ernsterer Fall, über den die Vereinigten Staaten Grund hatten, sich zu beschweren. Der Kreuzer Alabama kaperte unter der Flagge der Südstaaten ein Handelssehiff des Nordens nach dem andern; er benutzte dabei beständig die englische Flagge zur Täuschung. Das war sein Recht gemäß der Praxis des Seekriegs. Aber die Alabama war tatsächlich mehr ein englisches als ein amerikanisehes Schiff; dasselbe galt von mehreren dieser :konföderierten" Kreuzer. Sie waren gebaut auf einer englisehen Werft, die Mannschaft war fast aussehließlich englisch; die Kanonen und die Kanoniere waren engliseh, viele der letzteren gehörten zur Königl. Marinereserve und waren im Solde der britischen Regierung. Diese stellte sich taub gegen die Vorstellungen des Gesandten der Union; so lange wenigstens, als an leren Niederlage geglaubt wurde. Und das war so lange, bis die Siege Grants und Meades sich nicht mehr verheimlichen ließen. Sie wurclen sehr übel aufgenommen in London. „,In einigen Klubs wurde geradezu sittliche Entrüstung laut, daß so etwas telegraphiert und in den Zeitungen gedruekt wurde." Als der Sieg des Nordens allzu offenbar wurde, schlug die Stimmung um. Die arbeitende Klasse war sehon unter dem Einflusse John Brights und einiger anderer Freunde des Nordens für dessen Sache gewonnen seit Verkündung der Sklavenemanzipation durch Lineoln (22. Sept. 1862).

Die Alabamafrage blieb Jahre lang ein Gegenstand des Streites. Sie wurde schließlich einem in Genf tagenden Sehiedsgerichte unterworfen. Dessen Sprueh (vom 15. Sept. 1872) machte England haftbar für die durch Alabama und zwei andere Kaperschiffe verursachten Verluste. England mußte eine Entschädigungssumme (nebst Zinsen) in Höhe von 151/2 Millionen Dollar wegen Bruchs der Neutralität an die Vereinigten Staaten zahlen.

So endete die mehr als ideelle Parteinahme - denn das war sie - der englisehen Regierung für die Sache der Sklavenhalter von Amerika.

\section{Der indische Aufstand.}

An unmittelbarer Bedeutung für das britische Weltreich wurden alle diese Angelegenheiten weit übertroffen dureh die Robellion in Indien 1857-1859, die unter dom Namen ,indische 
Meuterei" als eine bloße Söldnerrevolte bezeichnet wird, obgleich sie ohne Zweifel mehr war oder wenigstens wurde als das. Sie bedeutete den Zusammenbruch des Regiments der ostindischen Kompagnie.

Es wird noch heute in England gestritten, ob die Annexionen Dalhousies und die Methode seines Regiments den Aufstand herbeigeführt haben oder nicht. Am auffallendsten war die Art, wie er das Königreich Oudh, aus dem sich die bengalische Armee rorzugsweise rekrutierte, vernichtet hat unter grober Verletzung feierlich geschlossener Verträge. Es gilt für sicher, daß dies wesentlich dazu beigetragen hat, die gesamte britische Herrschaft rerhaßt zu machen. Úberall hatten die Engländer die religiösen Gefühle sowohl der Hindu als der Mohammedaner mißhandelt und die Kastenvorurteile jener verletzt. Meuterei der eingeborenen Söldner waren so alt wie das Institut dieses Söldnerheeres. Die Besorgnis, außerhalb des Landes verwandt zu werden und dadurch Kaste zu verlieren, wirkte besonders stark auf die Gefühle. Der kleine Krieg, den England 1856 in Persien führte, gab dazu neuerdings Anlaß. Überdies war es ein verbreiteter Glaube, daß die britische Herrschaft in Indien 100 Jahre dauern werde: 1757 war die Schlacht bei Plassey geschlagen, der große Sieg, der Clive die Herrschaft über Bengalen gab.

Die Gesehichte des Aufstandes ist eine Geschichte der Heldentaten und Strapazen, aber auch der Grausamkeiten und Greuel ron beiden Seiten. Die endliche Unterdrückung hat in den Gefühlen Europas einen besonders tiefen und schrecklichen Eindruck hinterlassen durch die englische Methode, die Todesstrafe durch Binden der Opfer an den Mund von Kanonen zu vollstrecken, die dann entladen wurden. Jiese humane Hinrichtung ist schon 1764 an den Sipahi ausgeiibt worden ${ }^{1}$ ).

Nach der Unterdrückung wirde die Frage nach den Ursachen des Aufstandes brennend. Oberst Malleson, der (als Fortsetzer ron $\mathrm{Kaye}$ ) am eingehenrlsten rlie Begehenheiten historisch dargestellt hat, beantwortet die Frage dahin, daß die Hauptursache Treulosigkeit und Wortbruch der englischen Regierung gegen die Sepoys gewesen sei. „Dio Soldaten wurden bestraft dafür, daß

1) ,Schon 1764 war es notwendig, Meuterei auszurotten dadurch, daB man 30 Sepoys aus Kanonen wegblies." Ene. Brit. XIV, $\mathbf{1 4 6 .}$ 
sie sich weigerten, einen Vertrag zu erfüllen, den die Regierung gebrochen hatte!" Dies geschah 1843 ; und 1853 ,,versuchte die Regierung in höchst übelberatener Weise einen neuen Kontraktbruch"; Lord Dalhousie war hier der Schuldige. Seine hochfahrenden Maßregeln wurden gekrönt durch die Annexion von Oudh. ,,Von diesen Handlungen, von dem Versuch, das stumme Wachstum von Jahrtausenden außer acht zu lassen und okzidentalische Ideen einem orientalischen Volke aufzuzwingen und dabei Vorurteile mit Füßen zu treten, Verpflichtungen außer acht zu lassen, war die Menterei die allzu sichere Folge $\left.{ }^{1}\right) .{ }^{6}$

Vierter Abschnitt.

\section{Der neuere Imperialismus.}

..Blober cant, wie ernsthaft er auch in offiziellen Darstellungen vorgebracht werden möge, macht eine grebildete öfentliche Meinung nicht länger blind gegen die Tatsachen in diesen Akten internationalen Brigantentums."

W. Morgan Shuster.

(Ex-Schatzmeister von Persien), The strangling of Persia". 1912. (Die Erdrosselung Persiens) p. 222.

\section{6. Ägypten.}

Das Land der Pharaonen - Napoleon nannte es das wichtigste Land auf der Erde - ist seit der französischen Revolution ein Zankapfel zwischen englischen und französischen Eroberungsgelüsten gewesen. Und zwar standen diese hier unmittelbar im Dienste der ökonomischen und finanziellen Ausbeutung. $\mathrm{Zu}$ Kriegen der beiden Mächte wider einander ist es nach 1815 weder um diese noch um die wirklichen ,Kolonien" mehr gekommen. Es gelang eben der englischen Politik, Frankreich ohne Krieg immer mehr von sich abhängig zu machen. Sie hatte den ehemals so gewaltigen und gefüchteten Rivalen gezähmt und warf ihm

1) Malleson, History of the Indian Mutiny, Vol. III, 472-476 u. preface p. VIII. 
soviel Futter in den Rachen, als zu genügen schien, um seinen Blutdurst zu dämpfen.

Nachdem in der Seele eines österreichischen Ingenieurs die Idee gereift war, haben französischer Geist und französische Technik den Suezkanal unternommen und gebaut. Als Ferdinand de Lesseps sich 1864 an Lord Palmerston wandte, um den Widerstand, den die britische Diplomatie in Konstantinopel gegen das Projekt organisiert hatte, zu brechen, erklärte der Minister: „Nach Ansicht der britischen Regierung sei der Kanal eine physische Unmöglichkeit; wenn er gebaut würde, so werde er die britische Suprematie schädigen; und der Plan sei lediglich ausgeheckt, um die Einmischung Frankreichs in Orient zu befördern." Gewiß ein Musterbeispiel für die Weitsichtigkeit und Weitherzigkeit britischer Staatskunst, die überhaupt in Palmerston immer ihren typischen Vertreter findet. - Die Bestätigung der Kommission durch den Sultan wurde erst 1866 erreicht. Inzwischen hatte Lesseps eine Aktiengesellschaft für den Bau des Kanals gegründet, der im November 1869 eröffnet. wurde. 1875 kaufte Distaeli, in dessen Person der Finanzmann und der Staatsmann eine schöne Mischung eingingen, für die britische Regierung die 176602 Suczkanal-Aktien des Khediven. Damit beginnt die finanzielle und im Anschluß daran die territoriale Eroberung Ägyptens durch England. Der Staatsbankerott stand vor der Tür. Um ihm zu wehren, legt sich der Inkubus englisch-französischer Finanzkontrolle auf das Land. Im Jahre 1881 setzte eine Empörung, die sich zugleich gegen die Türken wandte, unter dem ägyptischen Offizier Ahmed Arabi dagegen ein; in den Worten Lord Cromers ${ }^{1}$ ), der schon 1878 Mitglied einer Finanzkommission, später (1884) Generalkonsul und (tatsächlicher) Gouverneur wurde, war es eine ,,echte Revolte gegen Mißregierung"; die Bewegung hatte Erfolg, Arabi wurde Kriegsminister. Dem Inkubus gefiel das nicht. Um die Interessen der Staatsgläubiger zu wahren, erschienen englische und französische Schiffe vor Alexandria; ein Aufstand in dieser Hafenstadt, bei dem britische Untertanen umkamen, gab den Anlaß zum Bombardement der schwachen Außenforts am 11. Juli 1882; das Bombardement hatte eine Vermehrung der Anarchie zur Folge.

1) Cromer, Modern Fgypt., I, 2. 
Der englische Admiral hatte nicht gänzlich auf eigene Faust gehandelt. Nach Völkerrecht fragte er nicht. Aber hinter ihm stand seine Regierung, die nunmehr für ihre Aufgabe hielt, die ,Rebellion“ niederzuzwingen. Es folgte die Besetzung des Nillandes, die bald, obgleich es erst viel später (1898) gelang, den Sudan zu unterjochen, der politischen Annexion gleichkam. Frankreich, dessen Regierungen jahrelang drängten, daß Ägypten geräumt werden müsse, wurde ausgeschaltet durch die En tente und den Vertrag von 1904, der einer Teilung Nordafrikas gleichkam. ,,Wir behalten Ägypten, ihr legt die Hand auf Marokko; andere Mächte haben dort wie hier nichts zu suchen. Will etwa Deutschland in Marokko seine kommerziellen Interessen wahrnehmen, so wird England euch schützen." Das der wahre Sinn jenes Abkommens. Daß ein Schatten von ,Recht" dabei in Erage kam, hat keiner der Kontrahenten zu behaupten gewagt. Es wäre denn das Recht, welches Shylock für sich in Anspruch nimmt.

Der Staatsmann Gladstone hatte schon 1877 geschrieben:

,Unsere erste Banstelle in Ägypten, sei es, daß wir durch Diebstahl oder durch Kauf sie erwerben, wird fast todsicher das Ei eines nordafrikanischen Reiches sein, das wachsen und wachsen wird ..., bis wir schließlich jenseits des Äquators mit Natal und Kapstadt unsere Hände verbinden, um zu schweigen vom Transvaal- und dem Oranjefluß-Freistaat auf der Südseite, oder von Abessinien oder Sansibar, die etwa als Reisezehrung unterwegs mitzunehmen und $\mathrm{zu}$ schlucken wären $\left.{ }^{1}\right) .{ }^{\text {" }}$

Derselbe Gladstone hatte als Premier das Bombardement von Alexandria zu decken. John Bright, der Mitglied seines Kabinetts war, schied aus dieser Ursache aus. Goldwin Smith (1858-1866 Professor der neueren Geschichte in Oxford, später nach Kanada übergesiedelt) schrieb an Bright: ,, Dies ist ein Krieg der Staatsgläubiger", und das war anch Brights Auffassung. Er hatte noch mit dem Kabinett das Bombardement autorisiert, und das bedrückte ihn schiwer. Er erklärte im Parlament, das Vorgehen Englands verstoße gegen das Völkerrecht und gegen das moralische Gesetz. Die Anstachelung war von Joseph Chamberlain, der damals noch radikales Mitglied

1) Gladstone, Gleanings IV, p. 357 . 
des GIad st on e schen Kabinetts war, ausgegangen. Unerschrocken und unermüdlich kämpfte dagegen für anständige und gerechte Behandlung der Ägypter Herr Wilfrid Scawen Blunt, der lange im Lande gelebt hat und mitten in den Begebenheiten von 1882 stand; er genoß das volle Vertranen Arabis, den er als einen edlen Schwärmer und treugläubigen Moslem schildert. Bismarck nannte Arabi einen Machtfaktor, mit dem man rechnen müsse. An Blunt schrieb inmitten der publizistischen Erregungen des Jahres (3. 8. 1882) aus Kapstadt der General Gordon, dessen tragisches Geschick in Khartum aus den Verwicklungen entsprang, die im Sudan der Besetzung Ägyptens folgten, einen zustimmenden Brief: er spottet über die Heimlichtuerei des damaligen Staatssekretärs Sir Ch. Dilke. ,Konnten die Dinge ein übleres Ende nehmen, wenn er alles gesagt hätte? Keine Kontrolle (der Finanzen) mehr - keine Beamten mehr, die jährlich 373000 £ (=61/2 Millionen Mark) herausziehen - kein Einfluß von Generalkonsuln mehr, eine Nation, die uns haßt - kein Tewfik mehr (der England ergebene Khedive) - keine Zinsen mehr - eine bombardierte Stadt, Alexandria, das sind die Ergebnisse der erhabenen geheimen Diplomatie“6 ... ,, Was Arabi angeht, was immer aus ihm persönlich werden mag, er wird für Jahrhunderte fortleben im Volke; sie werden niemals wieder, ,eure gehorsamen Diener “6 $\operatorname{sein}^{\mathbf{1}}$ ). Blunt hat für notwendig gehalten, noch 25 Jahre nach den Begebenheiten die früheren Rechtfertigungen seines Verhaltens durch ein Buch vollständig zu machen, das in den Anhängen viele interessante Urkunden, darunter mehrere Briefe des Ahmed A rabi enthält. In einer Vorrede zu diesem Buche, die schon 1895 geschrieben ist, sagt er u. a.: ,Es kann auch sehr wohl sich ereignen, daß die ägyptische Frage, wenngleich sie jetzt ruht, auf unerwartete Weise in einer dringenden Form sich wieder behaupten wird; sie wird dann von den Engländern eine neue Prüfung der Stellung erfordern, die sie clort einnehmen, der politischen wie der moralischen"; eben darum wolle er sein gesamtes Material zur Aufklärung beitragen. In dem späteren Vorwort (1907) erklärt er es zu eben diesem Zwecke für notwendig,

1) Wilfrid Scawen Blunt, Secret history of the English oocllpation of Egypt (1907), p. 28. 
daß man die Vergangenheit, wie sie wirklich war, sich vor Augen stelle, und nicht, wie sie so lange dargestellt worden sei durch die trügerischen Urkunden der amtlichen englischen Blaubücher. Er beruft sich darauf, daß Lord Cromer während keines Teils der revolutionären Periode in Kairo gewesen sei. Er stellt sich die Aufgabe, vollständig und im einzelnen ,das ganze Drama finanzieller Intrige und politiseher Schwäche" zu entrollen, wie es ihm offenbar geworden sei. Das Buch wiederholt zum Teil Eintragungen des Verfassers in sein Tagebuch. Sie sind sehr düster in bezug auf die Zukunft seines Landes. „Englands Verfall beruht auf Ursachen, die weit allgemeiner sind, als daß irgendein Einzelner oder eine Partei dafür verantwortlich sein könnte. Wir haben Unglück, weil wir nicht mehr ehrlich, nicht mehr gerecht, nicht mehr Leute sind, auf die man sich verlassen kann."

Herr Blunt glaubt also, daß es mit der Ehrlichkeit und Gerechtigkeit der englisehen Politik ehemals wenn nicht gut, so doeh viel besser bestellt gewesen sei.

Seine Darstellung ist natürlich hart angefochten worden. Die anerkannte Autorität über das neue Ägypten und die englische Eroberung ist das zweibändige Werk von Lord Cromer, Modern Egypt ${ }^{1}$ ), geworden. Bei aller Anerkennung für diese ausgezeichnete Schrift muß man doch Blunt recht geben, daß Cromer im Nachteil ist, sofern er eben während der kritischen Zeit nicht in Ägypten gelebt hat. Lord Cromer führt die Worte des berühmten Kenners der semitischen Sprachen, Prof. Sayce, ins Gefecht:

,Leute, die im Orient gelebt und versucht haben, mit den Eingeborenen zu verkehren, wissen, wie vollständig unmöglich es für den Europäer ist, die Welt vom Gesichtspunkt des Orientalen zu betrachten. Eine Zeitlang mag der Europäer wohl glauben, daß er und der Orientale einander verstehen, aber früher oder später tritt der Moment ein, wo er plötzlich aus seinem Traum erwacht und sich in Gesellschaft einer Seele befindet, die ihm so fremd ist, wie es die Seele eines Saturn-Bewohners sein würde."

Vielleicht wird es auch für die Beobachtung bestimmter Vorgänge gelten, daß gerade im Orient man sie erlebt haben muß, um sie richtig zu verstehcn. Uberdies lebte Blunt als reicher

1) Deutsche Übersetzung von Admiral Plüddemann. 
Privatmann in Ägypten. Cromer (vormals Sir Evelyn Baring) ist nur im Auftrage der englischen Regierung dort gewesen.

Indessen werden wir lieber unser Urteil zurïckhalten. Für sicher darf aber gelten, worin Cromer und Blunt übereinstimmen. Auch Cromer bestätigt am Schlusse seines Werkes in bezug anf Ägypten, was bald nach der Annexion des Pandschab von Indien gesagt wurde: ,Wir sind nirgends beliebt."„Mangel an Dankbarkeit einer Nation gegenüber ihren fremden Wohltätern" nemut er es, meint aber, dieser Mangel sei beinahe ebenso alt wie die Geschichte. An anderer Stelle ${ }^{1}$ ) beruft sich Cromer selber anf Seeleys Ausspruch: „Es wäresehr voreilig anzunehmen, daß irgend welche Dankbarkeit, die hier und da durch unsere Verwaltung wachgerufen sein mag, mehr als genügend sein kann, um die Unzufriedenheit aufznwägen, die wir unter denen erregt haben, welche wir aus Ansehen und Einfluß hinausgeworfen haben."

Aber Unzufriedenheit erfüllt nicht nur die ehemaligen Herrscher, sondern auch die Beherrschten. Fremdherrschaft ist als solche drückend. Sie wird als Last empfunden, selbst wenn sie willkommene Reformen gebracht hat. Die Unzufriedenheit wird erhöht und verschärft durch Zwischenfälle, bei denen sich zeigt, daß die Fremdherrschaft Mangel an Verständnis für heimische Sitten und Härte gegen Vergehen, in denen sich diese wahren, miteinander verbindet. Ein solcher Zwischenfall war in Ägypten die Begebenheit von Denshawai (Jumi 1906). Das Schießen von Tauben darf im Nillande nur mit Erlaubnis der Dorfschnlzen geschehen; denn die Landleute betrachten ihre halbzahmen Tauben als ein wertvolles Eigentum und behandeln sie mit zärtlicher Sorgfalt. Die englischen Offiziere schießen Tauben nach Herzenslust. So geschah es auf einem Marsche durchs Nildelta, daß ein Trupp von 5 Offizicren beim Taubenschießen betroffen und angehalten wurden. Man nahm ihnen ihre Gewehre ab. Eine Flinte ging los und verwundete mehrere, darunter eine Frau. Eine Panik entstand, die Engländer wurden arg verprügelt, einer starb nachher am Sonnenstich, sein Tod wurde aber empfangenen Wunden zugeschrieben. Ein besonderer Gerichtshof, der für solche Fälle be-

1) Edinb. Review, Jan. 1908, abgedruckt in Political and Literary Essays (1913), p. 13.

Tönnies, Englische Weltpnolitil. 
steht, verurteilte alsbald 4 Ägypter zum Tode, mehrere zu längeren Gefängnisstrafen, 7 zu je 50 Peitsehenhieben. Die Hinriehtungen und Auspeitsehungen wurden sogleieh vollzogen.

Sir Edward Grey war eben Minister der auswärtigen Angelegenheiten in der nenen liberalen Regierung geworden. $\mathrm{Er}$ rerteidigte nieht nur das harte Urteil, sondern warnte am 6 . Juli vor ferneren Ausbrüchen des Fanatismus in Ägypten, die möglieherweise extreme Maßregeln notwendig maehen würden. Darauf antwortete Mustafa Pasha Kamel, der neue Führer der ägyptischen Nationalpartei, er glaube mit seinen Landsleuten, daß Sir Edward Grey im Parlamente zu keinem anderen Zweeke gesprochen habe, als um die Diskussion der grausigen Tatsaehen von Denshawai zu erstieken. „Aber ist es Englands würdig, des Landes, das Menschliehkeit, Gerechtigkeit und Zivilisation vertreten will, die Taten derer zu billigen und sich zu eigen zu maehen, die der Welt das melancholisehe und furehtbare Schauspiel von Barbarei - die Exekutionen von Denshawai - gaben ?!‘

Auf diese Frage wird vielleieht die fernere Geschichte der englisehen Usurpation in Ägypten eine scharfe Antwort geben. An heftiger Opposition und rüeksiehtsloser Kritik hat es Sir Edward Grey innerhalb des Hauses der Gemeinen und innerhalb seiner eigenen Partei nicht gefehlt.

Mit einem Worte möge hier noch der Kämpfe um den Sudan gedacht werden, die sieh an die Eroberung Ägyptens anschlossen. Das tragisehe Sehieksal des berühmten Generals Gordon machte auf die Zeitgenossen, auch außerhalb seines Landes, einen tiefen Eindruek. Wiefern seine Regierung daran ummittelbar Schuld hatte, geht unsere Betrachtung niehts an. Úbrigens aber genüge es, einen lapidaren Satz des großen Philosophen Herbert Speneer anzuführen, den er nicht lange vor seinem Tode (1903) gesehrieben hat. ,Die Liebe zn meinem Vaterlande wird bei mir nicht gefördert, wenn ieh mir den Tatbestand in die Erinnerung zurückrufe: unser Premierminister hatte erklärt, daß wir ehrenhalber verpfliehtet seien, den Sudan für den Khediven zurückzuerobern - naeh der Rïekeroberung begamen wir flugs, den Sudan im Namen der Königin und des Khediven zu verwalten - d. h. (wenn auch nieht dem Namen naeh) wir annektierten ilm." In demselben kleinen Aufsatz begegnet der allgemeine 
Satz: ,Betrachtung der Taten, dureh welche England über 80 Besitzungen, Ansiedlungen, Kolonien, Protektorate usw. erworben hat .... erregt keine Gefühle der Befriedigung" "1).

\section{Der Burenkrieg.}

Die Eroberung des Transvaal und des Orange-Freistaats war, nach der Auffassung der Buren, die dadurch der letzten Stätten ihrer politischen Unabhängigkeit beraubt wurden, der Abschluß eines ,Jahrhunderts voller Unrecht". (So lautete der Titel einer Schrift, die der frühere Staatssekretär Reitz herausgab.)

Die ,Kap-Kolonie“, der Kern britischer Herrschaft in Südafrika, war eins der Beutestïcke, das bei Gelegenheit der Kämpfe gegen die französische Republik, dann gegen Napoleon, eingeheimst wurde. Zuerst 1795, dann 1806, endlich 1814 legte Großbritannien seime Hand auf die alte holländische Ansiedlung. ,,Der britische Rechtstitel auf die Kapkolonie ist begründet auf Eroberung, Vertrag und Kauf. Die Wünsche der Einwohner wurden nicht gefragt, und es herrschte Entrüstung unter diesen über die Art, wie man ïber ihre Zukunft verfügte" berichtet der Engländer Frank R. Cana ${ }^{2}$ ). Er weiß wohl, daß nur die Eroberung einen reellen, ,Rechtstitel" begründet hat.

Der Unwille über die englische Herrschaft, die in diesem Falle nicht Asiaten, auch nicht Neger, und nicht Kolonisten von englischer Abstammung, sonclern Abkömmlinge eines europäischen Nachbarlandes zu ihren Füßen sieht, hat sich vertieft, je mehr diese Herrschaft ausgebreitet wurde. Die Ereignisse, die dazu geführt haben, sind noch in frischem Andenken. Die Niederlage der Engländer bei Majuba Hill (1881), die Gründung des Afrikanderbundes (1882); die Entdeckung der Diamantenfelder und der Goldminen; das planmä fige Vorgehen von Cecil Rhodes und seiner privilegierten Handelsgesellschaft; die Politik des Präsidenten Kr üger; die Klagen der Uitlander im Staate Transvaal; der gewaltsame Einbruch Dr. Jamesons (Jameson raid), den Cecil Rhodes, damals Minister in der Kapkolonie, veranlaßt hatte; die nachhaltigen furchtbaren Wirkungen dieses Verbrechens:

1) Patriotism in ,Facts and Comments", p. 88, 89.

${ }^{2}$ Encycl. Brit., 2, 11. ed. South Africa (XXV, 470). 
„Es kann nicht geleugnet werden, daß die Umstände, die mit dem Einbruch verbunden waren, das holländische Element in der Kapkolonie stark erbitterten, und dessen folgendes Verhalten gegen die Transvaal-Buren beeinflußten`‘1). Im Jahre 1897 wurde Sir Alfred Milner, ein leidenschaftlich rüicksichtshoser Imperialist, zum Statthalter für Süclafrika und Gouvorneur der Kapkolonie ernannt. Dies bedeutete, daß die Gewaltpolitik wieder aufgenommen werden sollte, die eine Zeitlang geruht hatte. Denn hinter ihm stand als Kolonialsekretär Joseph Chamberlain. Er behandelte schon im roraus die Transvaal-Republik als einen zu Gehorsam verpflichteten Staat, obgleich dieser (durch Vertrag von 1884) nur völkerrechtlich in einer gewissen Abhängigkeit geblieben war, nachdem er aus der 1877 erfolgten Einverleibung ins britische Reich sich befreit hatte. Es folgte der 3jährige Krieg (1899-1902), die endliche Unterwerfung, die Ordnung der neuen Kolonien, die Einführung chinesischer Minenarbeiter unter Bedingungen, die sie in der Wirkung zu Sklaven machten; endlich die Gewährung der Eigenregierung und die Bildung der südafrikanischen Union als eines der Glieder des Britischen Reiches.

Der Krieg selber brachte anfangs schwere Niederlagen des britischen Hecres. Nachher hatte es auch Erfolge zu rerzeichnen. ,England sandte im ganzen Verlaufe des Krieges nach Südafrika fast 450000 Mann. Von diesen kamen amnähernd 340000 aus dem Mutterlande, der Rest aus Indien, aus den Kolonien und aus Südafrika selber. Die gesamte Streitmacht, die von den Buren ins Feld gefüht worden ist, war erheblich weniger als $75000 \mathrm{Mann}^{\text {“2). }}$. Mc. Carth y meint, es sei bei einem solchen Stärkeverhältnis $(6: 1)$ unmöglich gewesen, daß eine Dichterseele sich für den Sieg begeistert hätte, und wenn es sich um den Kampf zwischen 2 fremden Staaten gehandelt hätte, so wäre ganz sicher die Sympathie des englischen Volkes auf Seite des schwächeren Streiters gewesen.

Die Sympathie der gesamten nichtenglischen Kulturwelt war es in einer Weise, die eine schwere moralische Niederlage der englischen Weltpolitik bedentete. Die cant-Phrasen, mit denen der Eroberungskrieg in Umlauf gebracht wurde, waren diesmal

1) Encycl. Brit., a. a. O.

${ }^{2}$ ) J. Mc. Carthy, A Hist. of our own times, Orig.-Ausg. Vol. VII, p. 126 . 
nur Seheidemünzen; außerhalb der Landesgrenzen wollte niemand sie annehmen; sie wurden den Chamberlain, Milner und Genossen ins Gesicht geworfen.

Wenn schon im Jahre 1850 die Königin Victoria ihrem damaligen Premierminister gegenüber bemerkte, sie könne nieht ohne Kummer wahrnchmen, daß England allgemein verabscheut werde, so hätte sie 50 Jahre später, nachdem sie ihr DiamantJubiläum gefeiert hatte, noch viel mehr Ursache zu diesem Kummer gefunden. An ihrer Statt sprachen die Großen des Landes: sowohI der Regierung als der Opposition angehörende, wenngleieh die Opposition gegen den Krieg nur sehwach hervorzutreten wagte und gewaltsam erstiekt wurde.

Am 31. Oktober 1900 bezeichnete der Earl of Kimberley es als eine Tatsache, daß die Engländer in schr allgemeiner Weise gehaßt würden von den Ausländern.

Am 16. Dezember 1901 ließ der Earl of Rosebery, Ministerpräsident 1894 bis 1895 , sich dahin vernehmen: , Es gibt keine Parallele zu dem Haß und Úbelwollen, womit wir fast einstimmig von den Völkern Europas betrachtet werden."

Und Lord Salis bury selber, Haupt der damaligen Regierung, erklärte am 9. Mai 1900: dieses Land wird fast in jeder europäisehen Literatur mit Vorwürfen vor die Tür gesetzt. Und in einer späteren Staatsrede (am 5. Juni 1902) warf er die Frage auf: ob die Wurzel der Bitterkeit gegen England, die zu erklären er sich ganz außerstande sehe, nieht auf eine tiefgelegene Stimmung hinweisen möchte, ,mit der wir bei einer späteren Gelegenheit zu reehnen haben werden."

In Jahre 1902 ersehien auch die (früher erwähnte) interessante Schrift des Hon. George Peel ,Die Feinde Englands“, der diese Aussprüche entlehnt sind. Er meint, daß jene feindlichen Stimmungen sehon seit der zweiten Hälfte des 18. Jahrhunderts als ein allgemeiner Faktor in Europa vorwalten. Er hat gewiß reeht, denn ihren Herd haben sie immer in Frankreich gehabt: von dem Aussprueh des Minister-Kardinals Bernis (um 1750): ,England wird derDespot der Welt werden ", bis zu der Selırift des Je an de la Poulaine (1902), ,der Koloß auf tönernen Füßen" (Le colosse aux pieds d'argile), - welehe Register von Äußerungen französischen Unwillens über die „Insolenz“ der englischen Politik ließen sich ziehen! - 
Peel erkennt ganz richtig die Ursache und den Kern der „,tiefen, weitverbreiteten und althergebrachten" feindlichen Gesinnung, die England auf dem Kontinent sich zugezogen habe, darin, daß seine Politik regelmäßig jerler Macht, die ,nach dem Primat in der Welt strebte"1), ,auf einer gewissen Stufe ihres Fortschritts" sich widersetzt habe. „Nach Ausscheidung aller Bitterkeit bleibt dies der wirkliche Gegenstand zwischen uns und unseren kontinentalen Kritikern, und gemäß der Antwort auf die Frage, ob dieser unser Widerstand gerechtfertigt war, müssen wir uns bescheiden, in der Anschauung unparteiischer Geister zu stehen oder zu fallen."

Wenn er dann antwortet: ,Unsere Staatsmänner haben fortwährend unsere Sicherheit gesucht, welche in jeder wichtigen Epoche der europäischen Angelegenheiten zusammengefallen ist mit der Sicherheit von Europa", so ist das nicht cant (der diesem Autor fernliegt), sondern eine unzulässige Verallgemeinerung der Fälle Louis XIV . und Napoleons, von denen der zweite in Wahrheit mehr gegen die Utbermacht Englands als für die t'bermacht Frankreichs gekämpft hat.

Um auf den Burenkrieg zuriickzukommen, so war er ausschließlich durch das imperialistische Interesse Englands bestimmt, und hinter diesem stand wie immer das kommerzielle Interesse.

W. H. Lecky, der Historiker, politisch konservativ und Unionist, hat im Jahre 1900 eine Flugschrift rerfaßt, die in deutscher Übersetzung heißt ,Moralische Ansichten über den Krieg in Südafrika". Sie ist durchaus eine Verteidigung der englischen Politik und ein heftiger Angriff auf die Politik der Regierung des Transvaal. Und doch muß Lecky sich zu folgender Einräumung bequemen:

„Ich bin weit davon entfernt zu behaupten, daß unser Benchmen in anderen Beziehungen (natïrlich meint Lecky, Englands Politik sci ungemein friedfertig gewesen) fehlerlos war. Es gibt manche Sciten in der Geschichte ehemaligen englischen Vorgehens in Transvaal, die uns kcineswegs zur Ehre gereichen. Eine Bevölkerung von Gollgräbern, wie diejenige, die ihren Mittelpunkt in Johannisburg hat, gehört niemals zu den musterhaften,

1) Lies: die auf ihren eigenen Füßen stehen wollte. 
und in der gegenwärtigen Generation ist finanzielle Spekulation viel zu sehr, sowohl in England als in Afrika, mit der siidafrikanischen Politik vermengt worden. Der Parteigeist ist wild im Kaplande, und wenn dort eine holländische Partei war, die auf vollständige Oberherrliehkeit abzielte, so gab es a uch eine englische Partei, die gewaltsam, anmaßend und gewissenlos war. Der Einbruch (Jameson raid), obsehon ihm ohne Zweifel grobe Mißregierung vorausging, war sowohl eine große Torheit als ein großes Verbreehen. Unsere Regierung hatte nichts damit zu schaffen, und die Leute, die daran teilnahmen, wurden vor Gericht gestellt und bestraft, aber ein Teil des englisehen Publikums - in sehamloser Weise irregeführt durch einen sehr einflußreichen Flügel der englisehen Presse - nahm eine Haltungr in bezug auf jenen Einbruch an, welche in weitem Umfange und sehr natiirlieher Weise das tiefe Mißtranen gegen England vermehrte, das im Transvaal vorwaltete."

Lecky bezeiehnet dann als unzweifelhaft walı, daß Herr Rhodes den Einbruch vorbereitet und geplant habe.

Die stärkste und in der Tat vollkommene Verleugnung wurde dem Kriege zuteil dureh die Parlamentswahlen von 1906, die eine überwältigende Mehrheit für die bisherige Opposition ergaben. Die bitter geschmähten Pro-Boers und Little Englanders bildeten die starke Regierung, die sich dureh 2 fernere Wahlen (1910) erhalten konnte. Freilich hatte diese Regierung einen imperialistischen Einsehlag durch die Beteiligung von Sir Edward Grey und dem ehemaligen Tory Winston Churchill.

\section{Persien.}

Die „Erdrosselung Persiens" - unter diesem Titel hat ein ausgezeichneter amerikanischer Politiker die neueste Geschichte dieses Landes dargestellt ${ }^{1}$ ). Herr Morgan Shuster, im Jahre 1911 persischer Finanzminister, war, wie kein anderer Mann, berufen, unparteiisch und getreu über die Ereignisse Bericht zu

1) The strangling of Persia. A record of european diplomacy and oriental intrigue. ByW.Morgan Shuster, Ex-Treasurer-gencral of Persia. London u. Leipzig 1912. Vgl. „Englische politische Moral in Persien“, Ethische Kultur, Halbmonatsschrift für ethisch-soziale Reformen, 15. November 1914. 
geben, die er durch diesen Ausdruck bündig charakterisiert. Die vereinigten russischen und englischen Einflüsse vertrieben ihn ans seinem Amte, nachdem er 8 Monate lang emsig und uneigennützig für eine solide Reform der persischen Finanzen gearbeitet hatte.

In den Bestrebungen, Persien zu unterjochen und auszubenten, es zu diesem Zwecke in Wirrsale und Anarchie zu stürzen, hat Rußland fast das ganze 19. Jahrhundert hindurch die leitende Rolle gespielt. Großbritannien, durch die Gewaltherrschaft über Indien nach Afghanistan hingezogen, war von da aus wiederum genötigt, auch auf Persien seine Augen zu werfen Nachdem schon 1839 heftige Reibungen stattgefunden, kam es am 1. November 1856 zur Kriegserklärung. Es handelte sich um den Besitz ron Herat (in Afghanistan), den England dem Shah verwehrte. Vor allem aber nahm England von nun an - nach rasch errungenem Siege - die kommerzielle Herrschaft ïber den persischen Golf in Anspruch. Erst im newen Jahrhundert nahm die Rivalität zwischen England und Rußland akute Formen an (1902 bis 1907); aber ein Ausgleich erfolgte mitten in den Wirren der persischen Revolution, die an den Erlaß einer modernen Verfassung unmittelbar sich anschloß. An 31. August 1907 wurde die anglo-russische Konvention unterzeichnet, die in Wesen und Wirkung den Teilungen Polens vergleichbar ist.

Sir Edward Grey vertrat diesen Schiedsvertrag im Hause der Gemeinen. Darüber sprach die Londoner Wochenschrift The Nation, die wegen ihres Geistes und Freimuts hohes Ansehen genießt, folgendermaßen sich aus:

, Sir Edward Grey ist nicht nur über die Grenzen seiner Aufgabe hinansgegangen, um eine völlig überflüssige Verteidigung des neuerdings ron Rußland unternommenen Verfahrens zu liefern; er hat ausdrücklich die verstohlene Ausdehnung der anglorussischen Abmachung sanktioniert und angenommen, welche dem ganzen russischen Angriff zugrunde liegt .... Wir haben niemals geglaubt, daß jene Teilung Persiens in ökonomische Sphären mit der Integrität und Unabhängigkeit Persiens verträglich sei, und wir haben immer die Ansicht vertreten, daß sie gestreckt werden würde, gestreckt werden müsse, in eine politische Teilung. Schließlich ist das offene Eingeständnis erfolgt, und zwar anschcinend ohne jedes Buw 
der Abmachung einfach hintangesetzt worden sind. Das Wort ,,politisch" ist von Sir Edward Grey auf feine Weise eingeführt worden, um den Charakter der besonderen Interessen zu besehreiben, welehe jede Macht sich in ihrer eigenen Interessensphäre vorbehält. Wenn einmal das Wort gebraueht wird, so ist die Unabhängigkeit Persiens dahin und seine Teilung so gut wie vollendet."

„Wenn aber ein kleines Land ron einer Großmacht betreten und angegriffen werden darf, weil ein ausländiseher Beamter (das war Herr Morgan Shuster) im Dienste des kleinen Landes gewagt hat, einen wohldurehdachten und durehaus gemäßigten Brief an die Times zu schreiben, um Angriffen halboffizieller britischer und russischer Zeitungen $\mathrm{zu}$ begegnen, so müssen wir alle unsere Begriffe ron internationalem Verkehr einer Nachpriifung unterwerfen."

,Es ist ein Fall von Wolf und Lamm, so flagrant und so zynisch, daß man sich kaum versucht fühlt, ihn fernerer Untersuehung für wert zu halten." -

Und in einem zweiten Artikel stellt derselbe Publizist folgende Betrachtungen über den Fall an, die heute ein ganz besonderes Interesse in Anspruch nehmen:

„,Obsehon wir glauben, daß diese Politik unselig und töricht ist, so nennen wir sie darmm nicht unverständlich. Sie ist eine Folge, und zwar eine der übelsten Folgen, von Sir Edward Greys europäischer Politik. Ein einfaches und elementares Prinzip hat diese Politik von Anfang an beherrseht - die Furch t, daß die eine oder die andere Macht in das, was er den Dunstkreis der deutschen Diplomatie genannt hat, hineingezogen werden möchte. Jahrein, jahraus haben wir - freilich hauptsächlich in den Besitztümern anderer Leute - für die Genugtuung bezahlen müssen, gewisse Mächte davon abzuhalten, zu irgendeinem innigeren Verständnis mit Dentsehland zu gelangen. Die französische Seite des Kontos wird dureh die Verhandlungen iiber Marokko und ihre Folgen dargestellt. Rußland haben wir freie Hand über den größeren Teil von Persien gegeben. Es wäre immer ein hoher Preis gewesen, wofür aneh immer er gezahlt wäre."

Und der Autor resümiert seine Annsiht über die englische Politik in folgenden Sätzen. 
„Wir spielen eine kontinentale Rolle ohne kontinentale Hilfsmittel; und aus großem Ehrgeiz, der auf ungeeignete Kräfte sich stützt, muß schließlich entweder die Demütigung eines Verzichtes oder das Unheil einer Niederlage hervorgehen ${ }^{1}$ ).

Noch schärfer hat sich, wie ich der Halbmonatsschrift Ethische Kultur (15. November 1914) entnehme, der ,,Manchester Guardian" (die wohl am meisten mit Geist geleitete englische Zeitung) in Anknüpfung an Shusters Buch ausgesprochen. ,,Kein Engländer kann diese Erzählung ohne ein tiefes Gefühl von Scham und Verwunderung lesen - von Scham über die Schmach, mit der wir jeden Grundsatz geopfert haben, der unser Land in Asien groß gemacht hat, und von Verwunderung über die Gründe, die einen liberalen Staatsmann zu dem Agenten dieser Erniedrigung gemacht haben ..... Rußland stahl uns dort (in Persien) das Pierd, während wir mit Deutschland zankten, weil es nur ïber den Zaun hinüber gesehen hatte .... Schwerer wiegt die moralische Niederlage, die wir uns zugezogen haben, weil wir an einem großen Unrecht teilgenommen haben. Unsere Diplomatie ist ebenso erfolglos wie unmoralisch vorgegangen."

Sogar die Times wollte den Persern zugute halten, wenn die finanziellen Transaktionen Englands und Rußlands sie an die Methoden eines armenischen Wucherers erinnern möchten, der mit einem Lebemann in Teheran seine Geschäfte mache.

\section{Der Weltkrieg 1914.}

Am Abend des 2. August wurde die belgische Regierung vor die Wahl gestellt, für Deutschland oder für Frankreich sich zu entscheiden. Aber ihre Entscheidung war längst getroffen. Belgien war ein Glied der Entente cordiale zwischen Frankreich und Großbritannien. Diese Entente bedeutete scheinbar die Zusicherung englischer Hilfe für Frankreich. In Wirklichkeit bedentete sie, daß Frankreich und Belgien Werkzeuge der englischen Politik geworden waren. Belgien war, wie ein schwedischer Militärschriftsteller sich ausdrückt ${ }^{2}$ ), , des Inselreichs strat egischer Vorposten auf dem Kontinent". Es war dies in der Form eines selbständigen Staates, dessen Neutralität das europäische Konzert

1) The Nation (London), 2. Dez. u. 9. Dez. 1911.

$\left.{ }^{2}\right)$ Svenske Dagbladet, 15. Okt. 1914. 
von 1839 garantiert hatte; in welchem Konzert Großbritannien die erste Geige spielte.

Im Vertrauen auf englische und französische Unterstützung widersetzte sich die belgische Regierung dem Ansinnen der deutschen Regierung, eine dem Deutschen Reiche wohlwollende Neutralität einzunehmen und das Betreten belgischen Gebietes durch deutsche Truppen zuzulassen, obgleich volle Entschädigung fest versprochen wurde.

Die Úberschreitung der Grenze geschah am 4. August. Die deutsche Regierung war im Besitze zuverlässiger Nachrichten über den beabsichtigten Aufmarsch französischer Streitkräfte an der Maas - auf cler Strecke Giret-Namur; Nachrichten, die keinen Zweifel über die Absicht Frankreichs ließen, durch belgisches Gebiet gegen Deutschland rorzugehen. Auch waren die geheimen Abmachungen Belgiens mit England, wodurch es seine Neutralität preisgegeben hatte, dem deutschen auswärtigen Amte nicht verborgen geblieben, wenn auch die dokumentarischen Beweise dafür erst später an den Tag getreten sind.

Das Deutsche Reich stand im Kriege gegen Rußland und Frankreich. Sein Bundesgenosse Österreich-Ungarn hatte außerdem Serbien und Montenegro zum Gegner. In Petersburg war man - nach einem Berichte des belgischen Geschäftsträgers an den belgischen Minister der auswärtigen Angelegenheiten schon vor dem 30. Juli , fest davon überzengt, ja man hatte sogar die Zusicherung, daß England Frankreich beistehen werde". ,Dieser Beistand - schreibt in seinem geheimen Bericht der belgische Gesandte - fällt ganz außerordentlich ins Gewicht und hat nicht wenig dazu beigetragen, der Kriegspartei Oberwasser zu verschaffen."

Von allen Dokumenten, die ïber den Ursprung des Weltkrieges bekannt geworden sind, ist dies Dokument dasjenige, wodurch die Situation am schärfsten beleuchtet wird.

Englands Teilnahme am Weltkriege stand unter allen Umständen fest. Ja, sie verstand sich ganz von selbst, denn wenn England in der Folge der Ereignisse der letzte Faktor war - in der Verursachung der Ereignisse war es der erste Faktor. Kein Staat hatte ein so ungeheures materielles Interesse, wie England es hatte, die deutsche Macht durch eine europäische Koalition niederzuzwingen. Und die englische Diplomatio hatte 
viele Jahre lang unermüdlich ihre Fäden gesponnen, um den Hals des Deutsehen Reiches einzuschnïren, hatte zu diesem Behufe ihren alten großen Gegnern, Frankreich und Rußland, alle Einränmungen gemacht, die diese als Preis der Verschwörung frotienten.

Sarum war die Neutralität Englands durch kein Zugeständnis von seiten des Dentsehen Reiches zu erlangen, auch nicht durch das Zugeständnis, die belgische Neutralität nicht verletzen zu wollen.

Einer Macht, deren Feindschaft gewiß ist, maeht eine kriegführende Macht nur Zugeständnisse, wenn sie sich selber schaden will.

Darum war es allerdings, wie es in der Depesche des Staatssekretärs vom 2 August heißt, ,ein Gebot der Selbsterhaltung für Deutschland, einem Angriff Frankreichs zuvorzukommen“" So sehr moralische Grünce dafür sprachen, Belgiens Neutralität nicht anzutasten, die Notwehr, in der sich das Deutsche Reich einer ungeheuren Koalition von Mäehten gegenüber befand und noch befindet, rechtfertigte nicht nur, sondern heischte den Bruch eines völkerrechtlichen Vertrages, der nichts als eine Waffe in der Hand eines unbedingten Feindes war.

Diesem Bruch folgte unmittelbar die englische Kriegserklärung. ,Die Regierung Sr. Majestät fühlt sich verbunden, alle Schritte zu tun, die in ihrer Nacht stehen, um die Neutralität Belgiens aufrecht zu erhalten und die Beobachtung eines Vertrages, an dem Dentschland ebensowohl Teilnehmer ist wie wir selber" (Correspondence respecting the European Crisis (Cd. 7467 Nr. 159).

Daß England rer umbedingte Feind des Deutsehen Reiches war, geht zur Evidenz aus dem Memorandum hervor, das Sir Edward Grey am 2. August, also vor aller Entscheidung über Belgien, dem französischen Botschafter überreichte (Correspondence respecting the European Crisis $N r$. 148). Darin heiBt es: ,Ieh bin autorisiert (dureh das Kabinett), die Versicherung zu geben: wenn die deutsehe Flotte in den Kanal oder durch dio Nordsee kommt, um feindliche Operationen gegen die französische Küste oder die französische Schiffahrt zu unternehmen, so wird die britische Flotte allen Schutz gewähren, der in ihrer Macht steht." 
In der Depesche, womit Sir E. Grey diese Erklärung dem britischen Botschafter in Paris mitteilt, heißt es weiter:

,Ich legte dar, daß wir sehr breite Fragen und ungemein schwierige Streitpunkte zu erwägen hätten, und die Regierung fühle, daß sie sich nicht binden könne, Deutschland notwendigerweise den Krieg zu erklären, wenn morgen der Krieg ausbrechen wïrde zwischen Frankreich und Deutschland; aber es war notwendig für die französische Regierung, deren Flotte seit langem im Mittelmeer konzentriert gewesen war, zu wissen, wie sie ihre Anordnungen treffen solle bei dem völlig unverteidigten Zustand ihrer Nordküste. Wir hielten es daher für notwendig, ihnen diese Zusicherung zu geben. Sie verpflichtete uns nicht, mit Deutschland Krieg anzufangen, außer wenn die cleutsche Flotte in der angezeigten Weise handeln wïrde; aber sie gab Frankreich eine Sicherheit, die sie in die Lage versetzen sollte, die Verfügung über ihre eigene Mittelmeerflotte zu erledigen."

Ohne Zweifel wäre es Sir Edward Grey und seinen Hintermännem bequemer gewesen, wenn sie, ohne ein britisches Schiff und eine britische Kanone aufs Spiel zu setzen, der deutschen Niederlage hätten gewiß sein kömen. Wenn es hätte gelingen können, dem Deutschen Reiche seine Kriegführung so vorzuschreiben, sié in solche Schranken zu bannen, daß das Mißlingen dieser Kriegführung sich er war - dann allerdings hätte England gern neutral bleiben wollen und hätte dann noch schönere cantPhrasen über seine durch und durch friedliche Gesinnung im Munde geführt, als sie es jetzt über Freiheit und Gerechtigkeit, über seine Mission, die kleinen Nationen zu beschützen, für diejenigen predigt, die einfältig genug sind, den verkleideten Wolf für ein frommes Schaf zu halten.

Die Wahrheit der 'Tatsachen wird auch in England nicht dauernd verborgen bleiben.

Sie war es niemals völlig. Vor dem entscheidenden Beschluß des Kabinetts wurden die gewichtigsten Stimmen laut wider den Krieg zur Unterstützung Serbiens und Rußlands gegen das Deutsche Reich und Österreich. Es werde nur erinnert an flammende Artikel des Manchester Guardian, des New Statesman, ja der ministeriellen Westminster Gazette. Es werde erinnert an die Erklärung der Oxforder Professoren, die einen solchen Krieg eine Versündigung an der Kultur nannten, erinnert vor allem 
an das Ausscheiden der 3 Mitglieder des Kabinetts Morley, Trevelyan, Burns, ron denen jeder durch das Gewicht seines Namens ein Dutzend Churchills und Greys aufwiegen würde, wenn Geist und politischer Hochsinn wägbar wären. Es werde erinnert an das Manifest der ILP (Unabhängigen Arbeiterpartei), worin mit klaren und wahren Worten gesagt wurde: „England steht nicht im Kampf für unterdrückte Nationen oder für Belgiens Neutralität", und an das unerschrockene Auftreten des ehrlichen schottischen Arbeiterführers Keir Hardie im Hause der Gemeinen. Erinnert werde ferner an die Kundgebungen des bisherigen Hauptes der Labour Party, Ramsay Macdonald, und an das früher erwähnte Manifest Bernhard Shaws (Common Sense about the War). Endlich hat vor kurzem H. N. Brailsford darauf aufmerksam gemacht, daß der Bericht des belgischen Geschäftsträgers in Petersburg, von dem wir gesagt haben, daß er die Situation am schärfsten beleuchte, in England vollständig totgeschwiegen werde. Brailsford sagt: „Es gab ein Wort, das den Frieden gerettet hätte, das Wort Englands an Rußland: ,wenn ihr gegen Deutschland mobilisiert, ehe alle Hilfsmittel der Diplomatie erschöpft sind, dann werden wir euch als den Angreifer betrachten und keinen Mann und kein Schiff in Bewegung setzen, um euch zu helfen" - das Wort hat Sir Edward Grey nicht gesprochen." (Labour Leader nach Hamb. Echo 18. XII. 1914.)

Sir Edward Grey konnte dies Wort nicht sprechen, weil es sein geheimer Wunsch war, daß Deutschland zum Kriege gezwungen würde, wenn er auch lieber gesehen hätte, daß ohne britische Hilfe Deutschland eine schwere Niederlage erlitte. Weil er und seine Genossen glaubten, daß nur britische Hilfe diese Niederlage zur Gewißheit mache, darum versprach er sie und war außerstande, eine Bedingung anzugeben, unter der Deutschland der britischen Neutralität hätte sicher sein können.

\section{Schlußbetrachtung.}

Unser Gang durch die neuere englische Geschichte lehrt uns das englische Volk als cinen echten Epimetheus kennen. Immer von neuem mochte es sich sagen:

„Wie Nebel zerstiebte trübsinniger Wahn ${ }^{1}$ ) - “" Scham und Reve traten an die Stelle. Mit Scham gedenkt der ge-

1) Epimetheus in Goethes Pandora. 
bildete Engländer der Seeräuberei und Mordbrennerei, die sein Kolonialreich begründet haben. Mit Scham und Reue gedenkt er des Sklavenhandels, der einst als Säule des Reichs gepriesen wurde. Er weiß, daß die Eroberung Indiens Wege ging, die mit Betrug und Wortbruch, mit scheußlichen Gewalttaten aller Art gepflastert waren; weiß, daß planmäßige Mißhandlung die 13 Kolonien, die sich um das Sternenbanner scharten, zum Abfall gebracht hat, und daß der gleiche enge Handelsgeist seine Vorfahren die Partei der Emigranten gegen die französische Republik ergreifen ließ. Sogar die historisch nur schwach orientierten 6 Mitglieder der Oxforder Fakultät für moderne Geschichte wissen, daß England Dänemark ein großes Unrecht zugefügt hat 1807. Nur mit bitterster Reue gedenkt jeder Kundige in England der Katastrophe in Afghanistan 1837/41; an tiefe Scham und bleibenden Schimpf erinnert schon der Name des Opiumkrieges. Und der Krimkrieg? Wir hörten, daß ihn kein Einsichtiger mehr verteidigt, so sehr er in seinen Anfängen bejubelt worden ist, und daß er in einen Abgrund des Odiums gestürzt wurde. Von der Despotie, mit der die kleinen Staaten der jonischen Inseln und Jamaika niedergehalten, niedergeworfen wurden, werden nur wenige wissen; aber nienand, der die Tatsachen kennt, wird zu behaupten wagen, daß England dort für das Recht oder gar für die Freiheit eingetreten sei. Nur mit Widerwillen läßt sich das Selbstbewußtsein des heutigen Engländers daran erinnern, daß seine Väter und Großväter auf seiten der Sklavenhalter gegen Lincoln gestanden, während ganz Deutschland (das damals noch Österreich einschloß) lieinen Augenblick in seinen Sympathien geschwankt hat und in den Staaten selbst viele Tausende deutscher Männer und Jünglinge mit Begeisterung gegen die Institution der Sklaverei zu den Waffen griffen. - Daß der indische Aufruhr durch die schwere Schuld der ostindischen Kompagnie und des letzten für sie regierenden Gouverneurs verursacht war, ist als historische Tatsache auch durch die alsbald erfolgte Aufhebung dieser Kompagnie festgelegt worden.

Hingegen über die Ereignisse der neuesten Zeit: über die Eroberung Ägyptens, das Bombardement von Alexandria, das Bluturteil gegen die Bauern von Denshawai, über den Burenkrieg und über die Erdrosselung Persiens, sind die Akten noch 
nicht geschlossen. Aber schon gehört eine dreiste Stirn dazu, um zu behaupten, daß die Tatsachen, soweit sie bekannt geworden, der englischen Weltpolitik zur Ehre gereichen. Man darf sagen, daß auch in bezug auf diese Machinationen und Feldzïge unter rechtschaffenen Leuten die Empfindungen von Scham und Reue schon fast allgemein geworden sind.

Es ist daher zureichender Grund fürdie Vermutung rorhanden, daß sie auch in bezug auf die Ursprünge des gegenwärtigen Weltkrieges mächtig anwachsen und allmählich eine Höhe erreichen werden, die der furcht baren Größe dieser Ereignisse angemessen ist.

- Wir dürfen aus allem, was hier in unbefangener Weise, nach Zeugnissen bedeutender und berühmter englischer Autoren vorgeführt wurde, die Folgcrung ziehen, daß das englische Volksgewissen, wenn es zum Urteil iiber die englische Weltpolitik und ihre Beweggrïnde aufgefordert wird, nicht umhin kann, sie der ewigen Verdanmnis schuldig zu befinden.

\section{Eine Parabel.}

Als Theseus, der Athener, nach Kreta kam, ließ er sich das Ungehener, den Minot a u r us, vorführen, um ein Verhör mit ihm anzustellen.

Theseus sprach zu ihm: ,Du bist überführt, unzählige Kinder und Jünglinge gefressen zu haben. Warım hast du so übel getan?"

Minotaurus antwortete: ,Die Kinder habe ich alle aus Liebe aufgefressen."

„Und die Jünglinge?“ fragte Theseus. ,, Die Jünglinge aus sittlichen Beweggr ünden, " antwortete Minotaurus.

Theseus nahm sein Schwert und schlug dem Scheusal den Kopf ab. -

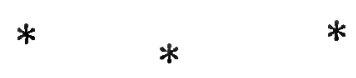

Auf die moralische Enthauptung der englischen Weltpolitik wird der nuwiderrufliche Spruch der Weltgeschichte lanten. Denn die Weltgeschichte ist das Weltgericht. 

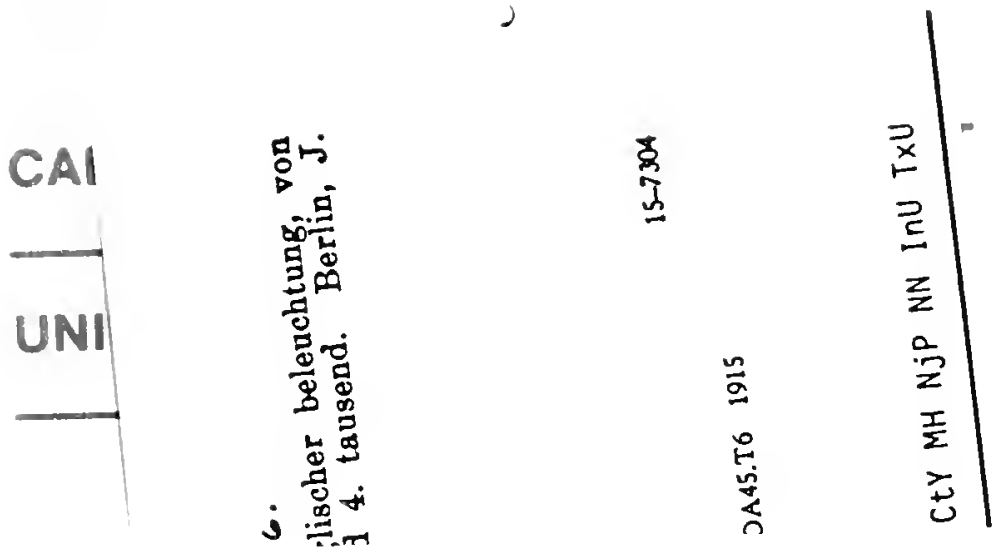



\section{Terlag von Julius splinger in Berlin}

Vor kurzem erschien 6. Tausend:

\section{Eine Frage!}

Wie erhalten wir der Zukunft die erhebenden Krïifte dieses Krieges?

Von

Johannes Marbod

Preis II, - ,50

Vor kurzom erschien 3. Tausend:

Der Krieg

und die Frauen

Von

Dr. Agnes von Harnack

$$
\text { Preis M. }-, 60
$$

Bei Bezug yon 10 Exemplaren an Preis je M. -,50

von 25 Exemplaren an Preis je M. -, 40

Zu beziehen durch jede Buchhandlung 


\section{Vom gleichen Verfasser sind erschienen:}

Gemeinschaft und Gesellschaft. Grundbegriffe der reinen Soziologie. 2. Auflage. Berlin, Karl Curtius. 1912. Preis 7,50 M., geb. 9,- M.

Thomas Hobbes, der Mann und der Denker. 2. Auflage von Hobbes' Leben und Lehre. - Osterwieck und Leipzig, A. W. Ziekfeldt. 1912.

Preis 4,- M., geb. 4,60 M.

Philosophische Terminologie in psychologisch-soziologiseher Ansicht. (Gekrönte Preisschrift.) Leipzig, Theod. Thomas, 1906. Preis 3,50 M., geb. 4,50 M.

Die Sitte. Frankfurt a. M., Ruetten \& Loening. 1909. Preis 1,50 M., geb. 2,- M.

Die Entwicklung der sozialen Frage. (Sammlung Göschen Bd. 353.) 2. Auflage. Preis $0,90 \mathrm{M}$.

Sehiller als Zeitbiirger und Politiker. Berlin, Buchverlag der „Hilfe“. 1905. Preis kart. 1,- M.

IIalifax Marquis, Charalsterbild eines Königs. Nebst moralischen und politischen Aphorismen. Berlin, K. Curtius. $1910 . \quad$ Preis 1,- M.

$\mathrm{Zu}$ beziehen durch jede Buchhandlung. 